UNIVERSITÉ DU QUÉBEC A CHICOUTIMI

\title{
LES PRATIQUES RITUELLES ENTOURANT LE MARIAGE DANS LES RÉGIONS DU SAGUENAY ET DE CHARLEVOIX
}

\author{
PAR \\ MARIE-JOSEEE HUOT
}

MÉMOIRE PRÉSENTÉ EN VUE DE L'OBTENTION

DE LA MAITRISE EN ÉTUDES RÉGIONALES

MAI 91 


\section{Bibliothèque}

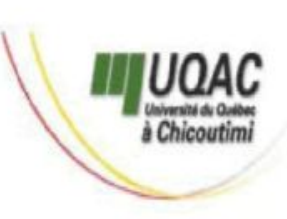

\section{Mise en garde/Advice}

Afin de rendre accessible au plus Motivated by a desire to make the grand nombre le résultat des results of its graduate students' travaux de recherche menés par ses research accessible to all, and in étudiants gradués et dans l'esprit des accordance with the rules règles qui régissent le dépôt et la governing the acceptation and diffusion des mémoires et thèses diffusion of dissertations and produits dans cette Institution, theses in this Institution, the I'Université du Québec à Université du Québec à Chicoutimi (UQAC) est fière de Chicoutimi (UQAC) is proud to rendre accessible une version make a complete version of this complète et gratuite de cette œuvre. work available at no cost to the reader.

L'auteur conserve néanmoins la The author retains ownership of the propriété du droit d'auteur qui copyright of this dissertation or protège ce mémoire ou cette thèse. thesis. Neither the dissertation or Ni le mémoire ou la thèse ni des thesis, nor substantial extracts from extraits substantiels de ceux-ci ne it, may be printed or otherwise peuvent être imprimés ou autrement reproduced without the author's reproduits sans son autorisation. permission. 
TABLE DES MATIERES

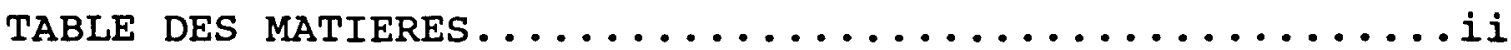

AVANT-PROPOS ...........................

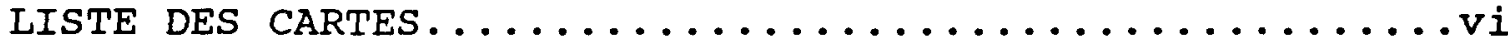

LISTE DES TABLEAUX.........................

LISTE DES GRAPHIQUES............................

LISTE DES ANNEXES........................

BIBLIOGRAPHIE..............................

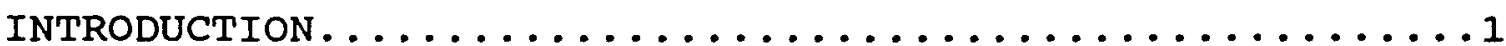

\section{PREMIERE PARTIE}

POSITION DU PROBLEME ET MÉTHODOLOGIE

CHAPITRE I: ÉTAT DE LA QUESTION................

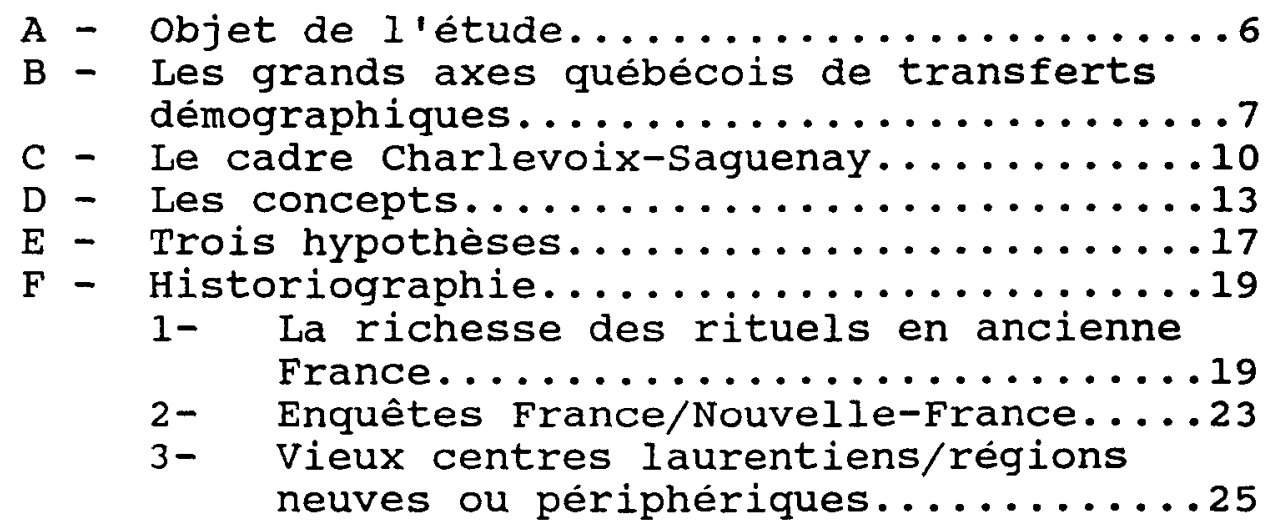


CHAPITRE II: MÉTHODOLOGIE.....................

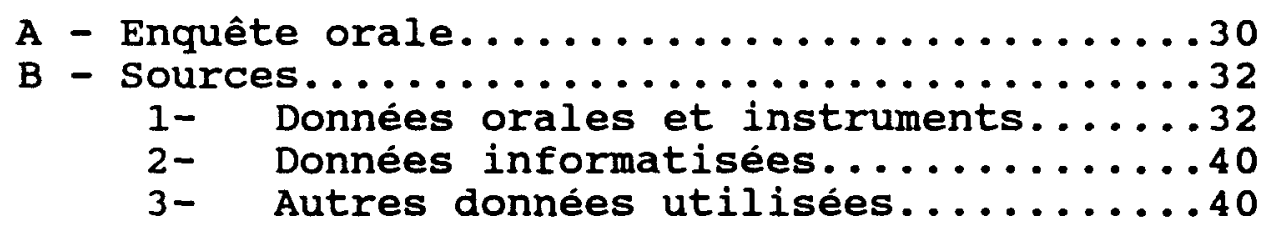

DEUXIEME PARTIE

LE MARIAGE SAGUENAYEN

CHAPITRE III: DE LA RENCONTRE AU MARIAGE..........43

A - Informations préliminaires..........45

1 - Les circonstances de la première rencontre............45

2 - La situation socio-professionnelle des conjoints.................47

3 - Les motivations au mariage.......48

4 - Les finalités de l'union.........48

B - Les fréquentations.................49

1 - Les données contextuelles et les contrôles................49

2 - Les échanges...................50

3 - Les stratagèmes galants..........52

C - L'accord des partis...................53

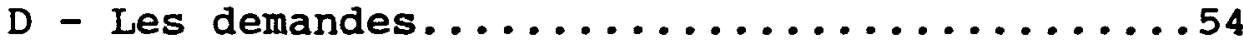

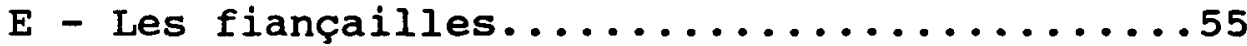

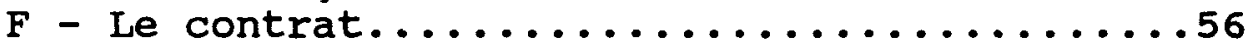

G- Les apports matériels au ménage.......57

H - L'enterrement du célibat............58

CHAPITRE IV: LA CEREMONIE DU MARIAGE............61

A - Les invitations.................62

B - La publication des bans............63

C - L'habillage des mariés.............64

D - Le transport vers l'église...........68

E - La cérémonie religieuse.............70

F - Le transport vers le lieu de la noce....7.73 
CHAPITRE V: LA NOCE ET L'ETABLISSEMENT DU MENAGE......75

A - La durée des noces.................76

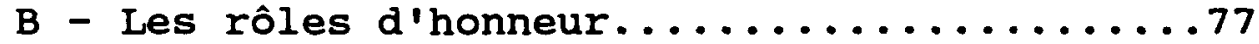

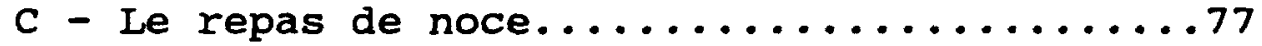

D - Les cadeaux de noce................81

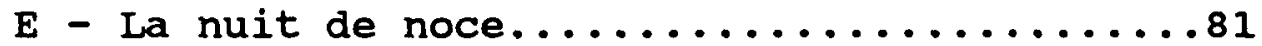

$F$ - Le voyage de noce..................84

G - L'installation au domicile...........84

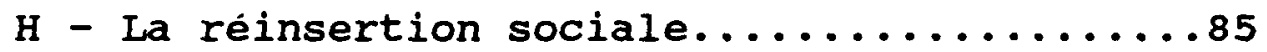

TROISIEME PARTIE

DONNEES COMPARATIVES

CHAPITRE VI: ANALYSE COMPARATIVE...............88

A - Données orales.....................89

1 - Les fréquentations...............90

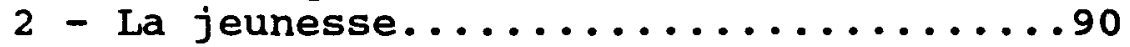

3 - Les conduites gestuelles...........91

4 - Le contrat de mariage.............91

5 - L'enterrement du célibat..........92

6 - La durée des noces................992

7 - Les divertissements.............92

8 - L'information sexuelle...........93

B - Données informatisées...............993

1 - Les mouvements saisonniers.........94

a) 1802-1841 - Charlevoix........994

b) 1842-1881 - Charlevoix/Saguenay..98

c) $1882-1921$ - Saguenay..........103

d) 1922-1971 - Saguenay.........106

2 - Les mouvements journaliers........110

a) 1802-1881 - Charlevoix/Saguenay.110

b) 1882-1921 - Saguenay.........117

c) 1922-1971 - Saguenay..........120

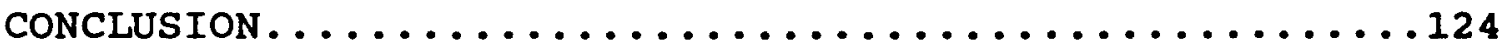

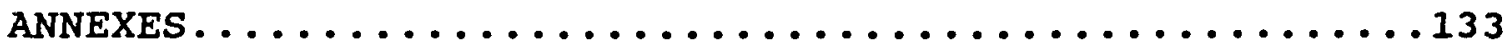


AVANT-PROPOS

Je veux d'abord dire merci à Michel simard pour sa compréhension et son encouragement pendant ces quelques années ainsi qu'à mes deux enfants Mathieu et corinne pour le réconfort qu'ils m'ont procuré.

Aussi, j'aimerais remercier sincèrement Monsieur Gérard Bouchard, professeur à l'Université du Québec à Chicoutimi et directeur du centre interuniversitaire de recherches sur les populations (SOREP) pour son constant soutien et ses précieux conseils.

J'aimerais enfin souligner toute l'aide que m'a apportée mon intégration à la vie du centre interuniversitaire de recherches sur les populations.

Cette recherche a été rendue possible en partie grâce à des subventions du Conseil de Recherches en Sciences Humaines ( CRSH) • 
$v i$

\section{LISTE DES CARTES}

\section{page}

Carte 1: Localisation du Saguenay et de Charlevoix dans la province de québec..............11

Carte 2: La région du Saguenay et ses sous-régions...36 


\section{LISTE DES TABLEAUX}

page

Tableau 1 : Distribution des informateur(trice)s selon

la période de naissance.................

Tableau 2 : Eléments constitutifs ou composantes relatives au déroulement du mariage.......38 
viii

\section{LISTE DES GRAPHIQUES}

page

Graphique 1 : Mouvement saisonnier des mariages. Charlevoix 1802-21...................95

Graphique 2 : Mouvement saisonnier des mariages. Charlevoix 1822-41.................96

Graphique 3 : Mouvement saisonnier des mariages. Charlevoix 1842-61.................999

Graphique 4 : Mouvement saisonnier des mariages.

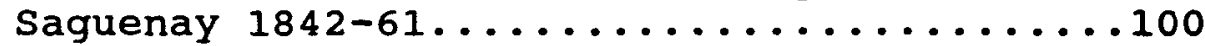

Graphique 5 : Mouvement saisonnier des mariages. Charlevoix 1862-71.................101

Graphique 6 : Mouvement saisonnier des mariages.

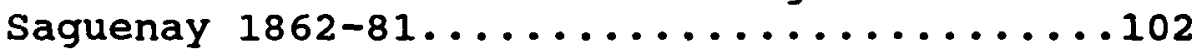

Graphique 7 : Mouvement saisonnier des mariages. Saguenay 1882-1901..................104

Graphique 8 : Mouvement saisonnier des mariages. Saguenay 1902-1921.......................

Graphique 9 : Mouvement saisonnier des mariages. Saguenay 1922-41..................107

Graphique 10: Mouvement saisonnier des mariages. Saguenay 1942-61...................108

Graphique 11: Mouvement saisonnier des mariages.

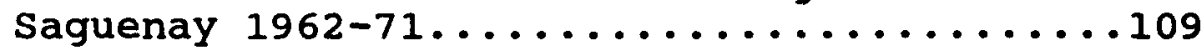

Graphique 12: Mouvement journalier des mariages. Charlevoix 1802-21.....................11

Graphique 13: Mouvement journalier des mariages. Charlevoix 1822-41.................112

Graphique 14: Mouvement journalier des mariages. Charlevoix 1842-61.................113 
Graphique 15: Mouvement journalier des mariages.

Charlevoix 1862-71.....................114

Graphique 16: Mouvement journalier des mariages.

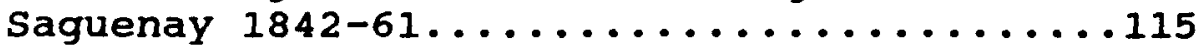

Graphique 17: Mouvement journalier des mariages.

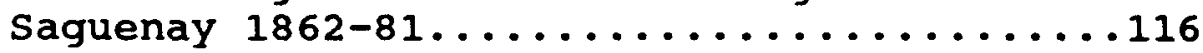

Graphique 18: Mouvement journalier des mariages.

Saguenay 1882-1901..................117

Graphique 19: Mouvement journalier des mariages.

Saguenay 1902-21...................119

Graphique 20: Mouvement iournalier des mariages.

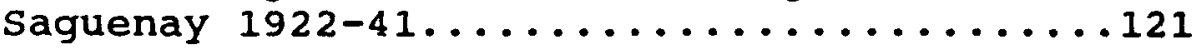

Graphique 21: Mouvement journalier des mariages.

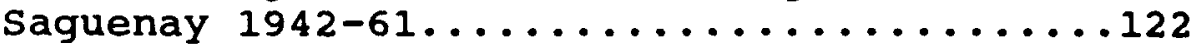

Graphique 22: Mouvement journalier des mariages.

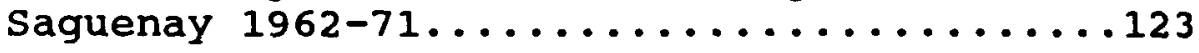




\section{LISTE DES ANNEXES}

page

ANNEXE 1. Données personnelles et socio-professionnelles sur les informateur(trice)s du Saguenay........134

ANNEXE 2. Données personnelles et socio-professionnelles sur les informateur(trice)s de Charlevoix......137 
INTRODUCTION 
L'espace québécois et les mouvements de population qui l'ont marque offrent un terrain de recherche tout à fait propice à celui ou celle qui s'intéresse à l'évolution de la vie culturelle d'une société neuve. on trouve ici un contexte original pour toutes les questions relatives au maintien des traditions, à la perpétuation des contes et des légendes ou encore aux mutations qui affectent d'une façon générale les pratiques rituelles dans une société.

Inséré dans un projet de recherche portant sur les problèmes de transfert culturel au Québec, ce mémoire vise premièrement à mieux identifier les contenus culturels et coutumiers reliés à l'institution du mariage dans les régions du Saguenay et de Charlevoix. Charlevoix ayant été la régionmère qui a déversé une partie de sa population au saguenay à partir des années 1840 , nous tenterons de voir comment a survécu sa dynamique culturelle lors du transfert démographique. La cérémonie du mariage, qui était à l'époque la règle pour l'ensemble des couples, servira de marqueur culturel puisqu'elle constitue un évẻnement important empreint du mode de vie d'une société.

Nous tenterons donc de comparer les contenus culturels retrouvés dans la région de Charlevoix avec ceux de la région du Saguenay. L'objectif sera de voir de quelle façon ces pratiques ont évolué ou encore ont été modifiées. 
Appuyé sur une quarantaine d'entrevues, cet exercice de recherche pourra s'ajouter aux autres travaux entrepris par SOREP sur diverses régions du Québec et permettra peut-être une vision plus élargie de l'évolution de la vie culturelle québécoise à l'échelle régionale. 
PREMIERE PARTIE

POSITION DU PROBLEME ET MÉTHODOLOGIE 
CHAPITRE I

ÉTAT DE LA QUESTION 


\section{A - objet de l'étude}

Cette recherche empirique se veut en fait le prolongement d'une enquête scientifique sur la dynamique culturelle des régions de peuplement au Québec amorcée par Gérard BOUCHARD (1986). C'est suite à la lecture de cet article que nous avons trouvé l'inspiration et l'énergie nécessaires pour entreprendre cette étude qui s'insère dans un projet portant sur le problème de la continuité et des transferts culturels entre les sociétés anciennes et nouvelles. Sur cette question, R. Cole HARRIS (1977) soutient que lors de migrations massives d'une population vers un nouveau territoire, les structures sociales en place dans I'ancienne société subissent des mutations importantes et, par conséquent, les pratiques et les coutumes reliées au mode de vie ne retrouvent pas les conditions nécessaires permettant la reproduction des modèles culturels. Ainsi, l'apprivoisement d'un nouvel environnement ne permet pas la réimplantation des mêmes pratiques sociales et culturelles. Selon HARRIS, on peut assister à une "simplification" des structures et des formes économiques et sociales. Dans son plaidoyer pour une recherche comparative sur les spécificités culturelles des régions de peuplement du Québec, Gérard BOUCHARD (1986) propose de voir comment les grands transferts démographiques qu'a connus le 
Québec ont influencé les comportements culturels des nouvelles régions. Plus spécifiquement, il se demande dans quelle mesure ces transferts démographiques d'une région-mère vers une région neuve s'accompagnent de phénomènes d'érosion ou de déperdition dans les pratiques culturelles.

Bien que la perspective d'enquête proposée par BOUCHARD (1986) réfère à différentes formes d'expression culturelle comme les vêtements, l'architecture, la cuisine, les contes et légendes, etc, nous réduirons ici l'angle d'observation en tentant de mesurer l'expression des contenus coutumiers reliés à l'institution du mariage, et ce, au Saguenay et dans Charlevoix. Dans ce cadre spatial, nous voulons voir si ces modèles culturels se sont modifiés lors du transfert démographique de la région de Charlevoix vers le Saguenay.

\section{B - Les grands axes québécois de transferts démographiques}

$\mathrm{Au}$ Québec, les mouvements de population ont marqué l'espace et donné naissance à plusieurs axes de transferts migratoires qui se sont doublés de phénomènes de diffusion culturelle. Dans le cadre qui nous intéresse, il est important de distinguer trois grands axes démographiques et spatiaux entre le XVIIe et le XXe siècle. 
A partir du milieu du XVIIe siècle, un premier axe se développe reliant la France à la Nouvelle-France. Lors de cette migration massive venant de l'Europe, quelque 10000 individus ayant vécu dans une société ancienne aux pratiques et coutumes très élaborées s'installent de façon permanente en sol québécois. Ces immigrants transportent avec eux un bagage culturel, économique et social caractéristique de diverses régions de France. Depuis les procédés de l'agriculture jusqu'aux modes de reproduction du groupe familial en passant par l'architecture, l'espace québécois devient le lieu d'une nouvelle société fondée à partir d'une autre très ancienne.

Au début du XVIIIe siècle, le premier axe de peuplement ayant permis la formation des trois principaux noyaux qui constituent la population québécoise, soit Montréal, Québec et Trois-Rivières, prend un second souffle alors que le peuplement se diffuse et irradie le long du corridor laurentien. De Montréal vers Lanaudière, de Trois-Rivières vers Nicolet, de Québec vers la Côte-de-Beaupré et le Bas-Saint-Laurent, cette seconde phase migratoire s'accompagne également d'un transfert socio-culturel. Soulignons toutefois qu'il est difficile de distinguer clairement le début et la fin de ces deux 
mouvements de population car ils se chevauchent ou se recoupent en partie.

Pour les fins de notre étude, notons que sur ce deuxième axe, nous nous intéresserons plus particulièrement aux migrations depuis la ville de Québec vers les régions du nord-est québécois. Sur la rive-sud, le mouvement migratoire s'étend jusqu'à la côte-du-sud et le Bas-Saint-Laurent tandis qu'au nord, le peuplement viendra occuper la côte-de-Beaupré et la région de Charlevoix. Cette dernière, caractérisée par ses montagnes et son relief accentué, constitue à cette époque un espace difficilement accessible et formera en aval de Québec une limite orientale au peuplement blanc.

Le troisième axe qui nous intéresse relie la région de Charlevoix à celle du Saguenay et se met en place à partir de 1835-40. Alors qu'en 1765, la région de Charlevoix compte 1000 habitants, elle en compte 13000 un siècle plus tard. Dès le début du XIXe siècle, cette poussée démographique extraordinaire que connaît cette région et l'insuffisance des terres agricoles, en particulier sur les plateaux, forcent ses habitants à chercher de nouveaux espaces (M.GUERIN, 1988) et donnent lieu à un éclatement vers l'arrière-pays qui déborde premièrement sur une région située plus au nord dans les 
Laurentides, le Saguenay, et plus tard sur la côte-Nord. La création de cette aire de peuplement nouveau, soit le Saguenay, à partir d'une région plus ancienne constitue la toile de fond de la présente recherche. Mais décrivons d'abord plus précisément ces deux régions qui sont les termes de comparaison de notre étude (cf-Carte 1).

\section{C - Le cadre Charlevoix-Saguenay}

Charlevoix est une région située en bordure du fleuve Saint-Laurent. A la fin du XIXe siècle, l'agriculture à caractère mixte qui se distingue par sa pluriactivité: culture du sol, élevage, chantiers forestiers, etc.) constitue son principal levier économique. La sous-région du littoral (en particulier de la Petite-Rivière-Saint-François à la Malbaie) vit alors dans un cadre ancien où les structures sociales et économiques se sont, au fil du temps, solidement mises en place. Les élites, surtout cléricales, veillent à maintenir la cohésion entre les diverses composantes de la société rurale. Mais parallèlement à la vie sociale et économique, il existe une culture intrinsèque au mode de vie rural.

Que ce soit dans la vie quotidienne ou en rapport avec des événements sortant de l'ordinaire, les gens de 


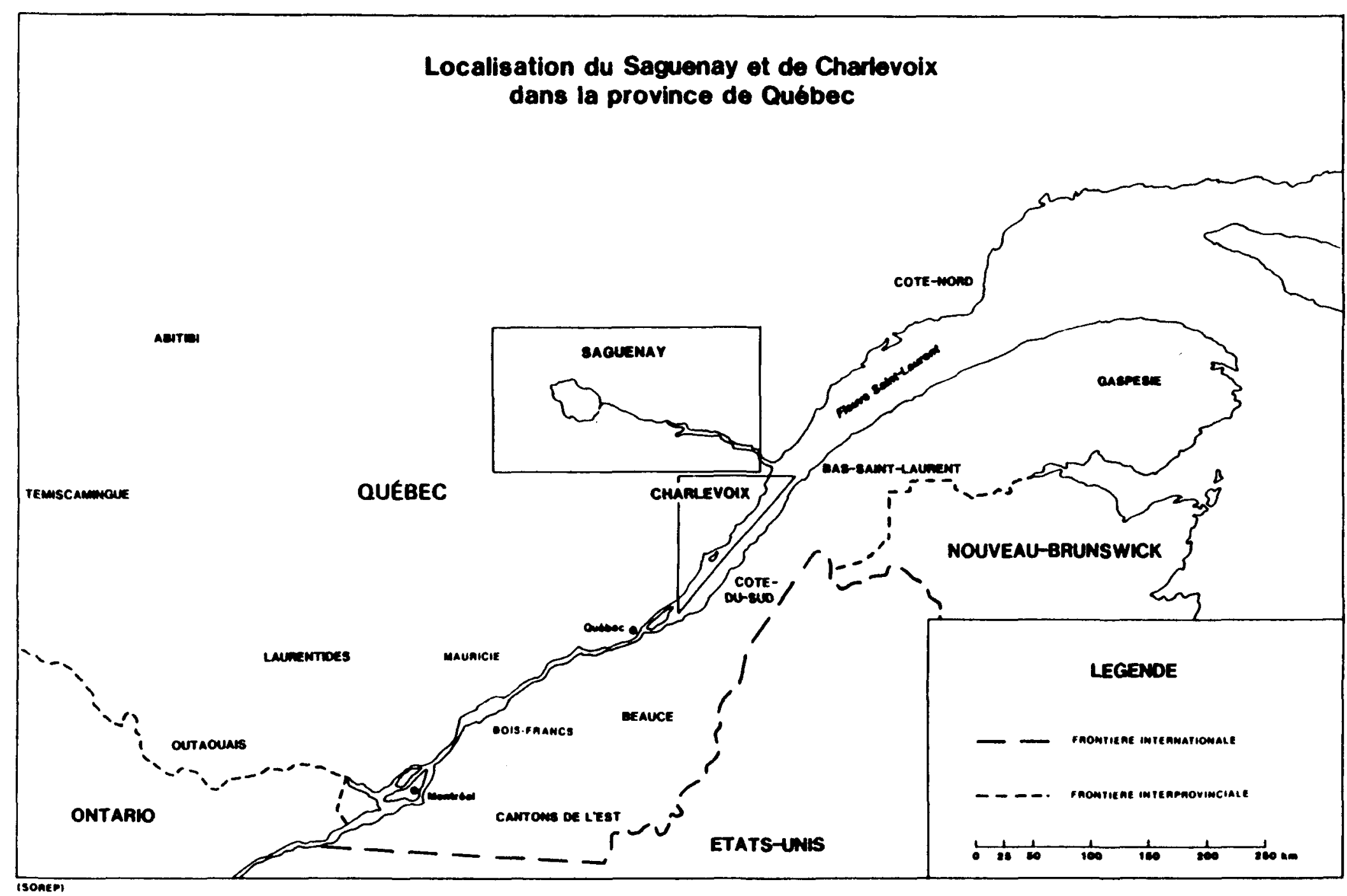

Carte 1 
Charlevoix ont hérité ou ont développé des habitudes de vie, des pratiques sociales et symboliques qui leur sont plus ou moins spécifiques. Ce langage, souvent non verbal, fait référence à des représentations et des valeurs véhiculées par le biais de gestes quotidiens ou de coutumes reliés à des événements plus ou moins importants. Par exemple, des coutumes telles que la naissance, la mort ou le mariage donnent lieu à des pratiques particulières imprégnées d'un symbolisme transmis d'une génération à l'autre. Ces formes d'expression, témoins d'une culture populaire vivante, sont créées par et pour le peuple lui-même et deviennent ainsi le ciment de la vie sociale. Par ailleurs, il est assuré que cette culture populaire n'est pas entièrement spontanée, qu'elle a absorbé de nombreux éléments ou influences de la culture des élites, ne serait-ce que sous forme dinterdits frappant telle ou telle pratique.

C'est une cohorte d'individus empreints de cette culture charlevoisienne qui alimente le premier courant d'immigration en vue de coloniser la région du Saguenay. Un nouvel environnement, des terres à défricher, une économie précaire ne sont que quelques facteurs qui caractérisent la vie saguenayenne au début de la colonisation. Même si la conquête du sol a été effectuée par le biais d'une migration de type familial (D.GAUVREAU, 
M. BOURQUE, 1988) les premiers habitants et leur famille se sont retrouvés dans un contexte général d'inorganisation sociale. Selon des témoignages recueillis lors d'entrevues réalisées entre 1935 et 1970 auprès de personnes âgées au saguenay et conservées aux Archives Nationales du Québec à Chicoutimi, l'existence était très rude et on serait tenté de dire que les préoccupations premières des pionniers saguenayens se situaient surtout au plan de la survie matérielle.

\section{D - Les concepts}

La vie quotidienne fournit aux chercheurs une foule d'exemples de gestes et de comportements susceptibles de témoigner de la richesse ou de la pauvreté des contenus coutumiers d'une collectivité. Afin d'appréhender les phénomènes de mutation du tissu culturel reliés aux transferts démographiques, nous devrons d'abord préciser la signification des concepts utilisés dans la présente recherche. Cet exercice consiste à placer quelques jalons indispensables à la formulation des questions qui seront abordées ultérieurement.

Un des concepts fondamentaux de l'ethnographie et de l'ethnologie concerne les coutumes. Arnold VAN GENNEP (1943-1958) en a proposé la définition suivante: 
" manières de vivre conformément à des règles non écrites ou écrites, admises par le consentement général, de bas en haut, spontanément et sans coercition etatiste ou gouvernementale, souvent même, selon les époques et les pays, malgré ou contre cette coercition, elle-même justifiée non pas d'abord, mais après coup, par une ou plusieurs législations, nécessairement toujours en retard sur l'évolution progressive ou régressive des coutumes, évoIution fondée à son tour sur celle progressive ou régressive des moeurs" (page 107, vol.1, tome 1)

Ces actes sociaux peuvent se greffer aux manifestations individuelles ou collectives reliées à des événements à caractère politique, culturel ou autre, d'où la création de contenus coutumiers propres à une collectivité (MOLIN, J.-B.,1974). Dans ces contenus, nous incluons ici toutes les pratiques collectives répétitives, étant bien entendu que ces concepts se chevauchent et sont difficilement dissociables. Il faut en effet rappeler l'importance de la notion de répétition du geste ou de l'action dans une étude comme celle-ci puisqu'il s'agit de mesurer l'évolution progressive ou régressive d'un comportement. 
Le concept de tradition est, pour sa part, ordinairement relié à un mode de vie où le changement social est lent. Les sociétés rurales pré-industrielles vivent largement selon la tradition, "définie de façon statique et passéiste comme la répétition des mêmes coutumes, pratiques et modes de pensée, de génération en génération" (M.SEGALEN, 1981).

Gérard BOUCHARD (1986) définit le rite comme:

"... une sorte de langage du temps social, qui découpe l'événement en de menus épisodes ou séquences et sanctionne le passage de l'une à l'autre" (page 477).

Les rites entourant d'importants événements tels que la naissance, le mariage ou la mort ont une fonction sociale particulière. Selon la nature de l'événement, le rite consacre les actions de l'individu et rend le nouvel état de celui-ci officiel aux yeux de la société. Dans le cas du mariage, les rites d'agrégation sont très importants puisqu'ils ont pour fonction d'unir les deux familles impliquées au même titre que les deux futurs époux (A. VAN GENNEP, 1981). 
La ritualisation (M. SEGALEN 1981) tenait un langage très élaboré dans les sociétés paysannes et rurales. Lors des rituels, qui ne laissent pas beaucoup de place à l'initiative ou l'improvisation, l'individu vit ses actions et ses émotions dans un cadre de référence établi qui le renvoie à tout un univers de symboles. Notons toutefois que l'on retrouve divers points de vue sur la représentation des gestes symboliques. Certains y voient l'autorité du futur époux sur sa femme (T. FOX, 1985), alors que pour d'autres, il s'agit simplement d'un effet de la division du travail domestique. Ces symboles font parfois référence aux instruments de travail de la terre, aux animaux, aux plantes sauvages ou cultivées; objets et choses qui se retrouvent plus difficilement dans un espace urbain. Aussi, les sociétés rurales et paysannes qui entretiennent un rapport étroit avec la nature, sont elles en mesure de mieux comprendre et de perpétuer toute la portée symbolique de certains actes ou gestes.

Toutes ces coutumes et ces pratiques ne sont pas statiques mais évoluent et se redéfinissent par rapport aux mouvements et aux changements sociaux. L'étude de la dynamique culturelle suggérée ici se traduit donc par 
l'analyse des évolutions qui se marquent dans la vie symbolique d'une société, celle-ci faisant référence à l'ensemble des représentations, des valeurs, des rites et coutumes qui encadrent les conduites et les relations entre les personnes. Dans le cadre qui nous intéresse, nous ferons plus précisément référence aux modèles culturels et aux pratiques coutumières reliés à l'institution du mariage.

Dans cette perspective de recherche, les formes de mutations qu'a subies la dynamique culturelle lors du transfert démographique de Charlevoix vers le saguenay auraient pu emprunter trois directions. Ainsi donc, trois hypothèses peuvent être envisagées quant aux formes nouvelles du tissu culturel.

\section{E - Trois hypothèses}

En premier lieu, on peut songer à une continuité intégrale des pratiques. La migration massive d'individus apparentés à différents degrés aurait permis la réimplantation du mode de vie familiale existant dans la région-mère. Par le biais d'une migration de type familial, la collectivité aurait su remettre en place les anciennes structures sociales et culturelles dans un nouvel espace. Ceci aurait permis la continuité ou la 
reproduction des pratiques reliées aux événements importants de la vie quotidienne.

En second lieu, on peut imaginer une sorte de déperdition de certains éléments coutumiers. Par ces termes, nous faisons référence au phénomène de "simplification" évoqué par R. Cole HARRIS (1977) et au phénomène d'"érosion" décrit par BOUCHARD (1986). Les conditions de vie nouvelles auxquelles ont fait face les premiers Saguenayens auraient favorisé une vie coutumière un peu fruste où les pratiques auraient été laissées à une relative improvisation, sans code ni cadre culturel de référence très rigide. Les structures sociales à peu près inexistantes, l'enorme fardeau de travail relié au contexte de la colonisation et d'autres facteurs associés à la vie pionnière auraient fait obstacle au maintien de cérémoniels très sophistiqués. La déperdition fait donc ici référence plus à des aspects formels qu'à des contenus comme tels.

Lé troisième hypothèse suggère un phénomène de redéfinition des anciennes coutumes. Dans un nouvel espace où l'environnement immédiat est peu propice à la continuité de la vie symbolique et coutumière, on peut imaginer que de nouvelles pratiques prennent forme, ou que d'anciennes coutumes subissent de nombreux réaména- 
gements. En ce cas, la déperdition culturelle ferait place à une redéfinition des coutumes. Il faut par ailleurs noter que les deuxième et troisième hypothèses sont loin d'être exclusives, Bouchard les présentant du reste comme tout à fait complémentaires.

\section{F - Historiographie}

1 - La richesse des rituels en ancienne France

Dans les sociétés traditionnelles, le mariage qui est la base de la reproduction sociale a pour objet d'unir non seulement deux individus mais également deux familles. De plus, on observe également que dans la société française, l'endogamie familiale est une tradition profonde. A cette occasion, on assiste à la réunion d'une "grande famille" (A.VARAGNAC, 1978) au cours de laquelle on en profite pour resserrer les liens de parenté et réintégrer les dissidents à leur famille respective, le tout sanctionné par des cérémonies à caractère religieux ou populaire.

L'institution du mariage consiste en effet en "un rituel religieux et un rituel populaire qui ne sont radicalement distincts $\mathrm{ni}$ dans leur histoire 
ni dans leurs fonctions" (A.BURGUIERE, 1978). Alors que la cérémonie religieuse du mariage présente un caractère juridico-sacramentel (le pouvoir sacré de I'Eglise consent à I'union des deux époux), le rituel populaire répond à une fonction essentiellement magico-sociale (rendre public le passage de deux jeunes dans le groupe d'adultes et écarter les mauvais sorts). André Burguière explique toutefois qu'avec le temps, le rituel religieux a intégré un grand nombre de rites populaires tandis que le rituel populaire répond maintenant très souvent à des préoccupations juridiques. Pour les fins de cette recherche, nous nous intéresserons aux pratiques coutumières qu'elles soient religieuses ou populaires, les prenant comme témoins de la dynamique culturelle d'une société.

La fonction symbolique des divers rites nuptiaux confère à l'institution du mariage un caractère à la fois amusant et empreint de solennité. Chaque rite consiste en effet à officialiser le passage des individus d'un état à un autre. En ancienne France, où les rituels du mariage étaient très nombreux depuis les fréquentations jusqu'au "retour des noces", on a l'impression que chaque geste suscitait un code, que rien n'était 
fait à l'improviste. Les participants connaissaient les règles d'usage et se conformaient à la coutume.

Ainsi, tout au long de la cérémonie, un certain nombre de rites nuptiaux, souvent organisés par la jeunesse, avaient pour fonction de repousser à plus tard l'union des époux. On pense ici aux rites de barrage que l'on retrouve à divers moments du scénario nuptial et qui consistent à retarder le passage des futurs époux vers l'église ou vers le lieu de la noce (N. Belmont, 1973). Pour que la barrière soit levée, l'époux devait verser une somme quelconque aux organisateurs de la noce (A.VAN GENNEP, 1943-1958). Ce geste était interprété comme une compensation versée par l'époux aux célibataires en échange de la future épouse.

Les cortèges revêtent également un caractère symbolique tout à fait intéressant. Selon Nicole BELMONT (1978), on retrouve trois étapes distinctes, soit:

1) la "départie", c'est-à-dire le départ de la maison de la jeune fille; 
2) la halte à l'église pour la cérémonie religieuse;

3) l'arrivée à la maison de l'époux ou de son père (au retour de l'église) ${ }^{1}$.

Que ce soit pour se rendre à la maison de la jeune fille, à l'église ou encore au lieu de la noce, les participants forment un cortège qui rend ainsi publique la nouvelle union. Ces trois étapes importantes constituent le schéma et le principe essentiel du mariage. Premièrement, le père remet sa fille au jeune homme. Deuxièmement, la fille est épousée et le don est consacré à l'église. Finalement, la fille change de maison et donc de condition. En des termes plus simples, la femme passe d'une maison à l'autre. Tout ceci bien sûr, accompagné de rites de séparation et de rites d'agrégation. Notons par ailleurs que dans le cas des rites déjà mentionnés, soit les rites de barrage et ceux du cortège, la fille ne pose pas d'action; elle est échangée, donnée, épousée. Elle joue un rôle tout à fait passif.

${ }^{1} \mathrm{Au}$ Saguenay, au retour de l'église, les participants se rendaient à la maison du père de la jeune fille. 
2 - Enquêtes France / Nouvelle-France

Dans la perspective du problème de l'évolution des contenus coutumiers, on ne dispose que de quelques éléments de comparaison ponctuelle qui font état d'une sorte de discontinuité culturelle sur 1 'axe France / Nouvelle-France. On pense en premier lieu à la monographie d'Anne-Marie DESDOUITS (1985) qui permet de faire la comparaison à partir de la communion solennelle telle que célébrée dans le pays de Caux et au Québec pendant la première moitié du XXe siècle. Contrairement à la cérémonie du pays de caux, où l'événement revêt une dimension sociale prépondérante, l'auteure trouve le rite québécois relativement réduit. Il s'agit peut-être là d'un exemple de mutation culturelle qui se situerait dans l'axe de transfert démographique France / NouvelleFrance et qui illustrerait un phénomène d'érosion.

Une autre recherche, dirigée par D. RODRIGUE (1983), amène des éléments très éclairants portant sur l'observation de coutumes en particulier, soit celles qui ont trait au carême (p. 195), au rameau bénit (p. 210), au vendredi saint (p. 229 et 232), aux oeufs de Pâques (p. 248) et à la st-Blaise (p. 41). L'auteure conclut également que ces coutumes 
auraient présenté des formes plus élaborées en France qu'au Québec.

De plus, toujours selon le premier axe de transfert démographique, Jocelyne MATHIEU (1985) s'est intéressée à la culture matérielle et à l'équipement domestique dans le Perche et en Nouvelle-France. La recherche démontre la même tendance que celles mentionnées ci-haut, soit une certaine érosion ou contraction des formes culturelles en Nouvelle-France.

Enfin, une étude récente (L. HERAULT, 1987) portant spécifiquement sur les rituels nuptiaux dans le haut bocage vendéen nous permet de voir qu'encore aujourd'hui, les rituels de fiançailles et de mariage dans cette région constituent un temps fort de la vie des communautés rurales. Même si cette étude ne permet pas de faire la comparaison avec les régions du Québec, il semble évident même aujourd'hui que les rites présents dans le haut bocage vendéen sont beaucoup plus élaborés qu'ils ne le sont dans les régions du Québec - dans la mesure où on peut en juger à ce stade-ci. On constate en effet que, loin d'être contractées, les formes culturelles ont survêcu, ont été remodelées 
ou ont été remplacées en faisant toutefois référence à ce qu'elles étaient naguère.

D'autres recherches ont été faites sur le mariage dans les sociétés traditionnelles (J.DUPAQUIER et alii, 1988; J.-M. GOUESSE 1981) . Les périodes retenues (soit du XVI-XVIIe siècles chez Dupaquier et du XVI-XXe siècles chez Gouesse) ne peuvent être étudiées qu'à partir de sources manuscrites; ces dernières permettent de faire la lumière sur les aspects plutôt démographiques du mariage, soit: I'endogamie, I'exogamie, le choix du conjoint, l'âge au mariage, etc. Quoique ces études ne soient pas faites dans une perspective comparative, elles rapportent néammoins des modèles reliés au choix du conjoint dans les provinces de la France et nous permettent donc de mieux connaitre ces populations susceptibles de migrer vers la NouvelleFrance.

3 - Vieux centres laurentiens - régions neuves ou périphériques

Jusqu'à très récemment, l'espace québécois n'a pas fait l'objet d'études comparées dans la perspective des recherches ci-haut mentionnées. Cependant, depuis peu, Anne-Marie Desdouits, professeure- 
chercheure à l'Université Laval, s'est jointe à l'équipe de SOREP et enquête sur les rites et pratiques reliées à l'institution du mariage sur le deuxième axe de transfert démographique soit celui reliant Québec à la Côte-de-Beaupré et à la Beauce. Les résultats de cette enquête pourront ensuite être comparés avec les résultats du présent mémoire puisque ce sont les mêmes instruments de recherche qui sont utilisés. Il en va de même avec l'enquête menée par René Hardy (Université du Québec à TroisRivières) sur la région de la Mauricie.

Par ailleurs, I'historiographie québécoise dispose de très peu d'ouvrages qui font état de l'évolution des formes culturelles et des pratiques coutumières au Québec dans la perspective de la présente enquête. On pense à une étude de Pierre DESRUISSEAUX (1973) portant sur les croyances et les pratiques populaires au canada français où il rapporte ce qu'il appelle des traits caractéristiques dans différentes régions. En ce qui concerne les fréquentations, le mariage ainsi que les rêves se rapportant au mariage, on retrouve des éléments qui témoignent d'un code prescrit quant aux "manières de faire" en ces occasions. On trouve aussi quelques corpus des faits ethnographiques (c. 
ASSELIN, Y. LACASSE, 1982; H. VACHON, 1982) qui dressent également l'inventaire des pratiques reliées aux événements importants de la vie dans des régions spécifiques. On y relève de précieux détails concernant les fréquentations, le mariage, etc. Dans un ouvrage portant sur la vie traditionnelle dans la vallée du Saint-Laurent, Jean PROVENCHER (1986) relate l'ensemble des circonstances entourant le mariage. Ces notes historiques dénotent un code élaboré visant à encadrer les jeunes gens dans leur démarche vers le mariage. D'autres recherches entreprises par Denise LEMIEUX et Lucie MERCIER (1987, 1989) permettent, dans une perspective plus féministe, de jeter un regard sur la condition des femmes et sur la famille québécoise au tournant du siècle. Quelques notes de recherches sur le mariage dans nos campagnes d'autrefois et en Nouvelle-France (J.E. ROY, 1923; R. DOUVILLE, J.-D. CASANOVA, 1965) rapportent certains détails sur la noce elle-même ou sur certains aspects reliés au mariage. Dans sa monographie sur le village de St-Denis, Horace MINER (1985) décrit le déroulement plutôt expéditif des événements qui mènent au mariage. Notons que le village de st-Denis est situé sur la rive sud du fleuve st-Laurent et qu'il entretenait des rapports avec la région de Charlevoix à cette époque. 
Ces ouvrages constituent un cadre de références très riche pour notre enquête. L'ensemble des notations empiriques qu'ils contiennent représente une sorte de cadre comparatif que nous mettrons à profit dans les chapitres qui suivent. 
CHAPITRE II

METHODOLOGIE 


\section{A - Enquête orale}

Depuis de nombreuses années, les spécialistes de l'enquête orale, qu'il s'agisse des folkloristes ou des ethnologues, ont enrichi notre connaissance de la cultures traditionnelle (voir par exemple CUISENIER J.,SEGALEN M.,1986). L'enquête orale s'est souvent penchée sur l'histoire des groupes dominés, et ce afin de recueillir des données, se contentant souvent de procéder à un inventaire exhaustif sans toutefois tendre vers l'analyse systématique des phénomènes étudiés. Mais elle a largement abordé aussi l'étude des populations paysannes. Le manuel de folklore écrit par Arnold VAN GENNEP (1943-58) est un exemple de description exhaustive où l'on présente des contenus coutumiers de façon très détaillée en s'abstenant d'élucider les relations et les variations quant aux symboles ou aux rites eux-mêmes. Depuis quelques années, les chercheurs en sciences sociales, tout en reconnaissant la valeur scientifique de la démarche folkloriste (P. JOUTARD, 1983; B. JEWSIEWICKI, 1987), l'utilisent dans de nouvelles avenues de recherche. Dans un mélange d'entrevues, d'observations participantes et d'histoires de vie (D. BERTAUX, 1976), les études sociologiques et historiques se sont donné les moyens d'explorer et de comparer, entre 
autres choses, les traits caractéristiques des identités régionales. Il faut mentionner aussi une importante littérature en ethnologie régionale, laquelle a abondamment recouru à l'enquête orale. C'est sur la base de l'enquête orale ainsi conçue que nous avons tenté de reconstituer les modèles culturels qui nous intéressent.

Bien qu'elle soit assez facile à mettre en oeuvre, l'enquête orale présente certaines difficultés spécifiques en rapport avec la collecte des données. Il convient ici d'en mentionner deux en particulier. Premièrement, l'établissement d'une relation chercheur(e)informateur(trice) qui est à la base du climat de confiance permettant d'explorer ensemble des souvenirs parfois confus et souvent très lointains. Deuxièmement, mentionnons qu'il est essentiel de valoriser les propos de l'informateur(trice) car à ses yeux (du moins au Saguenay), les événements qu'il ou elle a vécus sont souvent jugés très banals et parfois peu intéressants. Voilà deux difficultés rencontrées lors des entrevues qu'il est important de mentionner puisqu'elles sont, selon nous, conditionnelles à la réussite d'une collecte fructueuse. 
Toutefois, même si l'enquête orale auprès des personnes âgées présente un caractère particulier quant à ses difficultés d'exécution, cette source, de plus en plus exploitée depuis quelques années, rapporte souvent le non-dit et presque toujours le non-écrit. La mémoire vivante constitue une richesse inestimable qui transporte avec elle le passé d'une société dont aucun registre d'état civil, recensement ou rapport ne fait état.

Comme il a déjà été mentionné, retrouver les circonstances des mariages célébrés à la fin du XIXe siècle et au début du XXe siècle nécessite une collecte de données de base par le biais d'enquêtes orales. Bien que les informateur(trice)s se soient marié(e)s il y a une cinquantaine d'années, ces personnes gardent un souvenir assez clair du moment souvent considéré comme le plus important de leur vie. Elles peuvent aussi témoigner d'événements relatifs à leurs parents. Nous croyons donc que la mémoire individuelle est apte à restituer fidèlement $l$ 'information nécessaire à ce genre de recherche.

Par contre, ces enquêtes comportent évidemment aussi des lacunes. Les plus importantes résident sans doute dans les omissions, dont la plupart sont imputables soit à des fautes de mémoire, soit à la timidité ou à la pudeur des personnes interrogées. 
Toutefois, même si l'enquête orale auprès des personnes âgées présente un caractère particulier quant à ses difficultés d'exécution, cette source, de plus en plus exploitée depuis quelques années, rapporte souvent le non-dit et presque toujours le non-écrit. La mémoire vivante constitue une richesse inestimable qui transporte avec elle le passé d'une société dont aucun registre d'état civil, recensement ou rapport ne fait état.

Comme il a déjà été mentionné, retrouver les circonstances des mariages célébrés à la fin du XIXe siècle et au début du XXe siècle nécessite une collecte de données de base par le biais d'enquêtes orales. Bien que les informateur(trice)s se soient marié(e)s il y a une cinquantaine d'années, ces personnes gardent un souvenir assez clair du moment souvent considéré comme le plus important de leur vie. Elles peuvent aussi témoigner d'événements relatifs à leurs parents. Nous croyons donc que la mémoire individuelle est apte à restituer fidèlement l'information nécessaire à ce genre de recherche.

Par contre, ces enquêtes comportent évidemment aussi des lacunes. Les plus importantes résident sans doute dans les omissions, dont la plupart sont imputables soit à des fautes de mémoire, soit à la timidité ou à la pudeur des personnes interrogées. 


\section{B - sources}

1 - Données orales et instruments

La source primaire de ce travail est constituée de 40 entrevues en profondeur réalisées auprès de personnes âgées. Pour les fins de la comparaison, 25 ont été réalisées au Saguenay (Annexe 1) et 15 dans la région de Charlevoix (Annexe 2). Ces entrevues dont la durée varie de deux à cinq heures, ont eu lieu en général dans un centre gérontologique ou à la résidence des informateur(trice)s et sont conservées sur bande magnétique à SOREP. ${ }^{2}$

Il est certain qu'avec deux ou trois fois plus d'entrevues, nous aurions recueilli plus de matériaux. Néanmoins, nous avons cru bon de nous limiter à $40 \mathrm{vu}$ le cadre de la présente recherche. Comme les dernières entrevues n'ajoutaient que très peu d'informations nouvelles et que le rendement s'avérait décroissant, il devenait donc de moins en moins rentable de prolonger la collecte de données.

2 SOREP est un centre interuniversitaire de recherches sur les populations créé en vertu d'un protocole d'entente entre trois composantes soit l'Université du Québec à Chicoutimi, l'Université Laval et I'Université McGill. 
Les entrevues ont eu lieu en général en deux temps. Lorsque des questions avaient été laissées sans réponse, une deuxième rencontre avait lieu afin de compléter le questionnaire. La grande majorité des informateur(trice)s était des veuves quelquefois remariées qui, en présence du second mari, montraient une certaine gêne à parler de leur premier mariage.

Les personnes recrutées sont nées et se sont mariées au Saguenay ou nées et se sont mariées dans Charlevoix. Elles ont souvent été choisies par l'animatrice du foyer d'accueil ou encore m'ont été présentées en raison de leur bonne mémoire, de leur vivacité et de leur facilité d'élocution. Notons ici que ces personnes sont en général des femmes (80\%). Il s'agit de personnes nées à la fin du XIXe siècle ou au début du XXe siècle (Tableau 1). 
TABLEAU 1

Distribution des informateur(trice)s selon leur période de naissance

\begin{tabular}{|c|c|c|}
\hline Période & SAGUENAY & CHARLEVOIX \\
\hline $1886-1890$ & 0 & 1 \\
$1891-1895$ & 1 & 4 \\
$1896-1900$ & 7 & 2 \\
$1901-1905$ & 6 & 3 \\
$1906-1910$ & 11 & 3 \\
$1911-1915$ & 3 & 0 \\
$1916-1920$ & 0 & 1 \\
$1921-1925$ & 0 & 15 \\
\hline TOTAL & 28 & \\
\hline
\end{tabular}

Note: Le nombre d'informateur(trice)s pour la région du Saguenay est de 28 puisque trois entrevues ont été faites avec les deux conjoints.

Au Saguenay, les paroisses où ont été célébrés les mariages sont concentrées dans la sous-région $\mathrm{du}$ Haut-Saguenay (les trois sous-régions du Saguenay sont représentées à la Carte 2). Ce sont en général de vieilles paroisses où les formes culturelles présentes sont les témoins d'une culture 


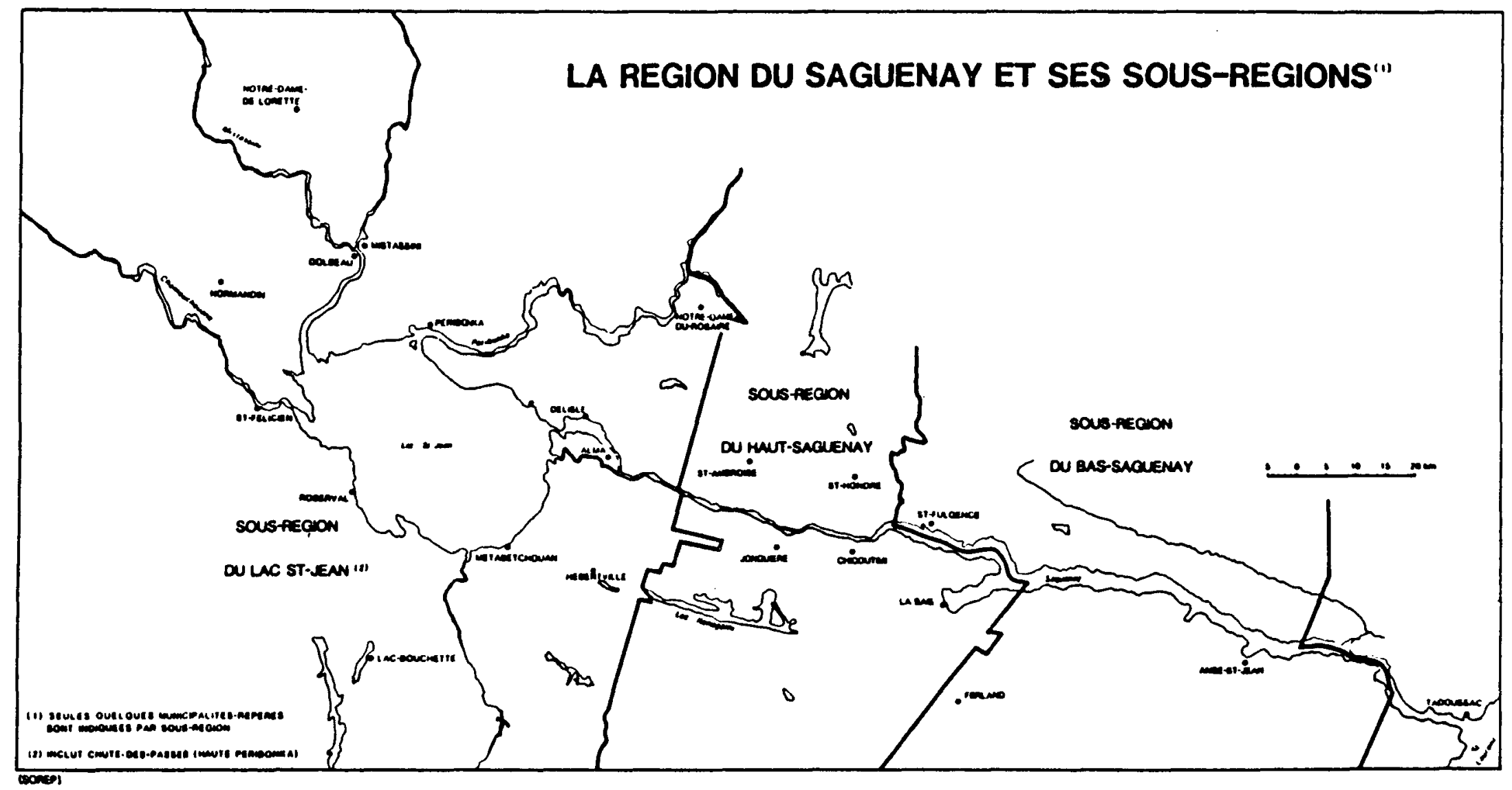

Carte 2 
tributaire du mode de vie des premiers immigrants venus lors de l'ouverture du Saguenay.

Le contenu de ces entrevues repose sur un questionnaire élaboré (A.-M. DESDOUITS et alii, 1986) qui scinde l'institution du mariage en 17 composantes ou rites (voir Tableau 2). Construit à partir des rituels populaires du mariage en ancienne France, cet instrument assure une sorte d'inventaire (incomplet bien sûr mais suffisant pour les fins de notre enquête) des pratiques coutumières reliées au mariage. Malgré son contenu très détaillé qui peut poser des problèmes lors de I'entrevue, ce questionnaire permet souvent à l'informateur de retrouver des détails banalisés qui, sans I'aide de cet instrument de recherche, ne seraient pas ressuscités. 
TABLEAU 2

\section{Eléments constitutifs ou composantes relatives au déroulement du mariage}

$\begin{array}{ll}\text { I- } & \text { Les informations préliminaires } \\ \text { II- } & \text { Les fréquentations } \\ \text { III- } & \text { L'accord mutuel } \\ \text { IV- } & \text { Les demandes } \\ \text { V- } & \text { Les fiançailles } \\ \text { VI- } & \text { Le ccntrat } \\ \text { VII- } & \text { La dot et transmission des biens } \\ \text { VIII- } & \text { L'enterrement de la vie de célibat } \\ \text { IX- } & \text { L'habillage des mariés } \\ X- & \text { Le transport vers l'église } \\ X I- & \text { La cérémonie religieuse } \\ X I I- & \text { Le transport vers le lieu de la noce } \\ X I I I-~ & \text { La noce } \\ X I V- & \text { La nuit de noce } \\ \text { XV- } & \text { Le voyage de noce } \\ \text { XVI- } & \text { La réinsertion sociale } \\ & \end{array}$

Chaque composante se décompose en séquences de rites, chacun de ceux-ci comportant un certain nombre d'éléments. 
Afin de repérer des constantes quant aux modèles culturels étudiés, les résultats des entrevues sont reportés sur une grille d'analyse (A.-M. DESDOUITS et alii, 1986) construite à partir du questionnaire, en l'occurrence sur la base d'un choix de réponses. Cette grille d'analyse permet de mettre en lumière rapidement la cristallisation ou la "saturation" ${ }^{3}$ de phénomènes ou de modèles. Chez Bertaux, ce concept désigne l'occurrence d'un comportement qui, à force de se répéter, finit par accréditer un stéréotype. Toutefois, pour les questions pouvant susciter des descriptions qui ne sont pas prévues par la grille, l'information est mise sur fiche pour ensuite être comparée avec d'autres renseignements tels que le costume de la mariée, le repas de noce, les invités, etc.

Il y a cependant une impression toute personnelle qui souvent se dégageait des entrevues avec les informatrices de la région du Saguenay. On sentait, au cours du récit, une certaine tristesse quant aux raisons et aux motivations qui les avaient menées à la célébration du mariage. La tête penchée, le regard fixant le sol, roulant entre leurs doigts la ganse de leur jupe ou de

${ }^{3}$ Daniel Bertaux (1986) insiste sur l'importance de la saturation d'un phénomène car il permet, entre autres choses, "de définir une population-cible qui a vécu avec ou sans passion l'événement ou l'espace qui nous intéresse" (page 28). 
leur chemise, elles ont souvent manifesté une sorte de regret de n'avoir pu profiter davantage de leur jeunesse. Cette attitude n'a pas été ressentie au cours des entrevues dans la région de Charlevoix. Pourtant, on se mariait à peu près au même âge dans l'une et l'autre région.

2 - Données informatisées

Nous avons également procédé à l'exploitation de quelques données informatisées contenues dans le fichier-réseau BALSAC ${ }^{4}$. A l'aide de ce fichier, nous avons $\mathrm{pu}$ faire ressortir quelques aspects quantitatifs qui sont en rapport direct avec l'institution analysée, soit les mouvements journaliers et saisonniers du mariage. Ces mouvements mettent en lumière le choix du moment du mariage pendant quelques décennies et permettent de comparer le modèle de Charlevoix à celui du Saguenay dans une double perspective, synchronique et diachronique.

${ }^{4}$ Le fichier-réseau BALSAC est un fichier de population informatisé fondé sur le jumelage automatique de données nominatives provenant principalement de registres de l'état civil. 
3 - Autres données utilisées

Le corpus d'entrevues saguenayennes conservées aux Archives Nationales du Québec à Chicoutimi et qui ont servi de point de départ à la réflexion sur la dynamique culturelle des régions de peuplement (G. BOUCHARD, 1986) a servi à attester ou valider quelques éléments de recherche. Diverses données ethnographiques puisées à cette source secondaire et relatives à la vie quotidienne des premiers Saguenayens ont permis de vérifier certaines hypothèses concernant les modèles culturels des débuts de la colonisation.

Les jalons nous permettant de situer notre étude ont été présentés. Voyons maintenant quels sont les résultats de l'analyse des diverses composantes reliées à l'institution du mariage. 
DEUXIEME PARTIE

LE MARIAGE SAGUENAYEN 
CHAPITRE III

DE LA RENCONTRE AU MARIAGE 
Dans cette deuxième partie, nous ferons l'analyse des données issues des entrevues réalisées au saguenay. Chaque composante ou élément constitutif relié à l'institution du mariage et étudié à partir du questionnaire fera l'objet d'une analyse. Pour des raisons évidentes toutefois, seuls les éléments pour lesquels nous avons recueilli de l'information (il arrivait que des informateur(trice)s ne puissent répondre à des questions par manque de mémoire) seront décrits de façon détaillée. Nous dresserons ainsi l'inventaire complet des rituels et pratiques présentes au saguenay. Par ailleurs, au besoin, nous indiquerons entre parenthèses le nombre de fois où tel rituel ou telle pratique a été mentionné lors des entrevues réalisées au Saguenay $(\mathrm{N}=25)$.

A cause du nombre élevé de composantes couvertes par le questionnaire, nous avons cru utile de diviser la présente partie en trois chapitres soit:

Chapitre III- De la rencontre au mariage

Chapitre IV- La cérémonie du mariage

Chapitre V- La noce et l'établissement du ménage

Ces trois divisions renvoient à trois étapes du phénomène à l'étude et elles servent de jalons à la présente recherche. 
Le déroulement des événements depuis la première rencontre jusqu'à la cérémonie religieuse constitue la première étape qui mène à la cérémonie du mariage. Nous tenterons de voir en détail les divers éléments qui soutiennent le choix des conjoints pour ensuite les mener au mariage.

\section{A - Informations préliminaires}

1 - Les circonstances de la première rencontre

Dans la société rurale, la vie sociale des jeunes gens était très influencée par les allées et venues de leurs parents et de leurs voisins. Les relations amicales entretenues d'une famille à l'autre pouvaient amener un jeune homme ou une jeune fille à faire la connaissance d'étrangers en promenade au village ou de parent(e)s en visite chez le voisin. En effet, dans l'organisation des rapports sociaux, les liens de parenté sont très importants et influencent souvent indirectement le choix du conjoint (D. LEMIEUX et alii, 1987; H. MINER, 1985). C'est en allant "se promener chez une tante ou un cousin" (N=3) que I'on pouvait rencontrer son amoureux. Dans des régions rurales comme le Saguenay, où le cadre social était assez restreint, les rencontres des jeunes avaient très 
souvent lieu grâce à des relations parentales $(N=8)$ ou de voisinage $(N=7)$. On observe le même modèle sur le choix des conjoints dans une communauté bocagère en Bresse (P.PONSOT, 1981).

Même si le clergé veillait de très près à la bonne conduite des paroissiens, ceux-ci organisaient, avec ou sans sa permission, des soirées au cours desquelles ils dansaient des "sets" ou des gigues (" il ne fallait pas trop se toucher en dansant") ${ }^{5}$. L'organisation de ces veillées n'était pas chose courante mais c'était une occasion privilégiée pour s'amuser, danser et chanter.

Les "grandes veillées" 6 données à l'occasion d'une noce ou les "petites" veillées organisées par un parent pour la jeunesse du rang ont également permis la rencontre de quelques jeunes gens $(N=6)$. Il arrivait aussi que des soirées soient organisées

\footnotetext{
${ }^{5}$ Pour des raisons de confidentialité, nous tairons le nom des informateur(trice)s dont les paroles seront citées. Par ailleurs, on trouvera en annexes 1 et 2 les données personnelles et socioprofessionnelles sur les informateur(trice)s qui ont bien voulu collaborer à la présente recherche.

${ }^{6}$ Suivant les circonstances et le nombre d'invités, les veillées sont qualifiées de "petites" ou de "grandes". Les "grandes" veillées surviennent à l'occasion des grandes fêtes: Noël, Pâques, une noce, etc. Elles permettent à la jeunesse du rang et du village (parfois les deux) de se regrouper et de faire nâtre des liaisons (A. TREMBLAY, 1948).
} 
par une tante ou une voisine spécialement pour permettre la rencontre de deux jeunes gens bien identifiés $(\mathrm{N}=3)$.

2 - La situation socio-professionnelle des conjoints

Dans Charlevoix et au Saguenay, l'espace rural fournissait un marché matrimonial masculin qui était caractérisé par une majorité de cultivateurs et de journaliers. Notre échantillon est représentatif de la distribution de ces professions au début du XXe siècle. Il est cependant intéressant d'observer que plusieurs de nos informatrices $(\mathrm{N}=10)$ ont ellesmêmes occupé un emploi avant de se marier. Le mariage écartant toute possibilité de conserver un emploi, les femmes mariées renonçaient à la carrière et consacraient tout leur temps à "tenir maison". on retrouve le même comportement féminin en BasseNormandie aux XVIIe et XVIIIe siècles (J.-M. GOUESSE, 1976). 
3 - Les motivations au mariage

Quelques qualificatifs reviennent très souvent lorsque l'on aborde les motivations et dispositions qu'entretenaient les futurs époux les uns envers les autres. Celles-ci ne diffèrent pas beaucoup, que l'on soit un homme ou une femme. On retrouve en premier lieu l'importance de l'attrait physique ("Il avait l'air fin", "C'était une belle grande brune", "Elle avait de beaux petits mollets"). En second lieu, le sens pratique ("C'était un bon travaillant", "Il était sérieux") prenait beaucoup d'importance puisque l'on craignait la misère et la pauvreté. La jeune fille s'assurait donc que son futur époux ait un sens pratique et qu'il soit ce que l'on appelle communément un "bon parti".

4 - Les finalités de l'union

Les raisons spécifiques qui amènent deux jeunes gens à se marier varient mais sont en général reliées au désir d'avoir des enfants. Pour certaines femmes, on se mariait par amour $(\mathrm{N}=8)$ ou pour toutes sortes de raisons, notamment parce que les familles étaient nombreuses et que la présence prolongée d'une fille au foyer était une charge de plus (J. PROVENCHER, 1986). Fonder un foyer $(\mathrm{N}=5)$, 
avoir des enfants (chez les femmes: $N=3$ ), prouver sa virilité (chez les hommes: $N=2$ ), sont quelques finalités retrouvées au cours des entrevues.

\section{B - Les fréquentations}

1 - Les données contextuelles et les contrôles

Comme on le rapporte dans la vallée du saintLaurent (J. PROVENCHER, 1986; H. MINER, 1985), les fréquentations étaient en général de courte durée, c'est-à-dire qu'elles variaient d'une semaine à un an. Dans bien des cas, les deux époux ne se connaissaient que très peu au moment du mariage ("on se mariait avec des étrangers"). Le domicile de la jeune fille était le cadre des fréquentations. Les maisons étaient vastes plutôt sans cloisonnement, et toute la famille veillait dans la même pièce. Pour passer le temps agréablement, on faisait des farces, on chantait, on jasait. Pour mieux surveiller ceux qui veillaient au salon, les procédés variaient: on installait un grand miroir, on perçait le journal pour entrevoir le couple au cours de sa lecture, etc... On ne laissait jamais les prétendants seuls. Comme le rapportent Carole ASSELIN et Yves LACASSE (1982), on improvisait un 
chaperon qui les accompagnait partout. Ces contrôles étaient pris en charge par la famille et non par le clergé.

Trois informatrices ont déclaré n'avoir jamais fréquenté leur futur époux. Ces derniers s'étant absentés pour les chantiers immédiatement après la première rencontre, les jeunes gens se mariaient au retour.

2 - Les échanges

Au cours des fréquentations, on procédait à des échanges. Un objet de peu de valeur ("c'était pas comme aujourd'hui, on était pas riche"), un petit cadeau acheté en ville à l'intention de la future épouse rendaient la liaison encore plus officielle. La nature du cadeau pouvait varier: du paquet de friandises à l'ensemble de brosse et peigne à cheveux. Le souvenir du premier (et parfois l'unique...) cadeau offert par son prétendant est très clair dans la mémoire des informatrices. Contrairement à l'ancienne France où la relation amoureuse semblait s'appuyer sur des échanges d'objets symboliques (M.SEGALEN, 1981), on ne retrouve pas de ces rituels de "courtoisie" au Saguenay. Il n'y 
a pas d'échanges d'objets (noix ou objets sculptés par le futur époux) qui se substituent à la parole pour signifier la poursuite des fréquentations. Par exemple, on signale qu'en France, c'est au jeune homme d'offrir le premier cadeau, et si la fille accepte celui-ci, c'est qu'elle consent à poursuivre les fréquentations. La nature des objets offerts varie selon les régions de France: des bagues, des noisettes gravées des initiales des deux jeunes gens, des cuillères incrustées, etc.

Dans les cas d'éloignement dû au travail, il arrivait que les futurs communiquent entre eux par correspondance. En particulier lorsqu'elles étaient écrites par eux-mêmes, ces lettres servaient à entretenir leurs sentiments pendant la période d'absence. Par ailleurs, on rapporte l'existence d'un guide de correspondance amoureuse qui facilitait la communication écrite en suggérant les formulations "exactes" pour traduire ses sentiments.

Toutefois, ce que les ethnologues appellent le "comportement gestuel" était réduit au minimum. En présence de la famille, on devait se conformer aux règles déjà établies. On se tenait par la main très rarement, on se volait un baiser en cachette. 
3 - Les stratagèmes galants

Les stratagèmes pour provoquer la rencontre d'un conjoint étaient peu connus. on évoque toutefois quelques croyances qui permettaient à la jeune fille de voir le visage de son prétendant pendant son sommeil. Notons, par ailleurs, que ces pratiques avaient lieu avant le coucher et qu'elles conféraient à la nuit un caractère plutôt magique. Ces pratiques n'étaient pas très répandues au Saguenay. Au cours des entrevues, nous avons trouvé les suivantes:

1 - Manger de la galette de sel avant de s'endormir pour rêver à son futur époux $(\mathrm{N}=4)$.

2 - Confectionner une petite échelle (en papier ou en bois) que l'on place sous son oreiller pour voir son prétendant pendant son sommeil $(\mathrm{N}=3)$.

3 - Faire une neuvaine pour rencontrer un amoureux $(\mathrm{N}=2)$.

P. DESRUISSEAUX (1973) rapporte de telles pratiques relatives à la découverte du futur époux en Nouvelle-France. Il rapporte le trait suivant: 
après avoir compté cent chevaux blancs ou noirs, le premier garçon aperçu deviendra son mari.

\section{C - L'accord des partis}

Peu de temps après la rencontre entre les deux jeunes gens (soit de un à six mois), le jeune homme prenait l'initiative de demander à la jeune fille si elle voulait bien l'épouser. Le moment où avait lieu cette demande semble avoir été improvisé. Cet accord mutuel est complètement dénué de toute pratique rituelle. De façon informelle et souvent à mots couverts, après une visite au domicile des parents de la jeune fille, le jeune homme demandait à son amie si elle l'aimait assez pour l'épouser. La jeune fille donnait sa réponse de façon également informelle. Selon nos entrevues, elles $\mathrm{n}$ 'ont pas toutes accepté la première demande en mariage. La plupart ont accepté $(\mathrm{N}=20)$ mais quelques-unes ont refusé $(\mathrm{N}=5)$. Le nombre d'informatrices qui ont refusé la première demande en mariage démontre que l'on se permettait de choisir quelqu'un qui plaisait et que l'on ne mariait pas nécessairement le premier venu.

S'étant engagés mutuellement à poursuivre leurs relations jusqu'à la célébration du mariage, les "futurs" envisageaient alors de procéder à la demande en mariage 
auprès du père de la jeune fille lors de la prochaine visite ou le dimanche suivant.

\section{D - Les demandes}

Dans un contexte de colonisation où chaque membre de la famille participait au travail de la terre, on pourrait croire que le fils demandait premièrement à ses parents la permission de quitter le milieu familial. De façon générale, on observe qu'il n'en est pas ainsi. Très souvent, le jeune homme se dit "en âge de se marier" et considère sa décision comme irrévocable. Il annonçait donc à ses parents ses projets futurs sans plus de manières.

De son coté, la jeune fille "en parlait" avec ses parents. Voyant les fréquentations se poursuivre,les parents se doutaient bien des intentions de leur fille. Il était mieux vu de "marier sa fille" que de la voir vouée au célibat.

La demande officielle en mariage (soit celle où le jeune homme demande la main au père de la jeune fille) semble s'être déroulée selon un modèle assez clair. Elle avait lieu, le plus souvent, le dimanche au cours de la visite suivant l'accord mutuel. Le jeune homme, vêtu 
pour la circonstance, demandait au père s'il voulait bien lui accorder la main de sa fille. Cela se faisait en présence du père et de la mère de la jeune fille. En quelques mots et de façon informelle encore là, le père consentait au projet en servant toutefois au futur gendre l'avertissement de veiller sur sa fille et d'en prendre bien soin. L'événement était dépourvu de cérémonial et il ne donnait lieu à aucune manifestation officielle. Un seul informateur a déclaré avoir pris une collation ("des fraises avec du sucre") après avoir formulé sa demande auprès du père. Une informatrice a toutefois déclaré que son mari étant trop timide pour faire la grande demande, elle a elle-même demandé à son père la permission de se marier. De plus, un informateur a dit ne pas avoir eu besoin de formuler sa demande verbalement; lui et son futur beau-père se connaissaient depuis longtemps et les intentions du jeune homme avait été pressenties par le futur beau-père.

\section{E - Les fiançailles}

On sait que les fiançailles avaient été abolies sous le régime français par le deuxième évêque de Québec, Mgr de Saint-Vallier (J. PROVENCHER, 1986). Le clergé, soucieux de la bonne conduite de la jeunesse, reprochait aux fiancés de prendre des libertés qui n'étaient 
permises qu'en mariage. On retrouve également cette méfiance à l'égard des fiançailles dans quelques régions de la France au XVIIe et au XVIIIe siècles (J. DUPAQUIER et alii, 1988); (A. BURGIERE, 1978). C'est beaucoup plus tard, c'est-à-dire vers le milieu du XXe siècle, que ce rituel réapparâ̂tra au Québec.

Quoi qu'il en soit, on ne relève au Saguenay aucune forme de fiançailles ni aucune activité qui aurait pu en tenir lieu.

\section{F - Le contrat}

La signature du contrat de mariage était chose courante au Saguenay dans la première moitié du XXe siècle. Dans le but de protéger ou d'avantager la future épouse, les jeunes gens passaient chez le notaire afin d'y signer un contrat qui dans la majorité des cas était "en communauté de biens". L'événement avait lieu rarement plus d'une semaine avant la cérémonie du mariage. Le tout se déroulait en présence du jeune homme accompagné quelquefois de sa future épouse ainsi que des pères et des témoins. Les mères étaient rarement présentes lors de la signature du contrat de mariage. J.-Edmond ROY (1923) rapporte qu'il existait une coutume voulant que le notaire soit le premier à embrasser la 
mariée après la signature des papiers. Ce privilège accordé aux notaires n'existe pas au Saguenay. I'événement se déroulait sans cérémonie et de toute évidence sans comportement gestuel de cette sorte.

\section{G - Les apports matériels au ménage}

La dot est l'apport matériel de la famille de la jeune fille au nouveau ménage. Dans un contexte de colonisation comme celui du Saguenay, la dot se composait ordinairement de quelques animaux (des poules, un cochon, une vache). Lorsque les parents étaient plus à l'aise financièrement, ils faisaient aussi don d'un lit et d'une armoire $(\mathrm{N}=13)$. Ces meubles avaient été achetés $(\mathrm{N}=7)$, ou étaient de fabrication domestique $(\mathrm{N}=3)$ ou encore provenaient du patrimoine familial $(\mathrm{N}=3)$.

Le trousseau, qui constituait l'apport de la jeune fille au ménage, se composait de pièces de lingerie, de vaisselle et de linge de corps. L'ampleur et le contenu variaient selon la situation financière de la famille. Dans certains cas, les fiancées et leur mère $(\mathrm{N}=20)$ avaient tissé des couvertures, des linges à vaisselle, des nappes, etc. Dans d'autres cas, les fiancées avaient acheté leur trousseau $(N=4)$. Une informatrice a déclaré n'en avoir eu aucun. On constate ici que le trousseau, 
propriété de la femme (A. FINE, 1984), n'est pas un élément essentiel au projet de mariage. A. Fine rapporte en effet que dans un village Lauragais au XVIIIe siècle, une jeune fille ne pouvait pas penser au mariage si elle n'avait pas préalablement acquis un trousseau. Pour le Saguenay, on remarque la rareté des objets de valeur, des souvenirs de famille qui auraient pu être transmis d'une génération à I'autre.

L'homme, de son coté, apportait au ménage les biens qu'il avait acquis auparavant. La nature de ces biens allait de quelques animaux à une terre défrichée, plus quelques instruments aratoires dont il avait hérité.

\section{H - I'enterrement du célibat}

L'enterrement de vie de célibat, rite réservé aux hommes, n'était pas très répandu au saguenay. Les rares enterrements évoqués ont eu lieu dans un milieu plutôt urbain et consistaient en une veillée au cours de laquelle on jouait aux cartes et on remettait un cadeau au jeune homme.

Les enterrements décrits par Laurence HERAULT (1987) dans le bocage vendéen sont de loin beaucoup plus élaborés que ceux présents au Saguenay. Elle rapporte 
des cérémonials autour desquels se greffe tout un langage symbolique allant du cercueil au rituel funéraire. Au cours du rituel, on prend soin de placer des bouteilles de vin dans un cercueil de bois qui sera ensuite enterré jusqu'à la naissance du premier enfant. Pour démontrer qu'il est maintenant capable de passer de son statut à celui d'adulte, le jeune homme est tenu de s'enivrer.

Au Saguenay, les rares fêtes mentionnées ont été organisées par des copains de travail de la compagnie Alcan ou Price; on soupçonne donc la grande industrie anglo-saxonne d'avoir introduit cette pratique au Saguenay. Il faut cependant mentionner que d'après les données que nous avons relevées, le groupe des jeunes adultes ("la jeunesse") ne semble pas avoir joué un rôle très actif dans ces circonstances. De plus, l'intervalle entre le moment de la demande en mariage et la cérémonie religieuse elle-même n'était pas très long, ce qui ne facilitait pas les choses.

Au Saguenay, on a toutefois relevé un rituel de séparation réservé aux futures mariées qui étaient sur le marché du travail. Pour une employée de banque, on organisait un "shower" qui marquait l e passage de la jeune fille au monde des adultes. Cette pratique a été retrouvée dans une paroisse d'Arvida qui était à l'époque 
une ville industrielle influencée par la culture anglosaxonne. En guise de cadeau, on offrait à la future mariée des tasses à thé ou un service à thé, symbole de respectabilité. on retrouve également cette pratique dans le nord de Halifax chez les travailleuses de la grande industrie (S.MARTON, 1989). Mais ici encore, il s'agit d'un fait urbain. 
CHAPITRE IV

LA CÉRÉMONIE DU MARIAGE 
Dans ce chapitre, nous analyserons la séquence des événements allant de la veille des noces jusqu'au cortège vers le lieu de la noce. Nous verrons quels étaient les rites de séparation et d'agrégation associés au temps fort de la noce au saguenay.

\section{A - Les invitations}

Les invitations au mariage se faisaient en général de vive voix. Les pères et mères des marié(e)s se chargeaient d'inviter la parenté et le voisinage. Le nombre d'invités variait selon la taille de la famille et la situation financière des parents. on pouvait compter 25, 50, 100 ou 200 invités. Même si la plupart du temps les invitations se faisaient verbalement. Quelques couples ont envoyé des cartes d'invitation écrites à la main $(N=4)$. Dans ce cas, il n'a pas été possible de déterminer si cette pratique était reliée au rang social. La jeune fille et ses proches veillaient à la bonne marche des opérations.

De façon générale, la famille de la jeune fille recevait à dîner après la cérémonie religieuse. Il était de rigueur pour un père qui "mariait sa fille" de payer les frais encourus pour la noce. Toutefois, les deux 
familles participaient à la fête en offrant tour à tour un repas pendant la journée.

Pour les invités qui venaient de l'extérieur, les noces commencaient dans la soirée précédant la cérémonie religieuse. Réunis chez les parents, ceux-ci jouaient aux cartes et préparaient la fête. Ces soirées n'étaient pas une pratique formelle mais elles avaient lieu dans les cas où quelques invités venaient de l'extérieur et séjournaient chez les parents. Les promis veillaient avec leurs parents respectifs et il était convenu qu'on ne se voyait pas la veille des noces. Il semble que dans la vallée du st-Laurent, il était de mauvaise augure de voir son fiancé la veille des noces ( $P$. DESRUISSEAUX, 1973)

\section{B - La publication des bans}

Ainsi qu'il est stipulé dans le traité de droit canonique (R. NAZ, 1954-55), la publication des bans devait se faire en bonne et due forme dans la paroisse où aurait lieu le mariage ainsi que dans la paroisse du jeune homme s'il ne résidait pas dans la même paroisse que la jeune fille. On devait publier trois bans, c'està-dire annoncer pendant trois semaines consécutives le mariage prochain entre les deux partis. Or, au Saguenay, 
on publiait un seul ban et on "achetait" les autres. On versait un montant d'argent pour n'être "publié" qu'une seule fois, et ce le dimanche lors de la grand-messe. Par ailleurs, notons que les "futurs" n'assistaient pas à la messe lors de la publication. On éprouvait une certaine gêne à voir annoncer publiquement ses intentions de mariage. On sent toutefois très bien que cette attitude embarrassée était tributaire du mode de vie très réservé des Saguenayens, du moins dans ces circonstances où ils étaient exposés à l'attention publique.

\section{C - I'habillage des mariés}

Dans la plupart des sociétés paysannes, I'habillage de la mariée était un moment privilégié où la fille se préparait à quitter le foyer paternel pour aller vivre dans une autre maison et souvent avec une autre famille. Durant cette période de préparation, la mère, la soeur ou une couturière procédait officiellement à l'habillage de la mariée. Tout ceci semblait prendre une importance particulière, comme si la réussite de la vie conjugale dépendait du déroulement de ces rites. En d'autres mots, l'absence de ce cérémonial pouvait mettre en péril le bon fonctionnement du futur ménage (M. SEGALEN, 1981). 
Au Saguenay, cet épisode était dénué de rituel et il se déroulait sans cérémonie. La jeune fille mettait moins d'une heure à se préparer. Levée tôt, elle faisait sa toilette, puis s'habillait elle-même $(\mathrm{N}=8)$. Dans certains cas, elle était aidée par une soeur $(\mathrm{N}=3)$ ou quelqu'un d'autre $(N=5)$. En général, elle se coiffait elle-même. La majorité des femmes ne se maquillait pas. Une d'entre elles a cependant appliqué sur son visage "le lait des dames". Cette application (dont il n'a pas été possible de connaitre la nature exacte) rendait le teint plutôt laiteux et à cette époque ceci était vu comme une coquetterie. Quelques informatrices ont déclaré qu'il arrivait que les prêtres refusent la communion à une femme maquillée.

Au moment de quitter la maison paternelle, les femmes déclarent s'être trouvées élégantes. Malgré l'esprit de fête que pouvait susciter un tel événement, on retrouve cependant chez les informatrices un certain regret éprouvé au moment de quitter la maison. La plupart des informatrices l'ont gardé secret. Toutefois des jeunes filles $(\mathrm{N}=3)$ ont pleuré lorsqu'elles ont quitté le foyer familial.

Il n'existait pas de rite spécifique relié à la "départie". On ne retrouve pas de coutume prescrivant 
au père de bénir sa fille avant de la marier. Cette pratique était rare au début du XXe siècle $(\mathrm{N}=4)$. Elle s'est répandue un peu plus tard, semble-t-il, vers le milieu du Xxe siècle.

Le couple portait des vêtements neufs pour la cérémonie du mariage. On investissait un peu d'argent pour l'achat ou la confection de l'habit ou de la robe. on pouvait acheter les vêtements en ville ou les confectionner à la maison. Lorsque la jeune fille n'avait pas les moyens de payer sa robe, le père de la jeune fille ou son futur époux contribuait de façon substantielle à cet achat. Il est assuré que pendant la période couverte par notre enquête, des changements sont intervenus sur ce plan à cause des influences culturelles urbaines mais nous n'avons pu les reconstituer avec précision.

La mariée portait une robe de couleur pastel ou encore un tailleur (veste et jupe) agencé d'un chapeau, d'un bouquet, de gants et de souliers. Lorsqu'ils étaient de fabrication domestique, ces vêtements reflétaient toute l'habileté ou le savoir-faire de ses créateurs. Des paillettes blanches, du velours rouge, de la crêpe bleu, des perles blanches "fines, fines, fines", de la dentelle, des fleurs, des fourrures 
s'ajoutaient très souvent aux toilettes pour leur donner un peu plus d'originalité et d'élégance. Il ressort de façon très claire que les Saguenayens et Saguenayennes portaient beaucoup d'attention à leur apparence extérieure. Que l'on soit agriculteur ou journalier, le souci d'"avoir I'air fin" est toujours présent.

Une informatrice, dont le père était décédé quelques temps avant le mariage, portait le deuil lors de la cérémonie. Elle était vêtue d'un costume, d'un chapeau et de bottines noires.

La mode des robes blanches, des voiles blancs et des livres d'heures ${ }^{7}$ est devenue courante un peu plus tard. on verra cette mode apparaître au milieu du xxe siècle. Par ailleurs, pour la période qui nous intéresse, lorsqu'une jeune fille était "Enfant de Marie" 8 , elle était coiffée d'un voile blanc au cours de la cérémonie religieuse. Dans la paroisse de Sainte-Brigide, Lucia FERRETI (1985) rapporte également qu'une épouse qui

${ }^{7}$ Le livre d'heures était utilisé pour remplacer le bouquet de noces. Il avait une couverture de cuir blanc et une tranche dorée. On le garnissait de longs rubans blancs qui traînaient au sol. On achetait cet accessoire chez les fleuristes.

${ }^{8}$ La confrérie des Enfants de Marie invitait les jeunes filles à vivre selon le modèle de la Sainte-Vierge. Le but de ce regroupement était de préserver ces jeunes filles des dangers qui les entouraient et de former leurs coeurs à la vertu (J. COTE, 1985). 
faisait partie de la confrérie des Enfants de Marie était coiffée d'une couronne et que la cérémonie religieuse était rehaussée de chants. Comme au Saguenay, la chorale des enfants de Marie se rendait disponible à cette fin.

De son côté, le jeune homme était également vêtu de ses plus beaux habits. De façon générale, il portait un complet de couleur noir, bleu marin ou gris. Sa tenue était complétée d'un chapeau et de gants assortis.

Par ailleurs, il est amusant de constater qu'à travers le récit des détails concernant les vêtements portés lors du mariage, on sentait une fois de plus, chez les hommes comme chez les femmes, une grande coquetterie.

\section{D - Le transport vers I'église}

Le transport vers I'église constitue la première étape du cortège. En ancienne France (N. BELMONT, 1978), il s'agit d'un moment important où le jeune homme vient chercher la jeune fille pour l'amener vivre dans une autre maison. Il existe également dans la vallée du Saint-Laurent ( $\mathrm{J}$. PROVENCHER, 1986) des pratiques relatives à la "départie" où le jeune homme et les "noceurs" viennent chercher la future épouse pour former un cortège et se rendre à l'église. Contrairement à ce 
que l'on rapporte en France et en Nouvelle-France, le Saguenay présente des pratiques très frustes en rapport avec ce premier cortège.

Dans une société rurale comme en France, où l'endogamie était chose courante, la distance entre les deux résidences était rarement plus élevée que cinq kilomètres (A. GIRARD, 1964). Au XIXe, dans la région de la Beauce en France, on se mariait de préférence avec quelqu'un qui habitait la région proche (moins de 20 kilomètres) (G. AUGUSTINS, 1985).

Au Saguenay, jusqu'en 1930-40, l'endogamie paroissiale était supérieure à 50\%. Dans la majorité des cas, les deux conjoints provenaient donc de la même paroisse, ce qui créait des conditions favorables à la coutume du cortège. De façon générale, nous avons pu déterminer que les deux époux allaient avec leur famille respective vers l'église. En voiture parfois décorée de rubans ou de pompoms par les amis ou la famille et tirée par leurs plus beaux chevaux, le conjoint ou la conjointe prenait place avec son père. La famille proche les accompagnait jusqu'à l'église. C'est toujours le père qui accompagnait son fils ou sa fille jusqu'au pied de l'autel. Lorsque le père était décédé, l'aîné des garçons ou un oncle prenait sa place. On décorait 
quelquefois les brides des chevaux de plumeaux ou de pompoms. La place réservée à la mère était très restreinte dans les cortèges et pendant la cérémonie du mariage. En effet, les mères étaient souvent absentes de la cérémonie religieuse et par conséquent du cortège. Pour des raisons qui semblent évidentes aux yeux des informateur(trice)s (la préparation des repas, le travail domestique, les soins d'un nouveau-né), les mères étaient souvent retenues à la maison. Les choses se faisaient ainsi sans qu'on se demande pourquoi.

\section{E - La cérémonie religieuse}

Avant de procéder à l'union officielle des jeunes gens, le curé menait une enquête pouvant déceler tout lien de parenté entre les deux époux. Lorsque l'on constatait des liens de parenté, l'Eglise catholique obligeait le couple à payer une dispense rendant ainsi leur union possible. C'est vers 1770 que l'Eglise catholique a accepté de donner des dispenses (M.-H. DARROW, 1985). Le coût de cette dispense était d'environ quatre dollars. 
On ne retrouve pas de rencontre préparatoire avec un prêtre avant le mariage. La seule rencontre est d'ordre administratif puisqu'il s'agit de la publication des bans et du paiement de la messe. L'Eglise offrait des messes de 1e, 2 e ou $3 e$ classe. Pour les cérémonies de première classe, l'église était décorée de fleurs, de banderoles ou rehaussée d'un tapis rouge. Leur coût était d'environ $20 \$$. La qualité des cérémonies de $2 e$ et 3e classe variait selon les paroisses. Selon nos informateur(trice)s, il arrivait que l'église soit décorée de fleurs $(\mathrm{N}=6)$, de banderoles $(\mathrm{N}=4)$. Il arrivait également que la cérémonie religieuse ait lieu sans aucune décoration $(\mathrm{N}=8)$.

Pour recevoir le sacrement du mariage, les "futurs" étaient tenus de se confesser en arrivant à la messe. cette pratique religieuse est présente partout au Saguenay. Lors de cette confession, les prêtres divulguaient le "secret du mariage" aux jeunes gens. Ce secret était relié à la vie sexuelle du nouveau couple. Le discours tenu par le confesseur prévenait la future épouse qu'elle se devait de "faire son devoir" et de ce fait, d'entrevoir la procréation comme son rôle principal au sein du couple. C'était là les seuls conseils d'ordre sexuel auxquels avaient droit les deux époux concernant la future vie conjugale. 
Les mariages avaient lieu à $\operatorname{six}(\mathrm{N}=2)$, huit $(\mathrm{N}=5)$ ou $\operatorname{dix}(\mathrm{N}=5)$ heures le matin et parfois plus tôt. Les raisons qui déterminent l'heure du mariage varient: se rendre dîner chez les parents du conjoint dans une autre paroisse, prendre le train qui allait au Lac st-Jean $(\mathrm{N}=1)$ ou à Québec $(\mathrm{N}=1)$, le nombre élevé de mariages dans la même journée, etc. Un seul prêtre, le curé de la paroisse, célébrait la messe. L. FERRETI (1985) rapporte des mariages célébrés très tôt dans la paroisse urbaine de Sainte-Brigide.

A la sortie de l'église, il arrivait que l'on fasse sonner les grosses $(\mathrm{N}=9)$ ou les petites $(\mathrm{N}=3)$ cloches. on lançait également des confettis $(N=6)$ ou du riz $(N=4)$. Au Saguenay, le symbolisme du riz et des confettis n'était pas nécessairement relié à la fécondité du couple. Les informateur(trice)s avouent n'avoir nourri aucune croyance particulière concernant les lancers à la sortie de l'église.

Dans certains cas $(\mathrm{N}=7)$, on a photographié les mariés et les invités. Sur les photographies du couple seul, on reconnaît l'épouse assise avec, à ses côtés son époux, qui se tient debout. Le même scénario se retrouve sur toutes les photos. Ces photographies ont été prises 
par un photographe professionnel $(\mathrm{N}=2)$, par des invités $(\mathrm{N}=1)$, ou quelqu'un d'autre $(\mathrm{N}=4)$. Il arrivait que l'on prenne des photographies des invités également.

\section{$F$ - Le transport vers le lieu de la noce}

Bien qu'il ait été de dimension réduite et dépourvu de cérémonial, le cortège vers le lieu de la noce constituait une étape importante au saguenay. Les cortèges qui ont été décrits par les informateur(trice)s avaient un caractère familial (N=12). Dans des véhicules tirés par des chevaux, dans des automobiles ou à pied, les nouveaux mariés, accompagnés des parents, des "suivants" 9 des amis et des voisins se dirigeaient vers le lieu de la noce. En tête du cortège, on retrouvait les mariés et les suivants. Les père et mère le cas échéant, les frères et soeurs ainsi que les invités (les amis, les voisins, etc) suivaient dans un ordre qui ne semblait pas être prescrit. Dans les cas où les mariages avaient lieu en hiver et lorsque les conditions étaient très difficiles, les cortèges étaient réduits et tout se déroulait un peu à l'improviste. Les manifestations extérieures étaient très rares, et ce pour plusieurs raisons: la température, l'heure matinale de la cérémo-

\footnotetext{
${ }^{9}$ Les "suivants" sont les gens d'honneur qui avaient été choisis par les futurs époux.
} 
nie, l'attitude réservée des Saguenayens, déjà évoquée antérieurement ("on n'était pas applaudisseux"). Notons toutefois qu'il y avait, pour différentes raisons, des mariages où les "noceurs" se rendaient directement à la maison indépendamment du cortège. Les conduites de bruit, la présence des gestes symboliques qui aux XVIIe et XVIIIe siècles répondaient à des préoccupations juridiques telles que légitimer un lien ou le rendre public (A. BURGUIERE, 1978) ne sont pas incluses dans la composition des rituels de mariage au saguenay. 


\section{CHAPITRE V}

LA NOCE ET L'ÉTABLISSEMENT DU MÉNAGE 
Lorsque l'union est bénie, on passe à la fête. Les nouveaux mariés, "les suivants", les parents et les invités se rassemblent pour fêter et célébrer l'accès des deux jeunes au statut d'adulte et de couple. Ce changement de statut ne donne toutefois pas lieu à des rituels de sociabilité comme ceux rapportés dans les provinces de France (A. VAN GENNEP, 1943-58). On peut penser ici au rite de barrage que constitue le seuil de la porte du nouveau domicile, aux concours de sauts à la sortie de l'église, à la saisie du coq, etc. Au Saguenay, l'entrée dans le monde des adultes se faisait sans aucun cérémonial de ce genre.

\section{A - La durée des noces}

Contrairement à ce que l'on rapporte dans la région de Beauharnois ( E. Z. MASSICOTTE, 1925; 1930), les noces saguenayennes duraient tout au plus une seule journée $(\mathrm{N}=22)$. La cérémonie avait lieu très tôt le matin et les invités avaient la journée entière pour célébrer l'événement. On dînait chez la jeune fille et on soupait chez le jeune homme $(\mathrm{N}=21)$. De longues noces comme celles décrites par Massicotte n'ont pas été signalées. 


\section{B - Les rôles d'honneur}

Dans la société saguenayenne, les gens d'honneur jouaient un rôle important. ceux-ci, que l'on appelait "les suivants", avaient la responsabilité d'organiser la veillée et de voir à ce que personne ne manque de rien. Les "suivants" étaient choisis par les futurs époux parmi la parenté ou encore chez les ami(e)s. Il arrivait que l'on jumelle deux jeunes gens avec l'espérance de les voir se fréquenter par la suite. Leur tâche consistait donc à "s'occuper de la visite", "faire le service de table", "s'assurer de la relève sur la piste de danse", etc.

\section{C- Le repas de noce}

Les repas de noces (le dîner et le souper) se déroulaient dans la maison familiale que l'on avait aménagée pour l'occasion. Très souvent, on dressait de grandes tables qui occuppaient l'espace du salon et de la cuisine. Ces tables étaient recouvertes d'une nappe blanche et décorées de fleurs, de feuillage ou autres. Mises bout à bout, elles permettaient à tous les invités de manger en même temps. Lorsque que les invités étaient 
trop nombreux, on organisait des tablées. Il fallait alors laver la vaisselle et changer les nappes entre les tablées. La première tablée était réservée aux aînés qui laissaient ensuite la place aux plus jeunes.

Les nouveaux mariés et les "suivants" occupaient la place d'honneur tandis que l'on retrouvait à leurs côtés les pères et un peu plus loin la famille proche. Les mères, souvent secondées par des parent(e)s ou des voisin(e)s, avaient la responsabilité du dîner ou du souper selon le cas. Il arrivait donc qu'elles n'aient pas le temps de s'asseoir avec les invités parce qu'elles avaient trop de travail. La place des invités à la table n'est pas formelle dans toutes les noces. Quelques informatrices ont déclaré que le repas de noces se déroulait sans règle ni pratique déjà établies. La seule constante qui se dégage des entrevues relève de l'abondance de la nourriture: "on ne manquait de rien", "de la nourriture, il y en avait à profusion".

L'élaboration du menu variait d'une famille à l'autre selon la situation financière, le nombre d'invités et la saison de l'année. Très souvent, au grand plaisir des invités, les tables étaient lourdement chargées de viandes apprêtées (ragout de noces, tourtière, rôti de porc, cochon de lait) et de volailles 
(dinde, oie, poulet). Le tout était accompagné de patates jaunes, de sandwichs, d'amuse-gueules, de "toutes sortes d'affaires...".

Pour le dessert, la mère de la mariée, la mariée elle-même ou quelqu'un d'autre fabriquait un gâteau de noce. Chez quelques informateur(trice)s, on sert deux gâteaux de noce; le premier lors du dîner et le second lors du souper. En général le gâteau avait plus d'un étage et était recouvert d'un crémage blanc. Mais nous n'avons relevé aucune croyance associée au gâteau luimême, à sa confection ou à son découpage. On agit sans code précis. Le ou la mariée coupait le gâteau sans que l'on associe à ce geste une croyance quelconque.

On servait également des boissons alcoolisées lors de la réception: du vin maison, de la bière ou autre boisson achetée. Le tout était à la discrétion des hôtes.

En après-midi, tout le monde se rendait chez les parents du jeune homme pour prendre le souper et continuer la fête en soirée. Une informatrice a déclaré que les invités chez ses parents n'étaient pas les mêmes que chez ses beaux-parents. Pour des raisons qui lui 
échappent, les invités étaient partagés dans leur famille respective.

Le deuxième repas de la journée était semblable au premier. Une grande table, des places d'honneur, beaucoup de nourriture, etc.

Les divertissements suivaient le souper et variaient beaucoup d'une famille à l'autre. La soirée était rehaussée de la présence de quelques musiciens. Que ce soit un père, un oncle, ou un musicien engagé, quelqu'un jouait de l'accordéon $(\mathrm{N}=3)$, du violon $(\mathrm{N}=7)$, du piano $(\mathrm{N}=4)$, de l'harmonica $(\mathrm{N}=2)$ ou de l'harmonium $(\mathrm{N}=1)$. Il Y avait assez souvent plus d'un musicien qui animait la fête. On a retrouvé de rares cas $(\mathrm{N}=2)$ où l'on chantait une complainte.

Pour la soirée, les voisins, invités ou non, se joignaient à la fête. Il était de rigueur que les nouveaux mariés et les principaux invités chantent tour à tour. Chacun faisait son petit numéro. On lisait rarement des adresses aux nouveaux mariés $(\mathrm{N}=3)$. Ces divertissements avaient lieu le plus souvent le soir et étaient sous la responsabilité des "suivants". Des mariages n'ont cependant fait l'objet d'aucun divertissement. Dans ces 
rares cas $(\mathrm{N}=2)$, une informatrice avait perdu son père quelques semaines avant le mariage et l'autre ne voulait aucune manifestation lors de son mariage.

\section{D - Les cadeaux de noce}

Les nouveaux mariés recevaient, bien sûr, des cadeaux de noce de la famille proche, des amis et d'autres personnes. En général, on offrait au nouveau ménage des plateaux, des assiettes, des ustensiles de cuisine ou quelques pièces de lingerie. Non seulement ces cadeaux avaient une valeur assez élevée monétairement mais ils ont pris une valeur sentimentale avec le temps puisque assez souvent, lors des entrevues, des informatrices étaient très fières de montrer un de ces souvenirs gardé précieusement.

\section{E - La nuit de noce}

Ce moment ultime du mariage est bien sûr entouré d'une grande discrétion. La sexualité étant un sujet encore bien difficile à aborder avec les â̂né(e)s, cet aspect du mariage n'a été traité que très brièvement au cours des entrevues. Aussi cette question n'a pas été étudiée comme nous aurions souhaité le faire. Seules les 
informatrice(teur)s qui se sentaient plus à l'aise pour en parler ont fourni quelques informations.

Selon A. FINE (1984), la chambre nuptiale faisait, en France, au XIXe jusqu'au milieu du XXe siècle, l'objet de plusieurs rituels reliés à la fécondité du couple. Pris en charge par la jeunesse, ces rites avaient lieu quelques jours avant la cérémonie religieuse et visaient à préparer la chambre nuptiale pour le nouveau couple. On veillait à mettre en place le lit garni et à ranger le trousseau de la jeune fille dans l'armoire. Deux jeunes filles encore vierges avaient la tâche de placer des draps blancs pour la nuit de noce. A cette occasion la jeunesse prenait plaisir à taquiner les futurs époux sur leur vie sexuelle. Le soir des noces, au moment d'aller au lit, les invités servaient au jeune homme une sorte de tisane que l'on croyait aphrodisiaque. Le lendemain matin, la jeunesse venait réveiller les nouveaux mariés et s'assurait que les draps avaient été bien étrennés. Tous ces rituels donnaient à la jeunesse l'occasion d'échanger sur la sexualité et de rendre cet aspect du mariage un peu moins caché.

$\mathrm{Au}$ Saguenay, les détails reliés à la vie sexuelle n'étaient en aucun cas discutés avant I'union des jeunes gens. Deux informateurs ont dit être allés, en compagnie 
de leur père, au cinéma ${ }^{10}$ afin de visionner un film sur la sexualité. Les femmes n'ont, pour leur part, eu aucune information. "On ne parlait pas de ces choseslà", rapporte I'une d'entre elles.

Le choix de la date du mariage était fait sans que l'on tienne compte du cycle menstruel de la femme. Par ailleurs, tous ont insisté sur l'importance de la virginité. Dans un milieu où le clergé veillait à la bonne conduite des paroissien(ne)s et où l'extraversion des femmes était jugée de façon péjorative (parler fort, rire fort, aller en voiture avec quelqu'un que l'on ne fréquentait pas, danser, etc.), il était très important d'épouser une "bonne fille".

Par ailleurs, plusieurs couples ont été victimes de tours ou de plaisanteries le soir des noces ou le matin suivant. On raconte avoir dû placer la commode devant la porte pour la nuit, avoir trouvé un bocal de crème lubrifiante dans sa valise ou encore avoir été dérangés très tôt le matin par des frères déguisés en agent de police. Ces tours étaient assez répandus et ils variaient d'un mariage à l'autre.

${ }^{10}$ Nous n'avons pas retracé le nom des films signalés par les deux informateurs. Ces films étaient présentés au "théatre". 


\section{F - Le voyage de noce}

Le voyage de noce n'était pas chose courante au Saguenay. On dit très clairement que "ce n'était pas la mode dans ce temps là". Les travaux de la terre étaient exigeants et ne permettaient pas de s'absenter bien longtemps. En général, on reprenait donc le travail le lendemain des noces. Toutefois, on retrouve cinq couples qui sont allés en voyage de noce à l'extérieur de la région. Ces derniers n'étaient pas des agriculteurs. Ils étaient également un peu plus à l'aise financièrement. Ils avaient acheté des vêtements neufs pour l'occasion. Le départ avait lieu le soir des noces ou le lendemainф matin. On partait en bateau, en train ou en voiture. Le retour du voyage de noce n'était pas souligné officiellement.

\section{G - L'installation au domicile}

Plus de la moitié des nouveaux mariés ont emménagé chez les parents du jeune homme. La brué s'intégrait à sa nouvelle famille et était initiée aux travaux de la maison par sa belle-mère. Il arrivait que plus d'un couple nouvellement marié depuis peu vivent dans la maison familiale. on évoque des relations familiales parfois difficiles. Les tâches de la maison étaient 
distribuées selon le nombre de femmes dans la famille. C'est la venue du premier enfant qui marquait pour les nouveaux mariés le moment de quitter la maison familiale.

\section{H - La réinsertion sociale}

Dans les semaines qui suivaient la noce, les frères et soeurs du nouveau couple recevaient ces derniers et la parenté. Le souper était suivi d'une soirée au cours de laquelle on jouait aux cartes et on plaisantait au sujet du nouveau ménage. On peut penser ici à une sorte de rituel d'intégration des nouveaux mariés à la vie sociale des couples déjà mariés. Cette pratique était très courante au saguenay. Comme les familles étaient très nombreuses, cette période de réinsertion sociale pouvait s'étendre sur un mois. Gérard FILION (1989) relate cette même pratique pour la rive sud du saintLaurent au début du XXe siècle. 
TROISIEME PARTIE

DONNEES COMPARATIVES 
CHAPITRE VI

ANALYSE COMPARATIVE 
Cette dernière partie comporte un seul chapitre qui nous permet de completer cette recherche dans sa perspective comparative. Premièrement, à partir des données orales, nous verrons quelles sont les composantes des rituels du mariage dans Charlevoix qui diffèrent de celles retrouvées au Saguenay. Deuxièmement, nous pourrons comparer les mouvements mensuels et journaliers des mariages dans une perspective synchronique et diachronique. 


\section{A - Données orales}

Les quinze entrevues que nous avons faites dans la région de Charlevoix proposent de façon générale le même modèle culturel relatif au mariage que celui retrouvé au Saguenay. Toutefois, des détails donnés par quelques informateur(trice)s portent à croire que les rituels du mariage dans la région de Charlevoix ont été, avant le XXe siècle, un peu plus élaborés que les présents rituels. Mentionnons en effet qu'avec seulement 15 entrevues dans Charlevoix, soit 10 de moins qu'au Saguenay, on retrouve néanmoins des différences non négligeables et ceci constitue un argument en faveur de l'hypothèse d'une érosion culturelle au Saguenay.

Cette érosion des contenus coutumiers au Saguenay aurait, selon nos sources, eu lieu à une période antérieure à celle que nous avons étudiée. Voyons donc parmi les composantes du modèle charlevoisien, celles qui laisseéraient à penser qu'il y a eu une évolution du tissu culturel. 
1 - Les fréquentations

A la lumière des données recueillies, il semble que les circonstances entourant les premières rencontres sont le fruit de rencontres familiales ou de voisinage. Contrairement au Saguenay, tous les conjoints de charlevoix se connaissaient déjà avant de se fréquenter. Les fréquentations sont en général de courte durée mais peuvent aller jusqu'à trois ans. Il y a en effet trois couples qui se sont fréquentés pendant plus d'un an et deux pendant plus de deux ans. Ceci ne se retrouve pas au Saguenay.

2 - La jeunesse

La présence de la jeunesse est beaucoup plus marquée dans la région de peuplement ancien. on rapporte qu'une fois la semaine, on organisait des veillées pour la jeunesse. Même si ce n'était pas permis par le clergé, on dansait et on s'amusait. on prenait soin toutefois de s'en confesser le dimanche suivant. Ces veillées avaient lieu dans des maisons différentes de semaine en semaine. 
3 - Les conduites gestuelles

Les conduites gestuelles semblent être plus élaborées lors des fréquentations. La présence de la jeunesse et les soirées organisées tendent à favoriser un climat propice aux rapprochements et à l'expression des sentiments éprouvés. On dit s'être embrassés seule à seul $(\mathrm{N}=4)$ ou en présence de la famille $(\mathrm{N}=1)$. On dit également ne pas s'être donné "juste des petits becs" $(\mathrm{N}=2)$. L'informateur semble vouloir dire ici qu'ils avaient l'occasion de faire plus ample connaissance physiquement...

4 - Le contrat de mariage

Trois informatrices n'ont pas signé de contrat de mariage avant de se marier alors qu'au Saguenay chaque célébration du mariage était précédée de la signature d'un contrat de mariage. 
5 - L'enterrement du célibat

On n'a retrouvé aucun enterrement de vie de célibat dans la région de Charlevoix. Ceci corrobore l'hypothèse voulant que l'industrie anglo-saxonne ait introduit cette pratique.

6 - La durée des noces

A l'occasion d'un mariage célébré dans Charlevoix, on rapporte une noce qui a duré une semaine $(\mathrm{N}=1)$. L'informateur a parlé d'une semaine entière au cours de laquelle les nouveaux mariés et la parenté avaient dansé dans son logement nouvellement aménagé. Dans un autre cas, une informatrice a dit avoir fêté pendant deux jours $(\mathrm{N}=1)$.

7 - Les divertissements

Parmi les divertissements rapportés, on note le vol du soulier de la mariée $(\mathrm{N}=1)$. L'informateur âgé de 85 ans précise que les "vieux" s'amusaient à voler le soulier pour ensuite faire un procès qui durait quelquefois 3 ou 4 heures. Il dit avoir été témoin de cette pratique. On retrouve également le vol de la valise contenant les vêtements de l'épouse $(\mathrm{N}=1)$. 
8 - L'information sexuelle

Pour ce qui est de l'information sexuelle, deux informateurs ont dit avoir des connaissances quant à la vie sexuelle. Mais ils faisaient alors référence au comportement des bêtes en période de reproduction et lançaient à la blague qu'ils n'étaient pas plus ignorants que les animaux pouvaient l'être.

\section{B - Données informatisées}

Même si les mouvements saisonniers et journaliers des mariages ne relèvent pas des coutumes telles que nous les avons définies dans la première partie, le choix du moment du mariage peut témoigner d'un modèle culturel. Cet indicateur apporte des éléments intéressants qui nous éclairent sur certains modèles véhiculés dans une société.

Les mouvements saisonniers et journaliers présentés ici ont été construits à partir des données informatisées du fichier-réseau BALSAC. Ces indicateurs couvrent la période 1802-1872 pour la région de Charlevoix et 1842-1971 pour la région du Saguenay. Il faut ici mentionner que nous ne pourrons comparer les deux 
régions que sur trois décennies puisque au moment de construire ces mouvements, les données de charlevoix n'étaient pas encore entièrement disponibles.

1 - Les mouvements saisonniers

Sur le plan méthodologique, le total des mariages a été ramené à 1200 sur une base annuelle, ceci afin d'éliminer le problème causé par les mois de durée inégale et de standardiser les distributions mensuelles. La période 1802-1971 présente quatre sous-périodes ayant chacune des modèles distincts.

a) 1802-1841: Période traditionnelle (Charlevoix)

Pour cette période (Graphiques 1-2), la région de Charlevoix présente le même mouvement que celui de la Nouvelle-France (H. CHARBONNEAU et alii, 1987; L.DECHENE, 1974). Ce dernier est caractérisé par deux sommets importants, soit ceux de janvier/février et de novembre. Cette préférence pour les mariages en hiver est probablement reliée à des facteurs culturels, économiques ou sociaux mais il n'a pas été possible de les préciser. 


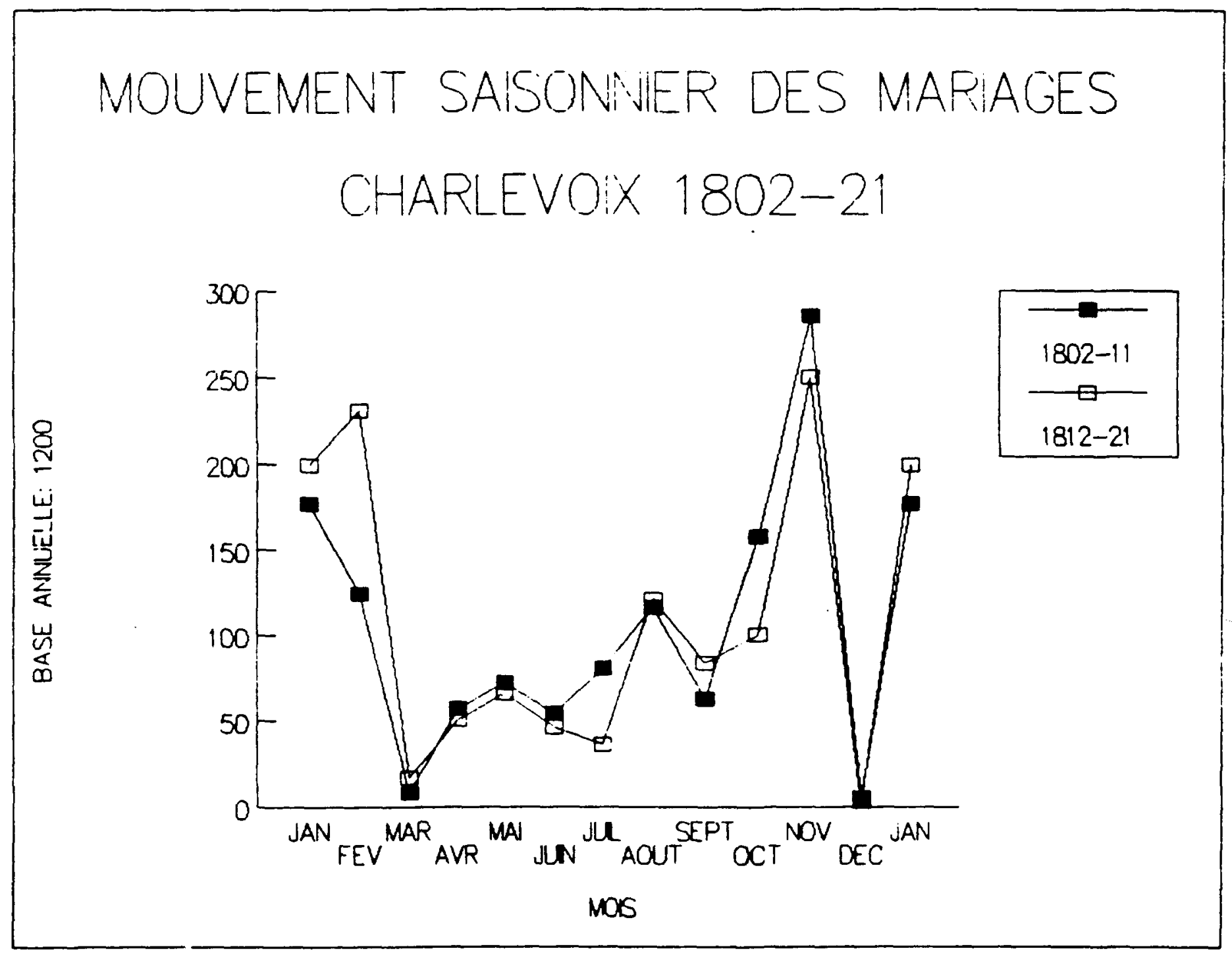




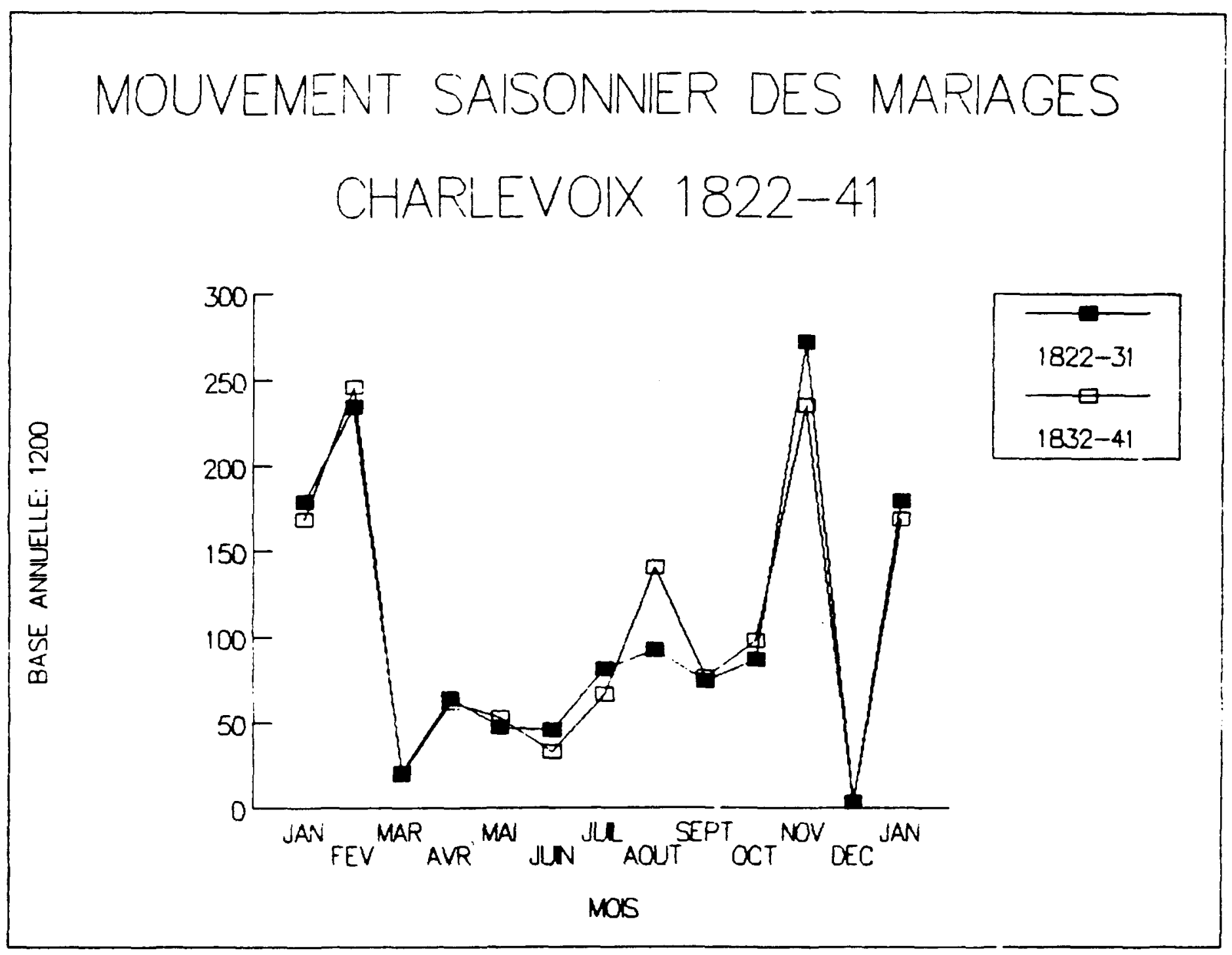

Graphique 2 
Par contre, on retrouve deux mois d'hiver (mars, décembre) où très peu de mariages sont célébrés. Il s'agit là du respect des règles de l'Eglise pour qui il était interdit de se marier pendant les "temps clos", c'est-à-dire pendant le Carême' ${ }^{11}$ et $1^{\prime}$ Avent $^{12}$. Notons que ce mouvement, caractéristique d'une population catholique, existe dans des communautés françaises telles que l'Ile-de-France, le Tarn, la Loire, Amiens, Lyon et Paris (D. CRESSY, 1985). G. Postolec (1985) retrouve le même modèle pour la paroisse de L'Ange-Gardien de 1667 à 1729 .

De plus, d'autres facteurs d'ordre économique ou social peuvent influencer le choix du moment du mariage. L.DECHENE (1974) évoque le mouvement estival des bateaux, le calendrier de travail du colon, la préférence pour les temps froids pour tuer le cochon gras, etc.

11 Le Carême est la période de pénitence qui va du mercredi des cendres au dimanche de pâques. Cette période est d'une durée de quarante jours.

${ }^{12}$ Pour la religion catholique, il est dit que l'Avent commence le quatrième dimanche avant Noël et se termine le 25 décembre. cette période est d'environ 25 jours. 
b) 1842-1881: Apparition d'un nouveau modèle (Charlevoix-saguenay)

Au cours de cette période (Graphiques 3 à 6), les deux régions démontrent des mouvements saisonniers similaires où l'on voit le sommet de novembre s'effondrer. Cette mutation témoigne bien d'une distribution des mariages qui ne se fait pas au hasard pendant I'année.

Par ailleurs, les "temps clos" sont toujours respectés et on observe en janvier et en février des sommets plus prononcés que dans la période précédente (1802-41). Les mois de janvier et de février deviennent en effet la période par excellence pour se marier. Situés entre les deux périodes de pénitence, ce sont en quelque sorte des mois de rattrapage. De plus, il s'agit là d'un temps de réjouissances puisque l'on célèbre la fête de Noël, le Nouvel An et Carnaval. Les futurs époux profiteront de la présence de la parenté et de la période des réceptions pour convoler en justes noces. On peut voir aussi dans cette coincidence un souci d'économie. 
MOUVEMENT SAISONNIER DES MARIAGES

CHARLEVOIX 1842-61

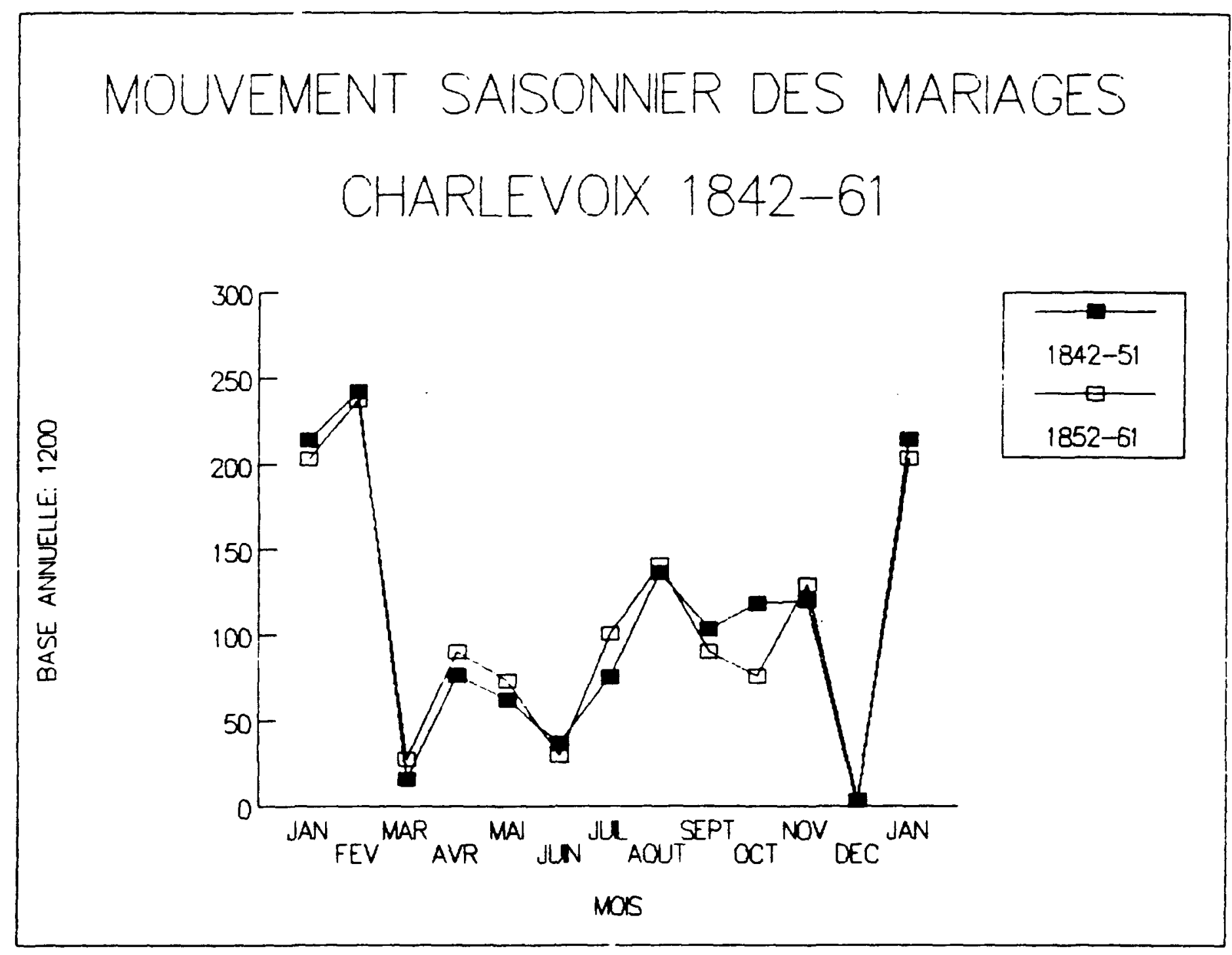




\section{MOUVEMENT SAISONNER DES MARIAGES}

SAGUENAY 1842-61

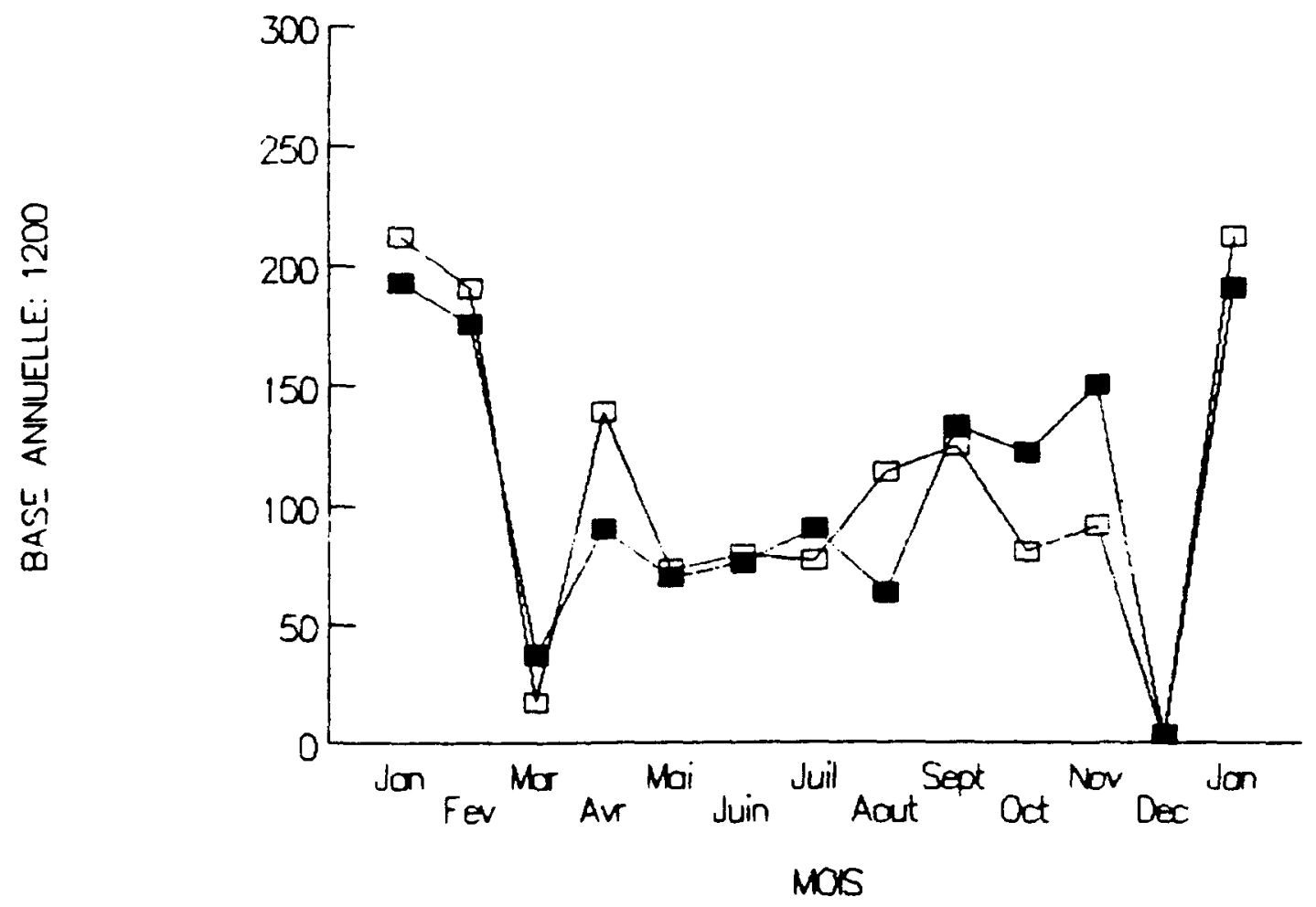

Graphique 4 
MOUVEMENT SAISONNIER DES MARIAGES

SAGUENAY 1862-81

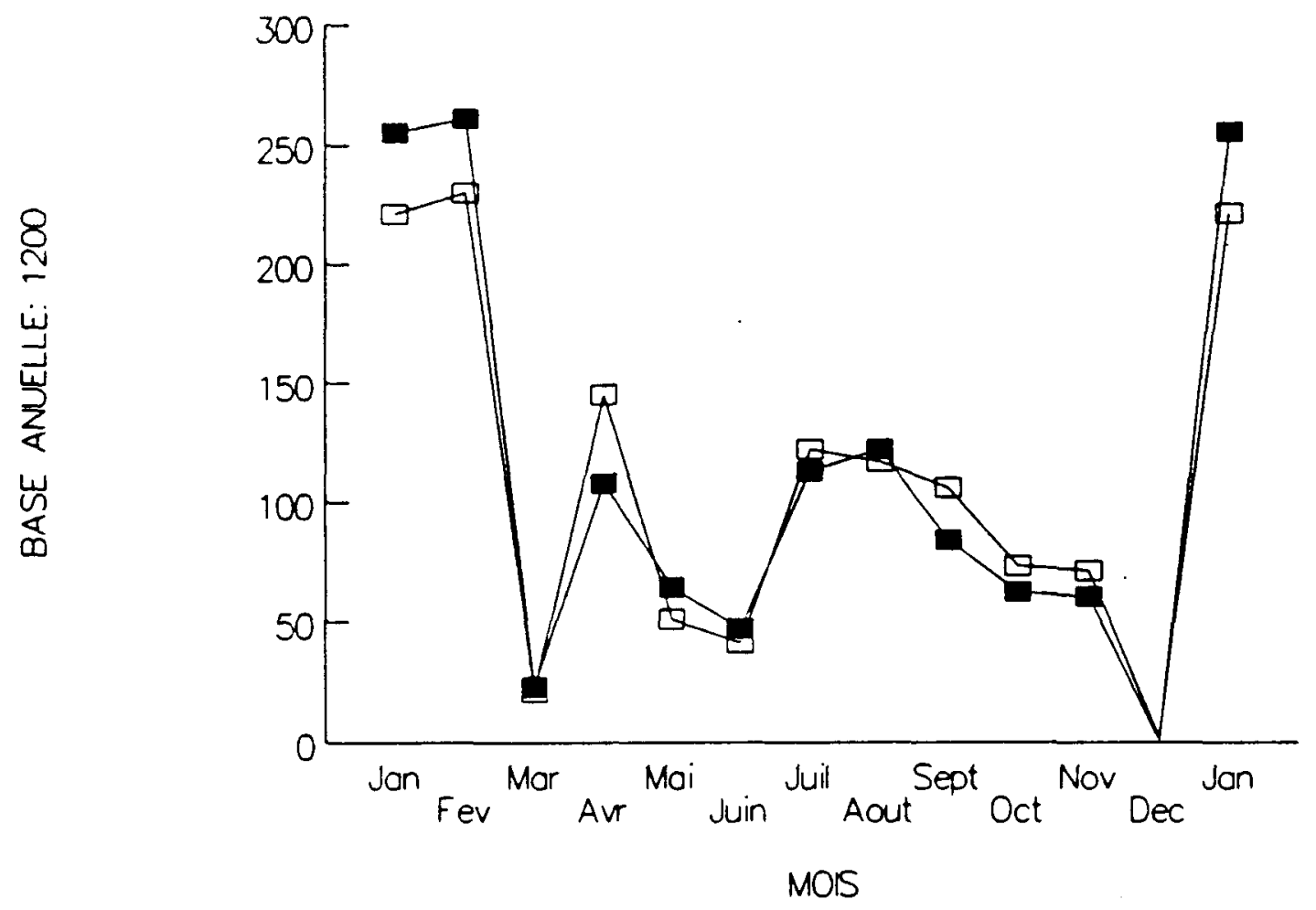

Graphique 5 


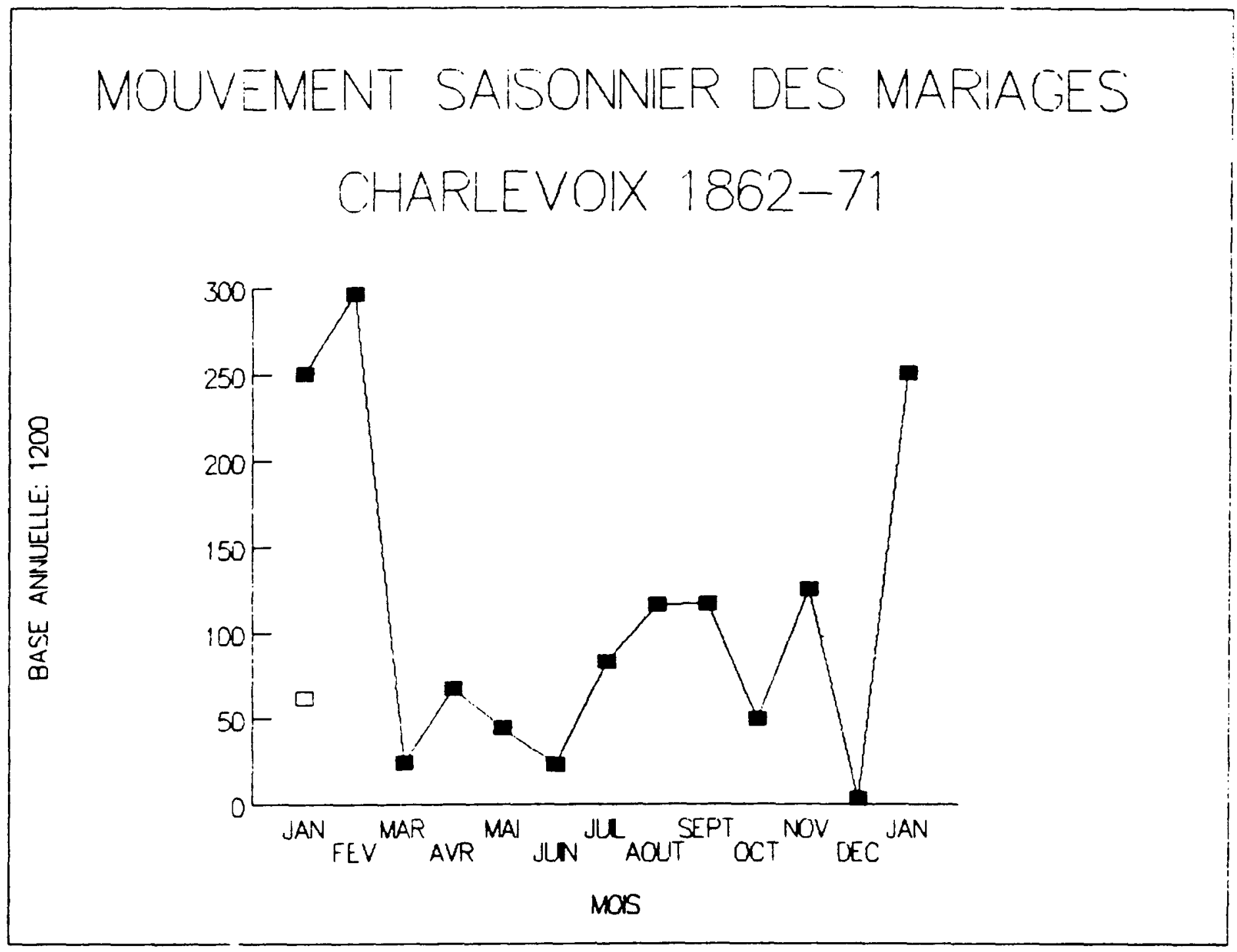

Graphique 6 
Bien que l'on puisse observer un léger gonflement en été, ces mois sont encore réservés aux travaux de la terre et les températures chaudes de l'été ne sont pas encore associées aux réjouissances du mariage. Dans sa description de la culture de l'Ile-verte, Marcel RIOUX (1954) présente des mouvements similaires à ceux-ci.

c) 1882-1921: Un troisième modèle (Saguenay)

Au cours de cette troisième période (Graphiques 78), on observe l'amorce d'un nouveau modèle qui prendra en fait quatre décennies à se mettre en place complètement. On voit en effet les sommets de janvier et février descendre sous la ligne de 200 (1882-1901) puis des 150 (1902-1921), alors qu'apparaît un gonflement assez important en été. Le Carême et l'Avent sont toujours respectés. Ces changements de comportements sont sans doute associés à l'amélioration des techniques agricoles qui facilitent l'organisation du travail et rendent ainsi la période estivale plus propice à la fête. 
吕

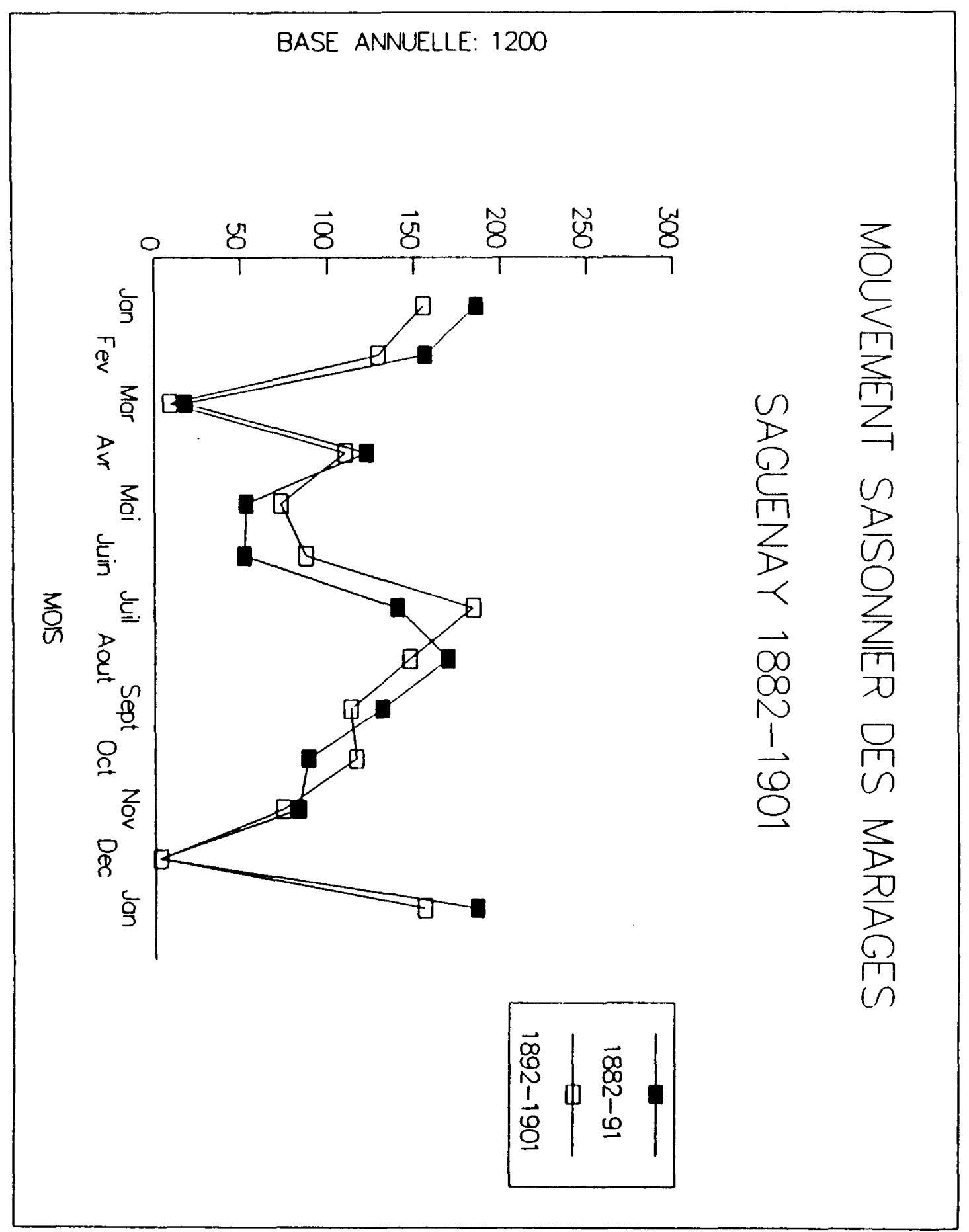

$\stackrel{\circ}{\circ}$ 
MOUVEMENT SAISONNIER DES MARIAGES

SAGUENAY 1902-1921

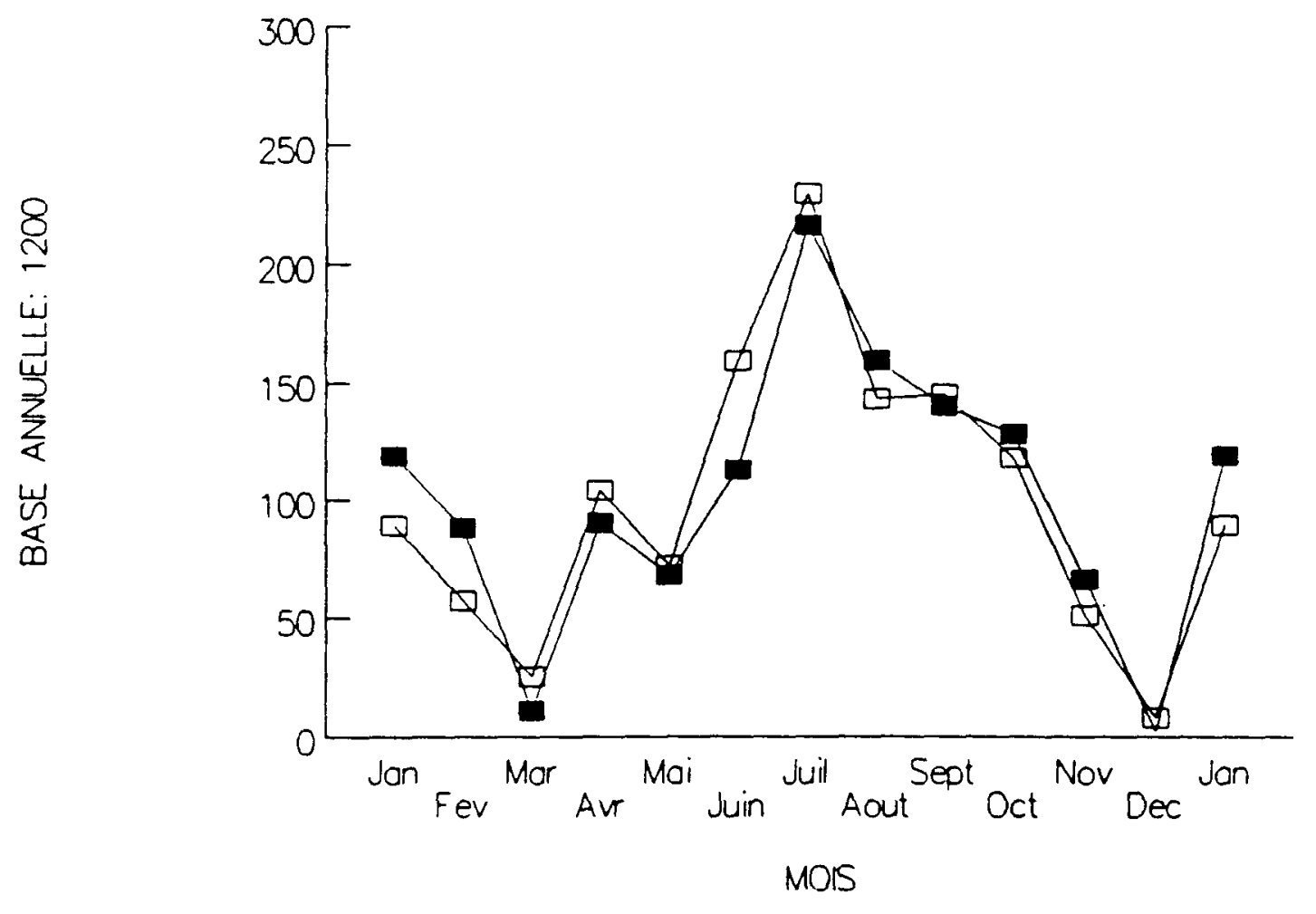


d) 1922-1971: Accentuation du modèle (Saguenay)

Au cours de cette dernière période (Graphiques 9 à 11), on assiste à l'accentuation du modèle précédent, c'est-à-dire au renversement complet du modèle traditionnel (1842-81). Les mois de janvier et de février sont délaissés totalement pour être remplacés par les mois de l'été. La saison estivale s'étend de juin à octobre. Le Carême continue d'être respecté tandis que la période de 1 'Avent semble être l'objet d'une désaffection (1932-41). Notons qu'en fin de période (1962-71), le Carême est toujours respecté tandis que l'interdit de l'Avent continue à perdre du terrain.

Les graphiques des mouvements saisonniers des espaces ruraux et urbains ont également été construits mais n'ont pas été inclus dans la présente recherche. Il n'ont montré aucune différence significative entre les deux espaces. 


\section{MOUVEMENT SAISONNIER DES MARIAGES}

\section{SAGUENAY 1942-61}

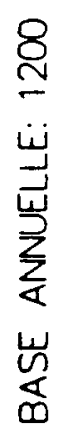

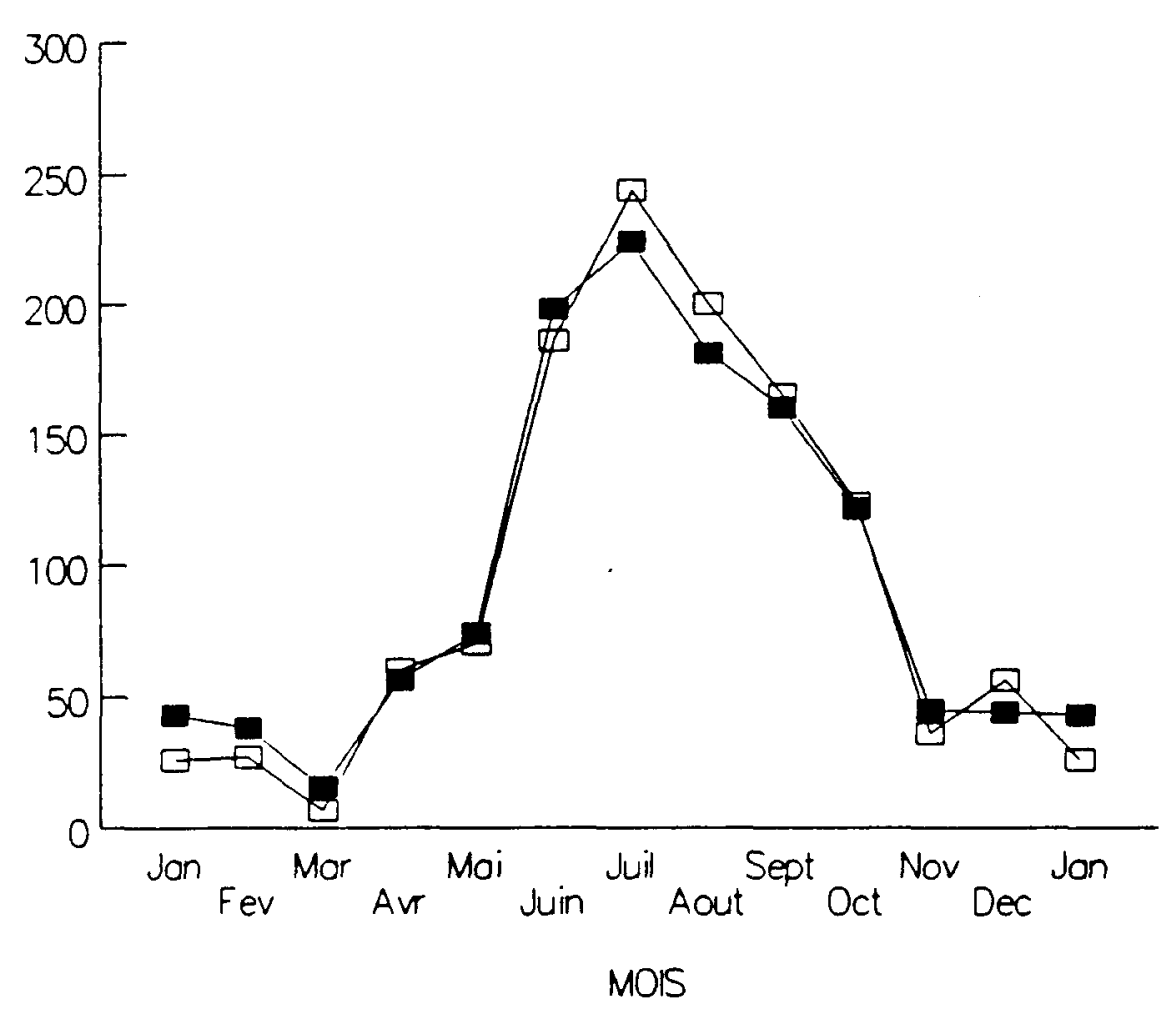


MOUVEMENT SAISONNER DES MARIAGES

SAGUENAY 1922-41

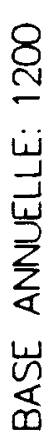

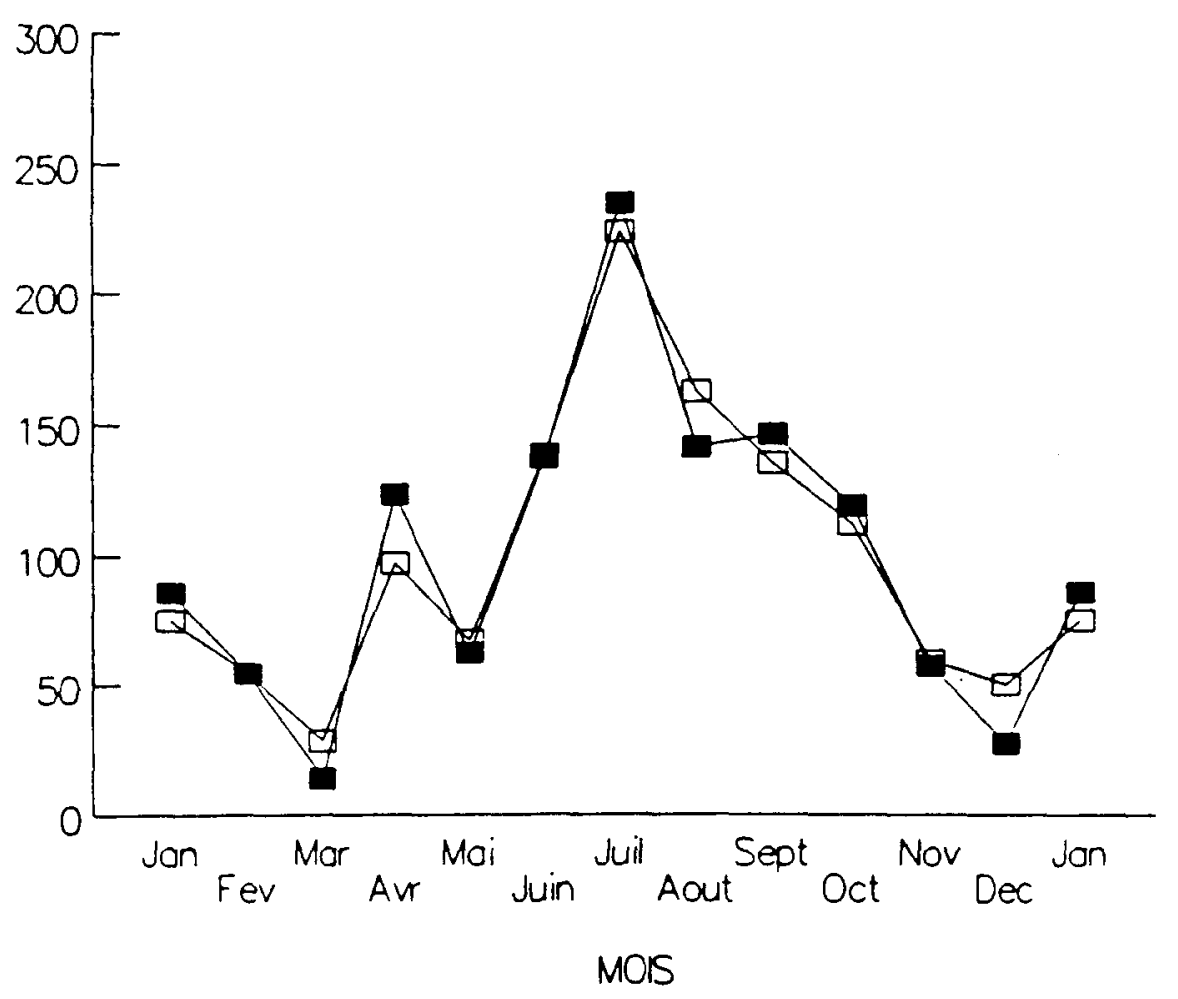




\section{MOUVEMENT SAISONNIER DES MARIAGES}

SAGUENAY 1962-71

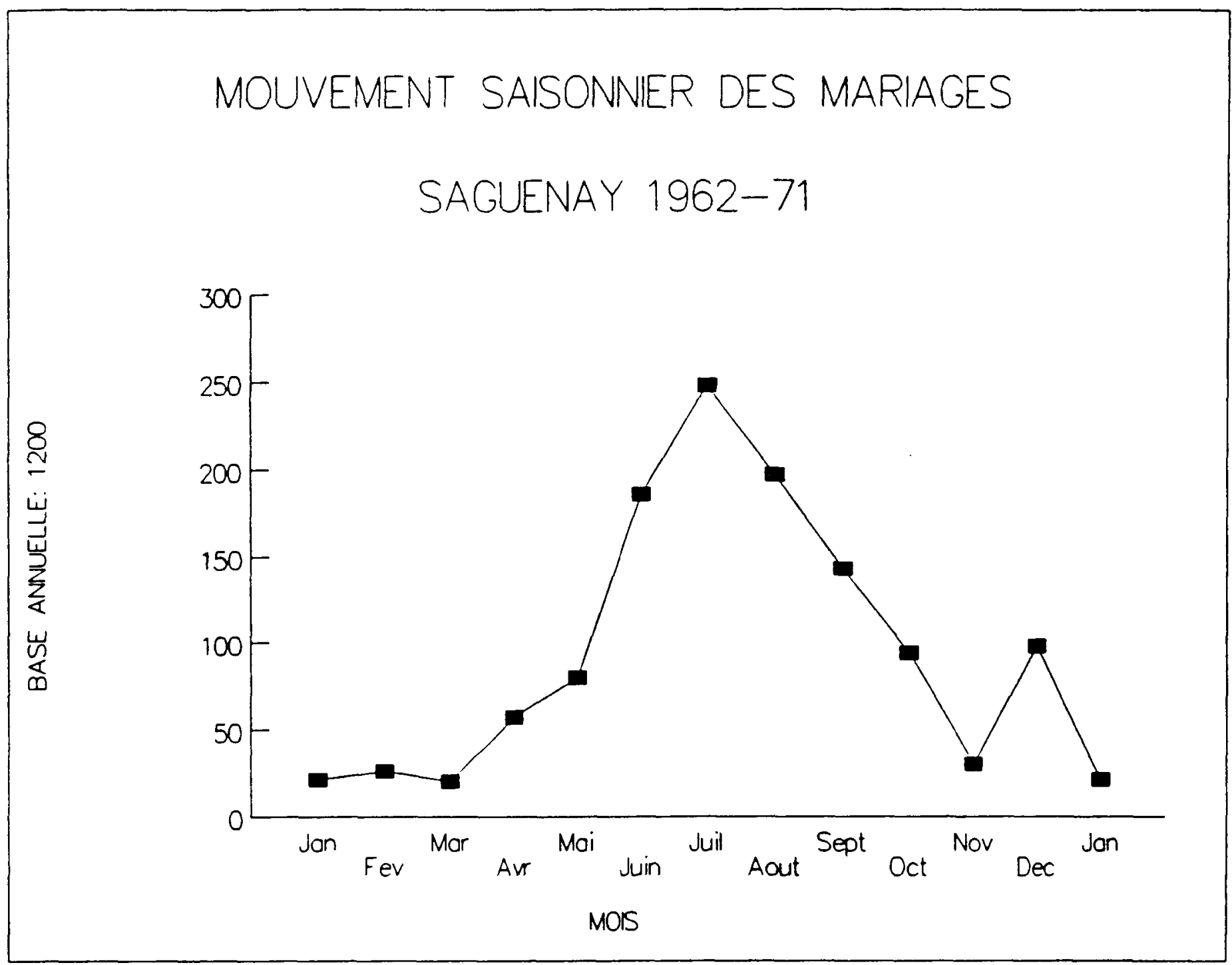


2 - Les mouvements journaliers

Les mouvements journaliers présentent le nombre réel de mariages célébrés pour chaque jour de la semaine.
a) 1802-1881 - Période traditionnelle (Charlevoix et Saguenay)

Le mouvement de cette période (Graphiques 12 à 17) produit un modèle où les lundis et les mardis sont, de loin, les jours par excellence pour célébrer les mariages, le mardi étant celui où l'on célèbre le plus de mariages de 1802 à 1861. Rappelons que l'évêque de Québec $a$, en 1790, reporté au mardi la célébration des mariages (J.PROVENCHER, 1986) pour ne pas que les habitants emploient les dimanches à préparer la noce. A peu près aucun mariage n'est célébré pendant les autres jours de la semaine. On rapporte qu'"on se mariait en début de semaine, c'était comme ça". Pour la région de Pontarlier en France aux XVIIIe et XIXe siècles, c. GRANDVOINNET et M. GRESSET (1980) ont construit des mouvements journaliers qui démontrent comme au Saguenay que le mardi est très populaire. Cependant on observe que l'on célèbre des mariages pendant les autres jours de la semaine également. 
111

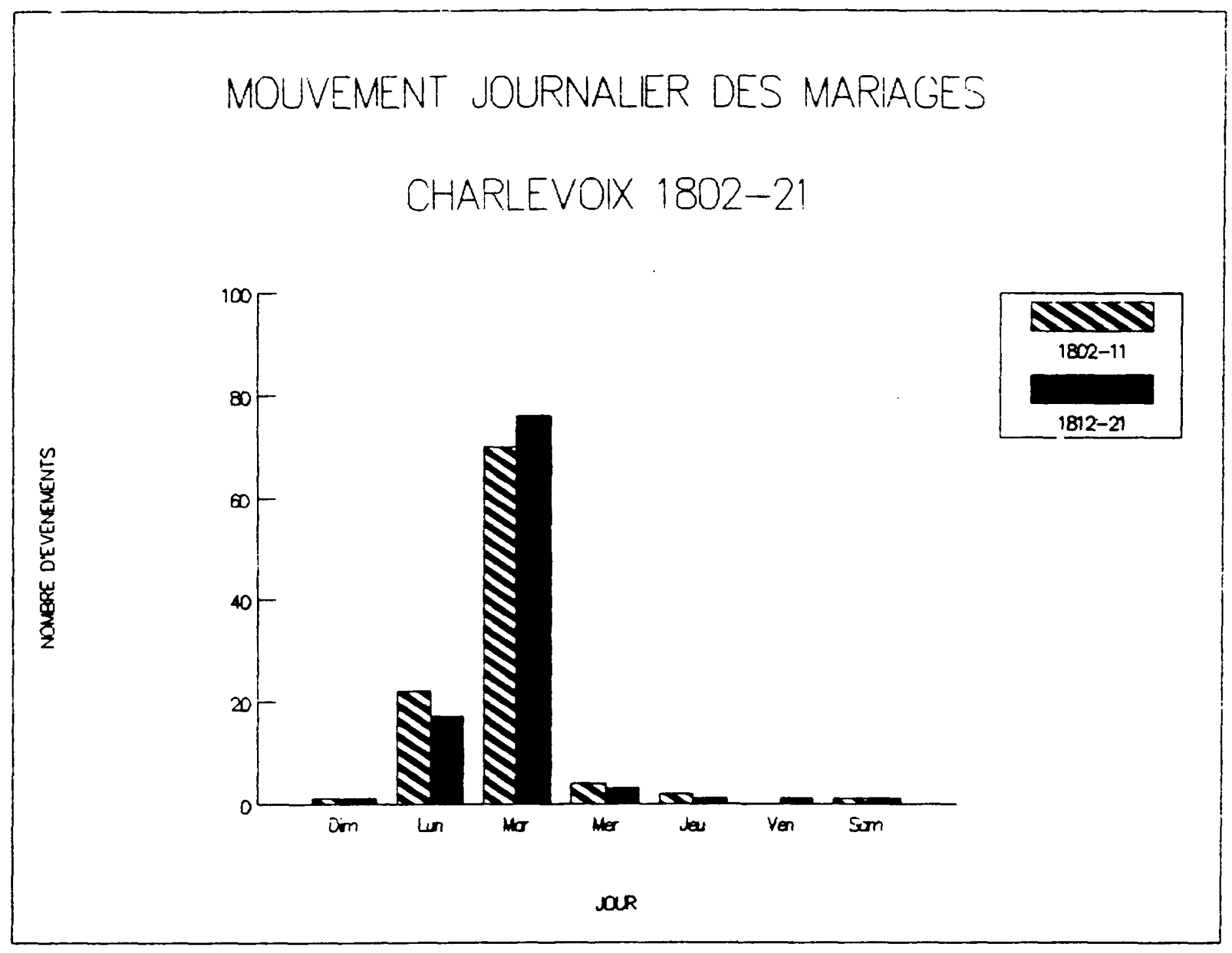

Graphique 12 


\section{MOUVEMENT JOURNALIER DES MARIAGES}

CHARLEVOIX 18:22-41
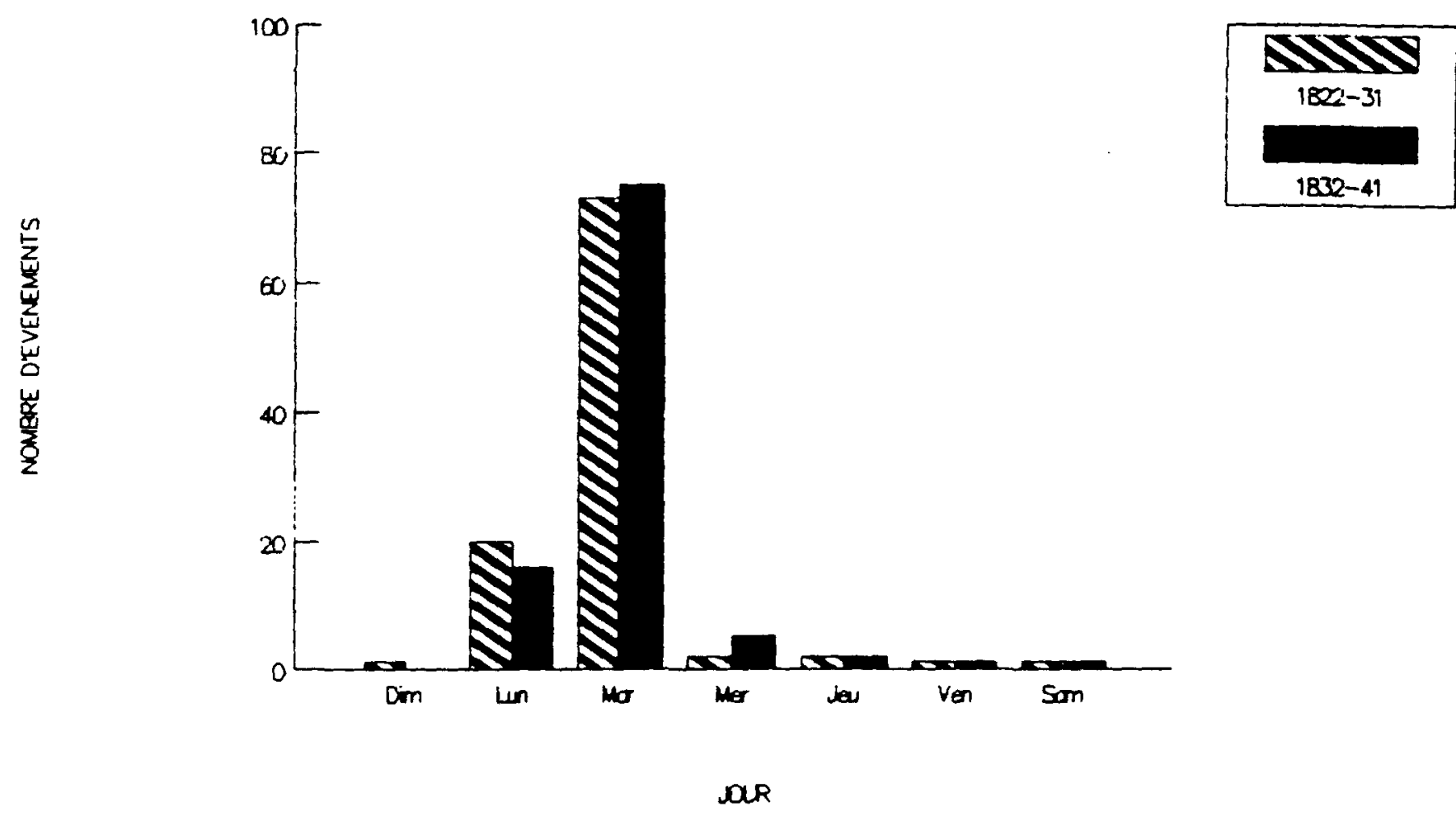

Graphique 13 


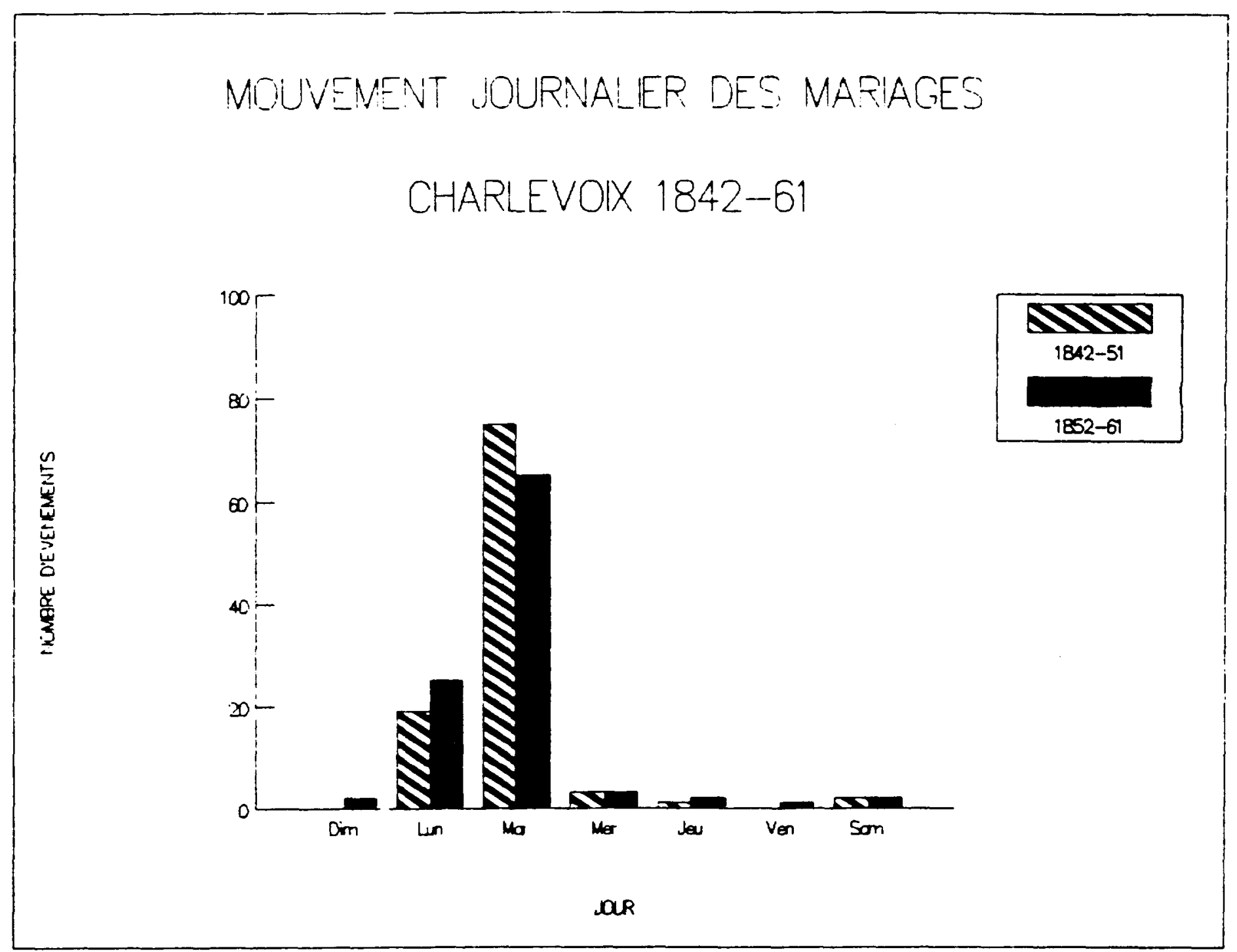


MOLVEMENT JOURNALIER DES MARIACEES

CHARLEVOIX 1862-71

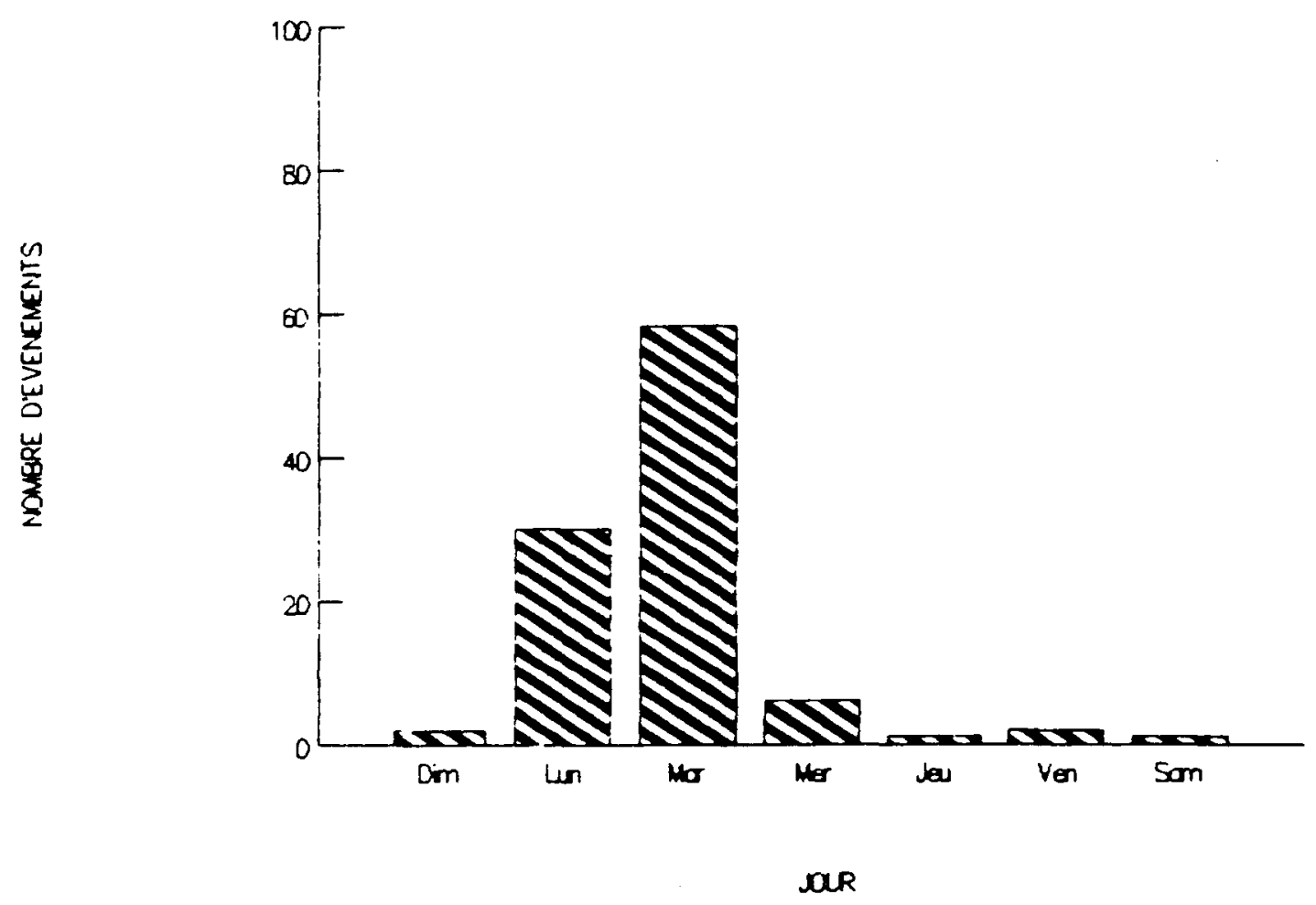

Graphique 15 
MOUVEMENT JOURNALIER DES MARIAGES

SAGUENAY 1842-61

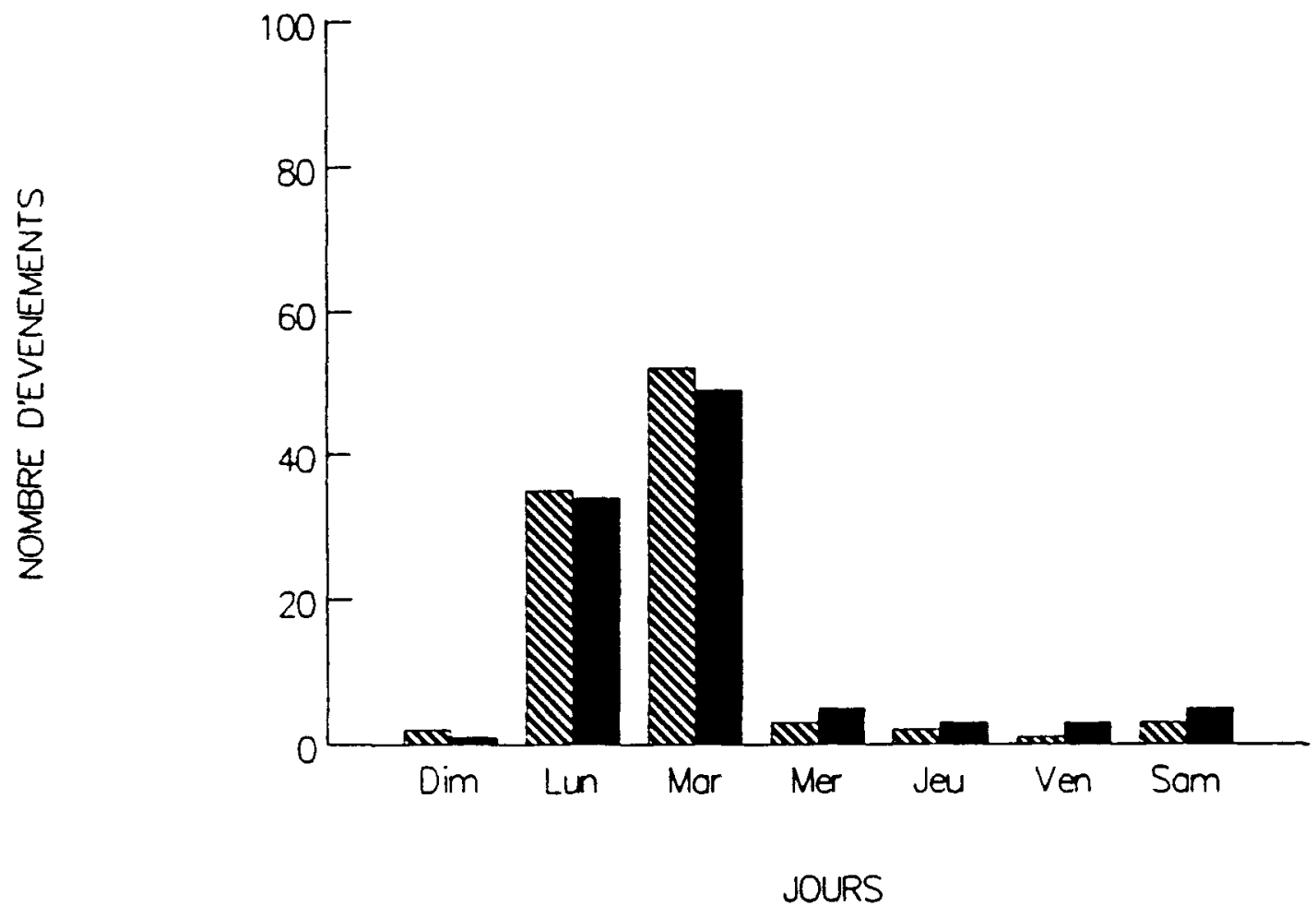




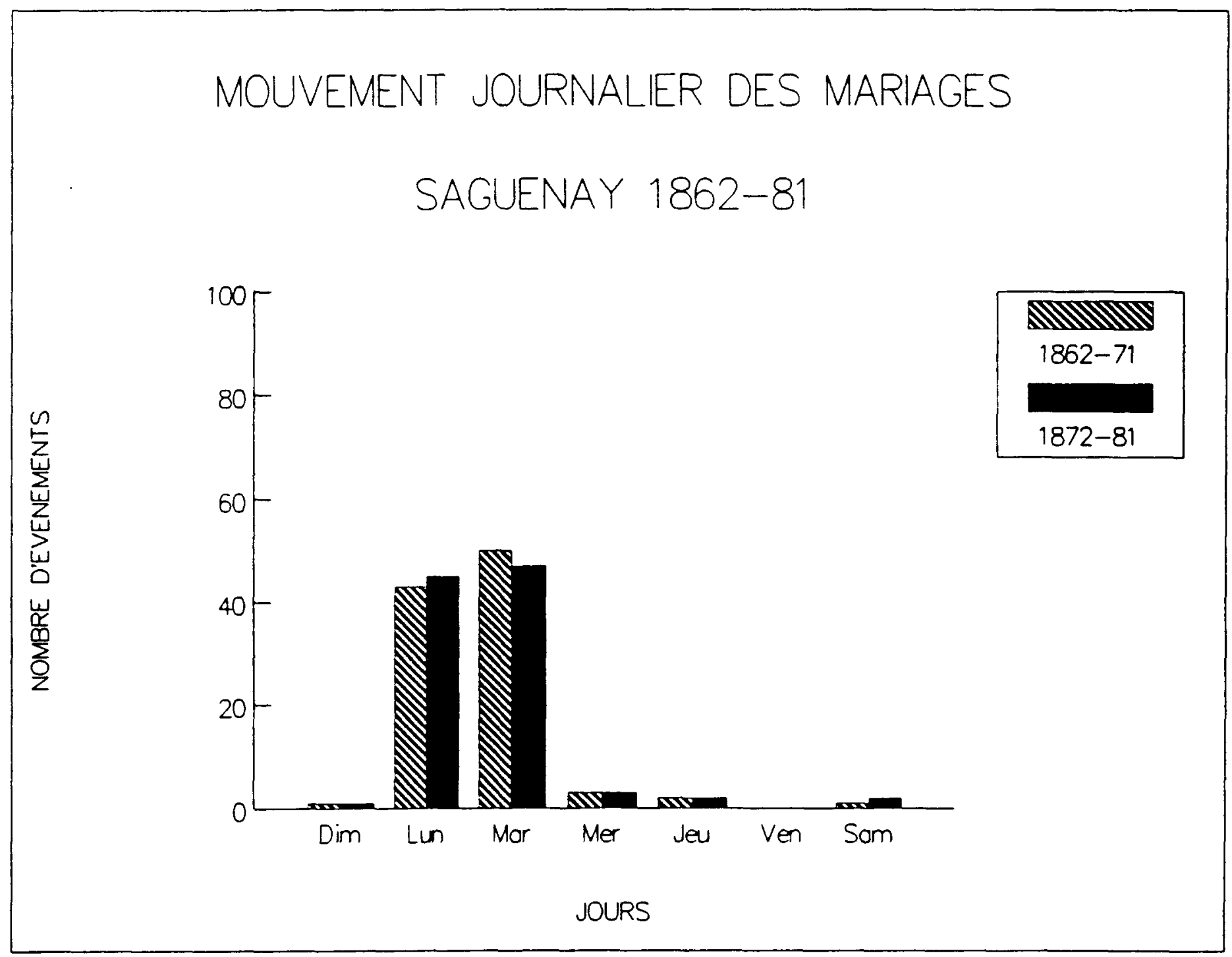


Pour les régions du Saguenay et de Charlevoix, cette popularité des lundis et mardis est certainement liée à l'horaire établi par les curés de paroisses. Les baptêmes, les sépultures, les mariages et les célébrations religieuses étant très nombreuses, il fallait, pour des raisons pratiques, organiser les horaires de façon à ne pas perdre trop de temps. On note toutefois qu'en fin de période, le mardi perd un peu de popularité et fait jeu égal avec le lundi.

b) 1882-1921 - Période charnière

Cette deuxième période (Graphiques 18-19) est en fait assez semblable à la précédente sauf que le lundi y prend la place du mardi. 


\section{MOUVEMENT JOURNALIER DES MARIAGES SAGUENAY 1882-1901}

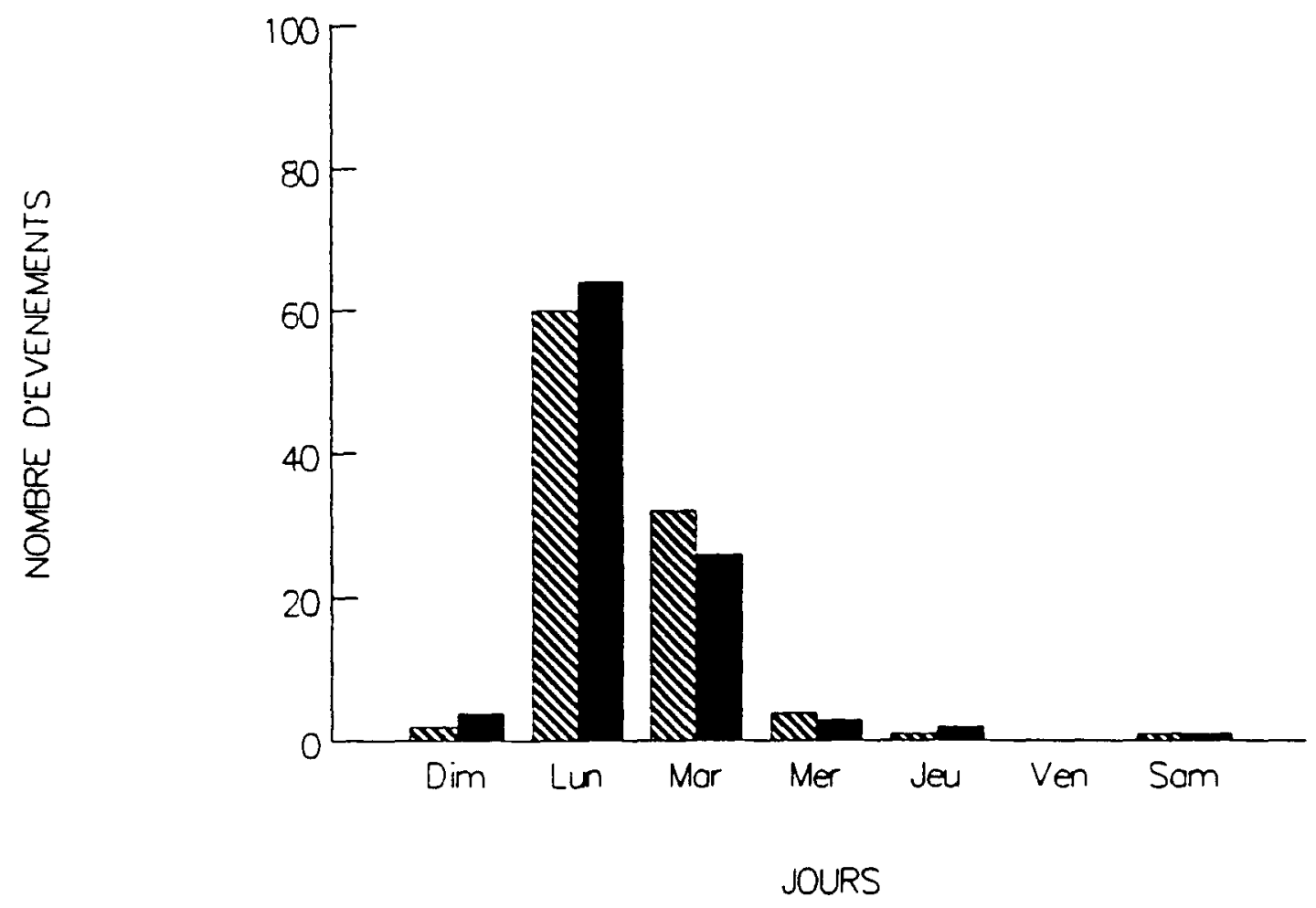


MOUVEMENT JOURNALIER DES MARIAGES

\section{SAGUENAY 1902-21}
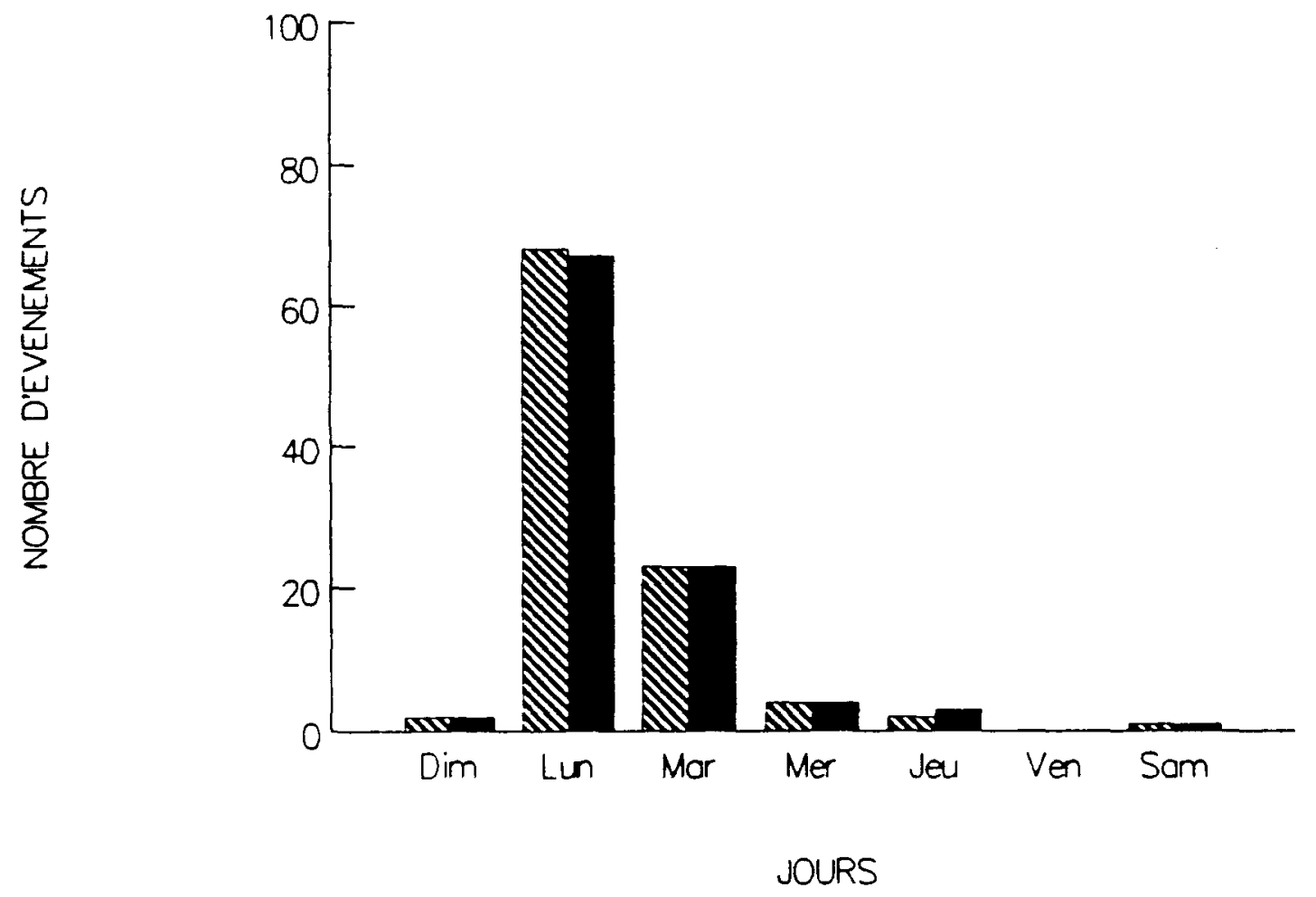
c) 1922-1971 - Evolution vers le modele contemporain

A partir de 1922 (Graphiques 20-22), les mariages commencent à se répartir sur tous les jours de la semaine. Le vendredi et le dimanche demeurent toutefois des jours de "jeûne" ou de "repos". La popularité du samedi se dessine graduellement depuis 1922 jusqu'en 1971. La semaine de travail de cinq jours, progressivement mise en place durant cette période, modifie les habitudes de vie et, par conséquent, le choix du jour du mariage. Cette période pourrait être qualifiée de période-charnière puisque plusieurs changements importants se feront sentir. A la fin de cette période (1962-71), on observe le modèle que l'on connait aujourd'hui, c'est-à-dire des mariages célébrés presque exclusivement le samedi. 


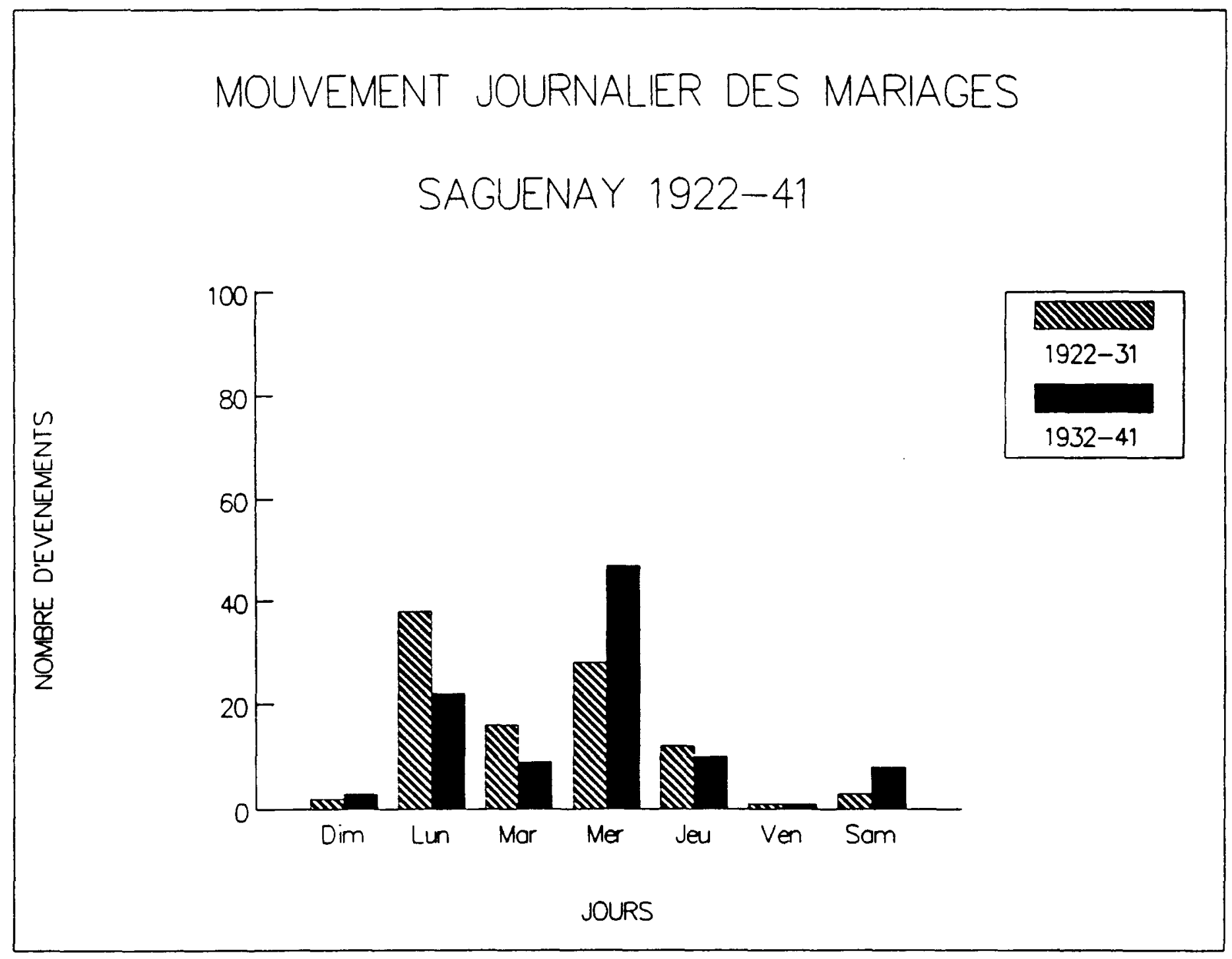

Graphique 20 


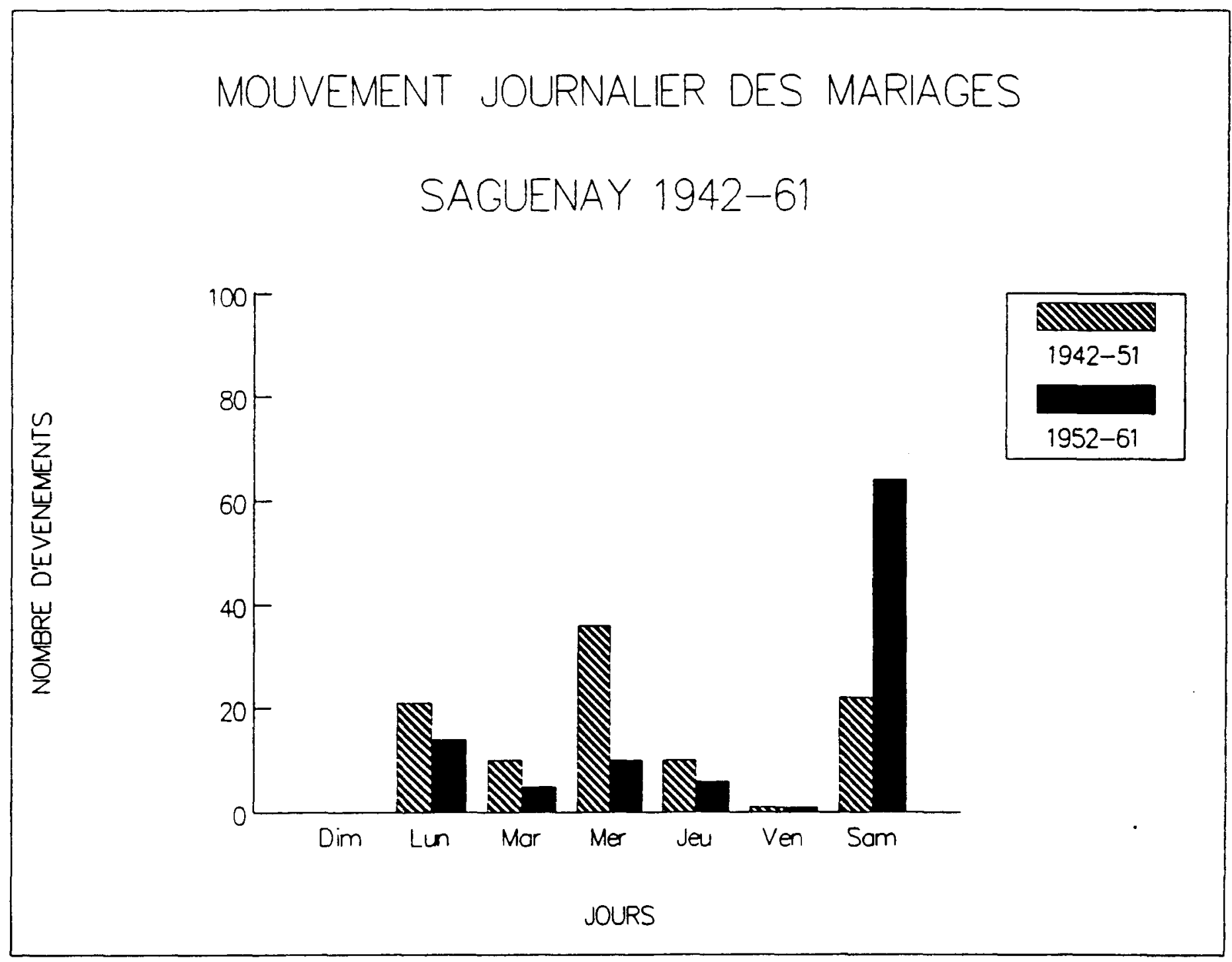

Graphique 21 
123

1

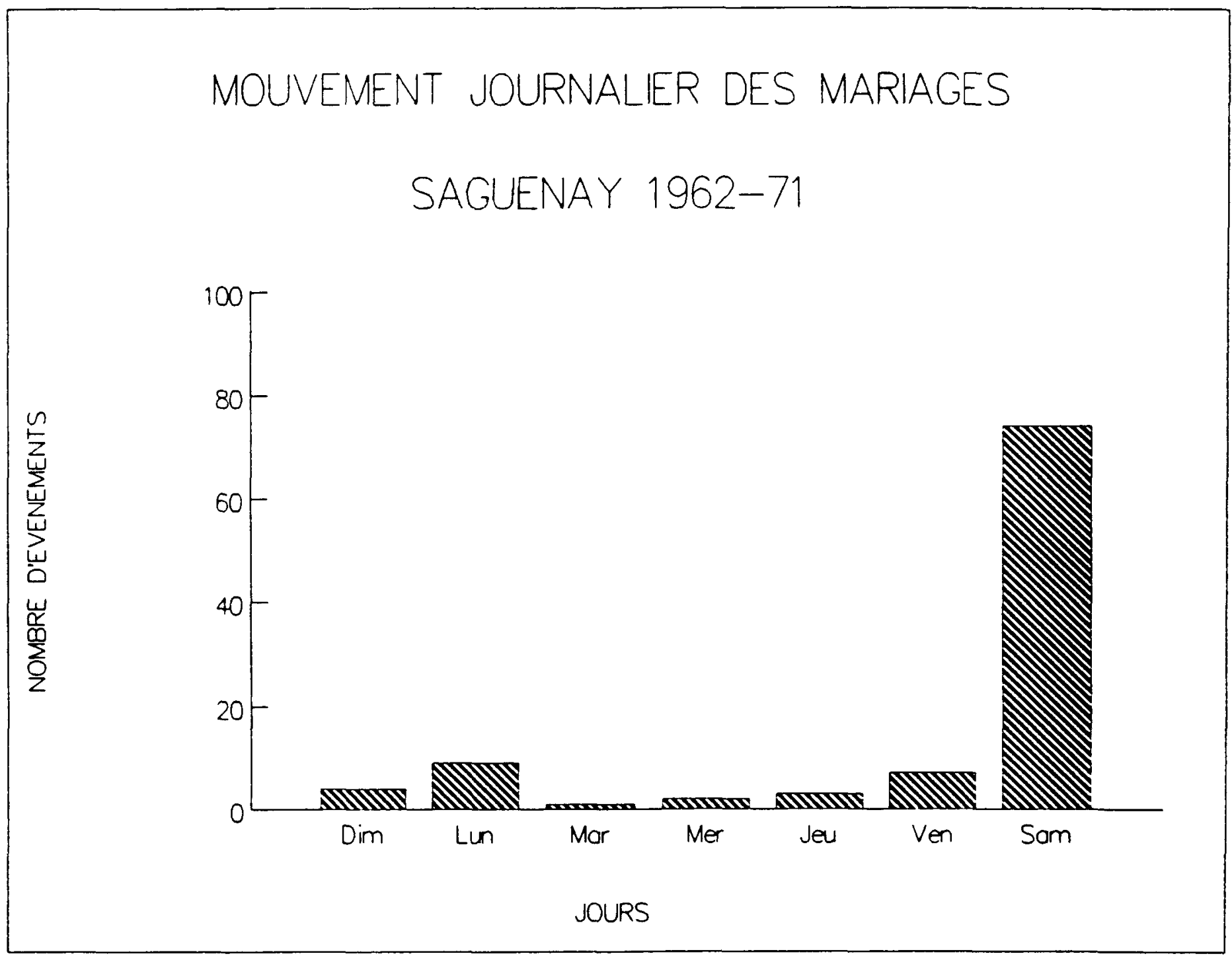


CONCLUSION 
Dans les deux cas, les régions étudiées présentent des modèles rituels à peu près semblables mais beaucoup réduits par rapport à ceux décrits par Martine segalen pour la France. Quelques détails semblent indiquer toutefois une sorte de "simplification" ou "contraction" alors que d'autres informations portent à croire qu'il $y$ a eu une expansion ou une redéfinition de rituels.

L'hypothèse de la "contraction" de la dynamique culturelie est en partie soutenue lorsque l'on pense aux conduites gestuelles, aux cortèges vers le lieu de la noce ou encore à la durée des noces qui, aux dires des informateur(trices), étaient plus élaborés dans la région de Charlevoix.

Pour ce qui est de la thèse de l'expansion ou de la redéfinition des contenus coutumiers, on soupçonne que des éléments extérieurs tels que l'action de l'Eglise ou l'influence de la ville industrielle avaient une certaine influence sur les comportements culturels au saguenay. On retrouve par exemple beaucoup plus de mariages notariés, la pratique étant, de toute évidence, une partie intégrante de l'institution du mariage. On voit également le rite du "shower" apparaître lorsqu'une employée décidait de se marier. 
Par ailleurs, la présence de la jeunesse est en général un élément important dans l'élaboration des pratiques et des rites du mariage. or la presence de la jeunesse charlevoisienne était beaucoup plus marquée et on peut penser que celle-ci contribuait de plus près aux célébrations dans Charlevoix, eu égard à ce qui a été observé pour le saguenay.

De façon générale toutefois, on retrouve deux modèles passablement uniformes, assortis de quelques variantes. Dans les deux régions, l'homogénéité d'un grand nombre de contenus témoigne d'un transfert culturel ayant permis une grande continuité du modèle déjà en place dans Charlevoix. En somme, c'est dire que des trois hypothèses présentées au début de ce travail, c'est finalement la première qui trouve les plus forts éléments de vérification. Par rapport à la France, on maintiendrait l'hypothèse d'une érosion des cérémoniels, mais nos résultats mènent à la conclusion que cette évolution serait principalement survenue avant l'époque des migrations Charlevoix-Saguenay. 


\section{BIBLIOGRAPHIE}

ASSELIN 1982

AUGUSTINS 1985

BELMONT 1973

BELMONT 1978

BERTAUX 1986

BERTAUX 1976

BOUCHARD 1986

BURGUIERE 1978
Carole, LACASSE Yves

Corpus des faits ethnographiques québécois. Saguenay-Lac-Saint-Jean (sous la direction de J.-C. Dupont), Québec, Gouvernement du Québec, Ministère du Loisir, de la chasse et de la Pêche, 433 pages.

Georges

"Choix matrimonial et réseaux d'alliance en Beauce au XIXe siècle", Terrain, no.4, Carnets du patrimoine ethnologique, Paris.

Nicole

"Mythes et croyances de l'ancienne France", Paris, Flammarion, 188 pages.

Nicole

La fonction symbolique du cortège dans les rituels populaires du mariage", Annales E.S.C., Vol. 33, no.3 (mai-juin), pp. 650-655.

Daniel

Les récits de vie: théorie, méthode et trajectoires types, sous la direction de Danielle Desmarais et Paul Grell, Montréal, Editions st-Martin, 180 pages.

Daniel

Histoires de vie ou récits de pratiques? Méthodologie de l'approche biographique en sociologie, Paris, Cordes, 224 pages.

Gérard

"Sur la dynamique culturelle des régions de peuplement", Canadian Historical Review, LXVIII, 4, pp. 473-490.

André

"Le rituel du mariage en France: Pratiques ecclésiastiques et pratiques populaires (XVIe XVIIIe siècle)", Annales E.S.C., Vol.33, pp. 637-648. 
CHARBONNEAU 1987

COTE

1985

CRESSY

1985

CUISENIER

1986

DARROW

1985

DECHENE

1974

DESDOUITS

1985

DESDOUITS

1986

DESDOUITS

1986
Hubert, DESJARDINS Bertrand, GUILLEMETTE André, LANDRY Yves, LEGARE Jacques, NAULT François Naissance d'une population, des Francais établis au canada au XVIIe siècle, Institut National d'études démographiques, Paris: Presses Universitaires de France, Montréal, Presses de l'Université de Montréal, 229 pages.

Jocelyn

Histoire de St-Bruno, Lac St-Jean, des origines à nos jours. st-Bruno, Corporation du centenaire de St-Bruno 1885-1985, 275 pages.

David

"The seasonnality of mariage in old and New England" Journal of Interdisciplinary History, XVI (Summer 1985) pp.1-21.

Jean, SEGALEN Martine

Ethnologie de la France, Paris, Presses Universitaires de France, 127 pages.

Margaret $\mathrm{H}$.

"Marital choice in eighteenth century France", Journal of Social History, Vol.19, no.2, pp. 261-272.

Louise

Habitants et marchands de Montréal au XVIIe siècle, Paris, PLON, 588 pages.

Anne-Marie

La vie traditionnelle au pays de caux et au Québec.L'enfance, de la naissance à l'entrée dans le monde du travail, thèse de doctorat en histoire, Québec, Université Laval, 733 pages.

Anne-Marie, BOUCHARD Gérard, HUOT Marie-Josée, DUPONT Jean-Claude

Les rites du mariage au saguenay et dans Charlevoix: questionnaire d'entrevues Document 11-c-120 de SOREP.

Anne-Marie, BOUCHARD Gérard, HUOT Marie-Josée, DUPONT Jean-Claude

Les rites du mariage au saquenay et dans Charlevoix: grille d'analyse. Document 11-c119 de SOREP. 
GOUESSE

1981

GOUESSE

1976

GRANDVOINNET 1980

GUÉRIN

1988

HARRIS

1977

HERAULT

1987

JEWSIEWICKI 1987

JOUTARD

1983

LEMIEUX 1987
Jean-Marie

"Le choix du conjoint", Annales de démographie historique, Rapport présenté par la Société de Démographie Historique, Editions de l'école des hautes études en sciences sociales, Paris, pp. 141-153.

Jean-Marie

"Migrations féminines et mariages. Quelques exemples bas-normands (XVIIe et XVIIIe siècles)" Annales de démographie historique, Editions de I'école des hautes études en sciences sociales, Paris, pp. 319-339.

Chantal, GRESSET Maurice

Le mariage dans l'est aux XVIIe et XIXe siècles, Bulletin d'information de la Société de démographie historique, no.31, octobre 1980.

Michel

Peuplement et dynamique de Charlevoix des origines à aujourd'hui, mémoire de mâtrise en Etudes Régionales, Chicoutimi, Université du Québec à Chicoutimi.

Coles

"The Simplification of Europe overseas", Annals of the Association of American Geographers, Vol.67, no.4, (december) pp.469-483.

Laurence

"La cheville et le brandon. Rituels de fiançailles et de mariage dans le haut bocage vendéen", Terrain, 8, (avril), p.42-51.

Bogumil, dir.

Récits de vie et mémoires: vers une anthropologie historique du souvenir, Paris/Ste-Foy, L'Harmattan/safi, 344 pages

Philippe

Ces voix qui nous viennent du passé, Paris, Hachette, 268 pages.

Denise, MERCIER, Lucie

"Familles et destins féminins. Le prisme de la mémoire, $1880-1940^{\prime \prime}, \quad$ Recherches sociographiques, (Numéro spécial: La famille de Ia Nouvelle-France a aujourd'hui, Vol.XXVIII, no.2-3, pp.255-271. 
LEMIEUX 1989

MASSICOTTE 1930

MASSICOTTE 1925

MATHIEU 1985

MINER 1985

MOLIN

1974

MORTON 1989

NAZ

1954-55

PONSOT 1981
Denise, MERCIER Lucie

Les femmes au tournant du siècle: 1880-1940: âges de la vie, maternité et quotidien, Québec, Institut québécois de recherche sur la culture, 398 pages.

Edouard-Zotique

"De la durée des noces", Le bulletin de recherches historiques, Vol.36, no.7, pp.391393 .

Edouard-zotique

"Une noce populaire d'il y a cinquante ans", I'almanach du peuple, Montréal, Beauchemin, pp.334-340.

Jocelyne

La notion de confort à la ville et à la campagne. Analyse comparative d'intérieurs domestiques du XVIIIe siècle dans le Perche et au Québec, communication donnée au colloque franco-québécois d'histoire comparée, Québec, septembre.

Horace

St-Denis: un village québécois, Québec, Hurtubise HmH, 392 pages.

Jean-Baptiste, MUTEMBE Protais

Le rituel du mariage en France du XIIe au XVIe siècle. Paris, Beauchesne, 348 pages.

suzanne

"The june-bride as the working-class bride; getting married in the North End of Halifax in the 1920" présenté à l'CHA à l'Université Laval en juin 1989 .

Raoul

Traité de droit canonique, Paris, Letouzey et Ane.

Pierre

"Voisine, marions-nous! Le choix du conjoint dans une communauté bocagère", Annales de démographique historique, Paris, Editions de I'école des hautes etudes en sciences sociales, pp. 189-193. 
POSTOLEC

1988

PROVENCHER 1986

RIOUX

1954

RODRIGUE

1983

ROY

1923

SEGALEN

1981

TREMBLAY

1948

VACHON

1982

VAN GENNEP

1943-1958
Geneviève

Les circonstances du mariage à 1 'Ange-Gardien. de 1667 à 1788 , mémoire présenté pour l'obtention de la maitrise en histoire. Université de Haute-Bretagne, Rennes II.

Jean

C'était I'hiver. La vie rurale traditionnelle dansla vallée du st-Laurent. Montréal, Les Editions du Boréal Express, 278 pages.

Marcel

Description de la culture de l'ile verte, ottawa, Musée national du Canada, Bulletin no. 13 .

Denise

"Le cycle de Pâques au Québec et dans l'Ouest de la France", Les Archives de Folklore (sous la direction de Luc Lacoursière), Vol. 24, Québec, Les Presses de l'Université Laval, 342 pages.

J. Edmond

"Les mariages dans nos campagnes d'autrefois", Le bulletin de recherches historiques, Vol.XXIX, no.7, pp.200-201.

Martine, CHAMARAGH, Josselyne

Amours et mariages de l'ancienne France. Paris, Berger-Levreault, 175 pages.

Antonin

Sur le plateau laurentien: Analyse sociale d'une communauté rurale. Notre-Dame-deI'Assomption des Eboulements, thèse de mâttrise en sciences sociales, Université Laval, Québec, 114 pages.

Herman

Corpus des faits ethnographiges. BeauceDorchester (sous la direction de J-C Dupont, Gouvernement du Québec, Québec, Ministère du Loisirs, de la Chasse et de la Pêche.

Arnold

Manuel de folklore francais contemporain, Paris, Picard, 7 tomes. 
VAN GENNEP

1981

VARAGNAC

1978
Arnold

Les rites de passage, Paris, Picard, pp.165207.

André, CHALLOT-VARAGNAC Marthe Les traditions populaires, Paris, Presses Universitaires de France, 127 pages. 
ANNEXE 1 
DONNEES PERSONNELLES ET SOCIO-PROFESSIONNELLES RELATIVES AUX INFORMATEUR(TRICE)S DU SAGUENAY

Informateurs

Informatrices (genre)
Année de

naissance
Profession

Agriculteur*

Agriculteur*

Institutrice

Cuisinière

Agriculteur*

Bûcheron

Agriculteur*

Commis

Institutrice

Femme de ménage

Agriculteur*

Courtier

Gérant

Institutrice

Agriculteur*

Agriculteur*

Infirmière

Femme de ménage

Institutrice

Femme de ménage

Agriculteur
Année du mariage

1919

1918

1934

1921

1925

1925

1925

1930

1944

1928

1928

1929

1936

1936

1916

1938

1942

1929

1923

1925

1916 


\begin{tabular}{|c|c|c|c|}
\hline 19. (F) & 1896 & Agriculteur* & 1916 \\
\hline 20. (F) & 1898 & Agriculteur* & 1915 \\
\hline 21. (F) & 1914 & Agriculteur* & 1931 \\
\hline 22. (F) & 1907 & Agriculteur* & 1927 \\
\hline 23. $(\mathrm{H})$ & 1900 & Commis & 1920 \\
\hline 24. (F) & 1902 & Agriculteur* & 1920 \\
\hline 25. (F) & 1910 & Agriculteur* & 1930 \\
\hline
\end{tabular}

* : Ces professions étaient exercées par les pères des informatrices. 
ANNEXE 2 
DONNEES PERSONNELLES ET SOCIO-PROFESSIONNELLES RELATIVES AUX INFORMATEUR(TRICE)S DE CHARIEVOIX

$\begin{array}{cclr}\begin{array}{l}\text { Informateur } \\ \text { Informatrices } \\ \text { (genre) }\end{array} & \begin{array}{l}\text { Année de } \\ \text { naissance }\end{array} & \text { Profession } & \begin{array}{c}\text { Année du } \\ \text { mariage }\end{array} \\ \text { 2. (H) } & 1889 & \text { Agriculteur } & 1904 \\ \text { 3. (F) } & 1906 & \text { Journalier } & 1925 \\ \text { 4. (H) } & 1922 & \text { Agriculteur* } & 1941 \\ \text { 5. (F) } & 1898 & \text { Agriculteur } & 1923 \\ \text { 6. (F) } & 1917 & \text { Commis } & 1940 \\ \text { 7. (F) } & 1902 & \text { Secrétaire } & 1924 \\ \text { 8. (F) } & 1895 & \text { Agriculteur* } & 1913 \\ \text { 9. (H) } & 1892 & \text { Agriculteur } & 1920 \\ \text { 10. (F) } & 1892 & \text { Agriculteur } & 1934 \\ 11 . & 1897 & \text { Agriculteur* } & 1920 \\ 12 . \text { (H) } & 1906 & \text { Journalière } & 1926 \\ \text { 13. (F) } & 1904 & \text { Agriculteur } & 1934 \\ \text { 14. (F) } & 1902 & \text { Agriculteur* } & 1921 \\ \text { 15. (F) } & 1935 & \text { Journalier* } & 1954 \\ \text { (F) } & 1903 & \text { Opératrice téléphone } & 1929\end{array}$

* : Ces professions ont été exercées par les pères de informatrices. 